
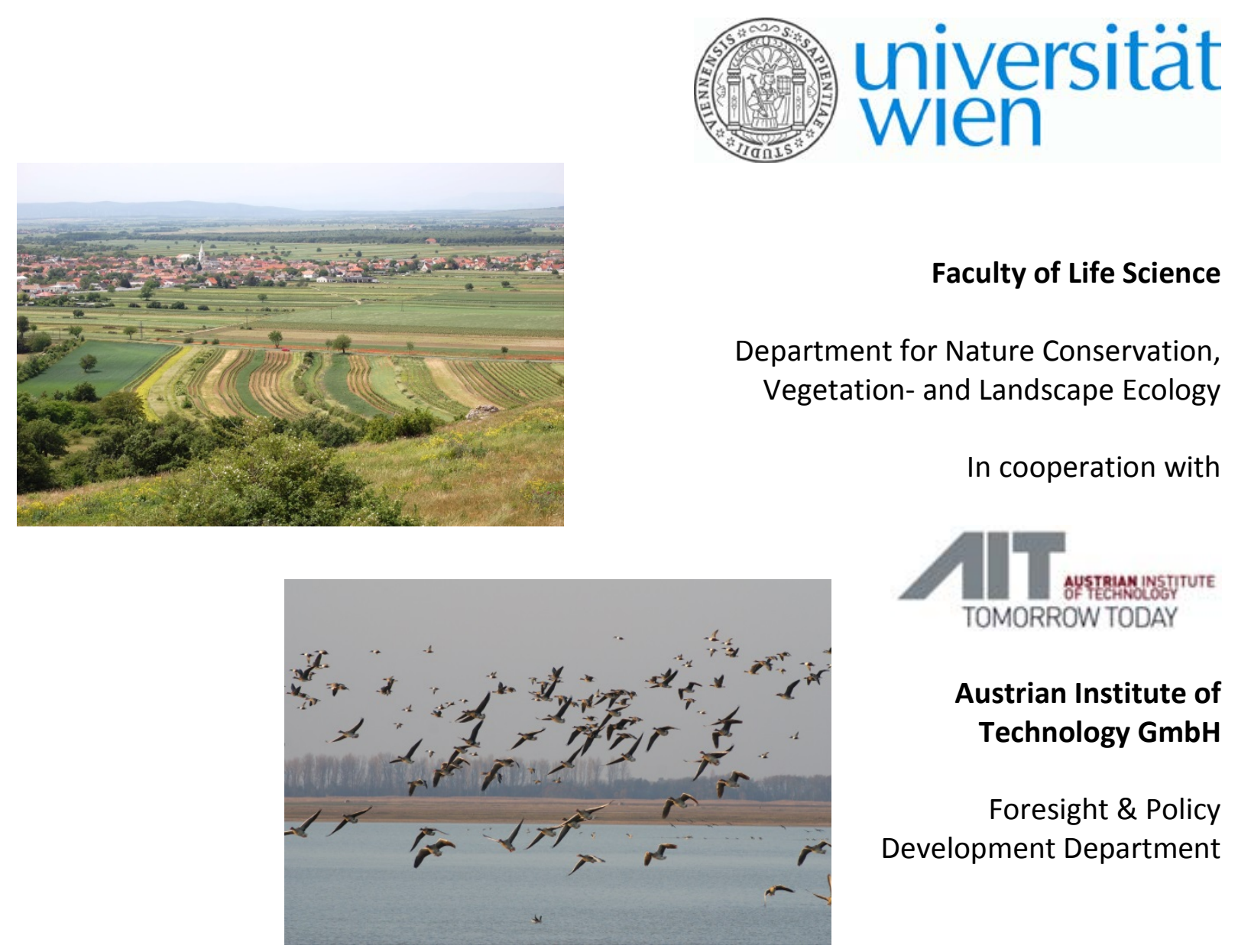

Faculty of Life Science

Department for Nature Conservation, Vegetation- and Landscape Ecology

In cooperation with

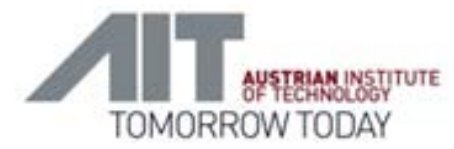

Austrian Institute of Technology GmbH

Foresight \& Policy Development Department

\title{
Global Change
}

'Climate Change Response of Ecosystem Services in the sensitive area of Neusiedler See-Seewinkel - CCR'

\section{Final report}

Funded by: Austrian Academy of Sciences ISBN-Online: 978-3-7001-7547-6

DOI: $10.1553 /$ GlobalChange-1 
Report by the funded institutions:

\section{University of Vienna}

Faculty of Life Science

Department of Nature Conservation, Vegetation- and Landscape Ecology

1030 Vienna, Rennweg 14

$\mathrm{T}+431$ 4277-54382

Ass.-Prof. Dr. Thomas Wrbka

Mag. Anna Schneidergruber

Mag. Michael Kuttner

Mag. Dr. Christa Hainz-Renetzeder thomas.wrbka@univie.ac.at anna.schneidergruber@univie.ac.at michael.kuttner@univie.ac.at christa.renetzeder@univie.ac.at

\section{Austrian Institute of Technology}

Foresight \& Policy Development Department A-1220, Donaucitystraße 1 - Techgate Tower $\mathrm{T}+43(0) 50550-4587$

Dr. Markus Knoflacher Mag. Mario Köstl

Project period

Oktober 2010 - December 2012 markus.knoflacher@ait.ac.at

mario.koestl@ait.ac.at 


\section{Table of contents}

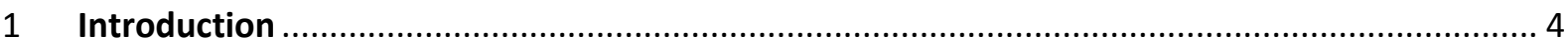

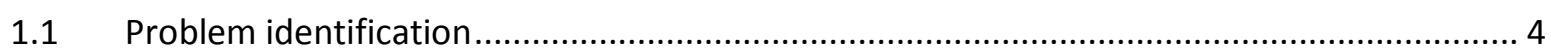

1.2 Objectives of the outlined project......................................................................... 4

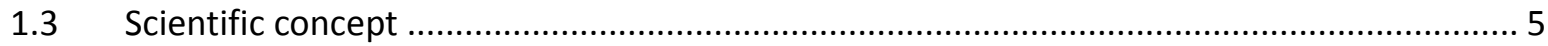

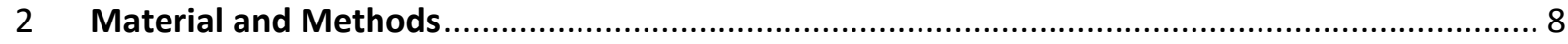

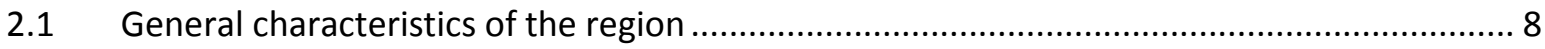

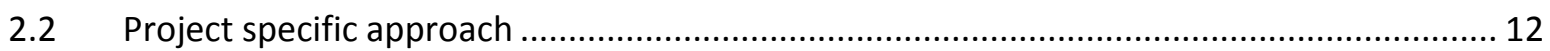

2.3 Climate scenarios and its implications for the Neusiedler-See region.............................. 12

2.4 Assessment of 'potential' ecosystem functions within the Neusiedler-See region............. 38

2.5 Assessment of 'recent' ecosystem functions within the Neusiedler-See region ................ 44

2.6 Historic assessment of ecosystem functions within the Neusiedler-See region ..................53

2.7 Assessment of 'future' ecosystem functions' potential under consideration of ongoing climate change phenomena within the Neusiedler-See region ........................................ 54

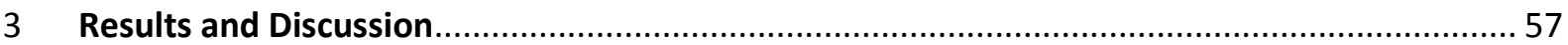

3.1 Comparisons between the 'potential', 'historical' and 'recent' ecosystem function provision of the 7 Landform Types within the study region Neusiedler-See................................... 57

3.2 Sensitivity of ecosystem functions to climate change in the study region Neusiedler-See.. 58

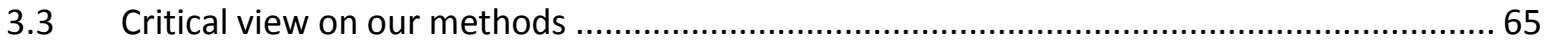

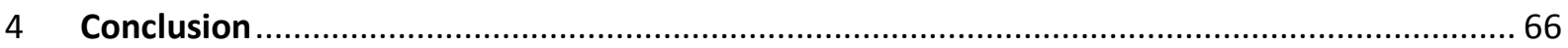

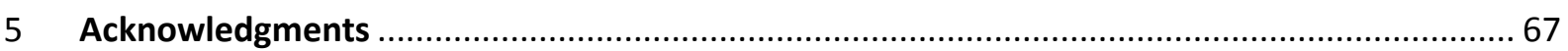

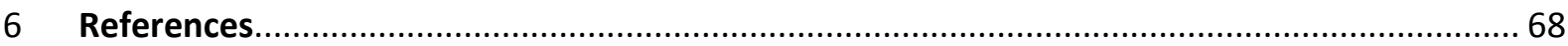

7 Appendices Spatially differentiated representations of scenario results by decades for the

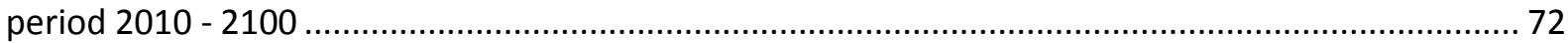




\section{Introduction}

\subsection{Problem identification}

Based on recent worldwide assessments, climate change is considered as a major threat to biodiversity together with habitat change, invasive alien species, overexploitation and pollution. Evidence for changes in ecosystems related to climate have been documented for the high European Alps, for the spreading of invasive species, for threats on plant diversity in Europe or for important ecosystems services such as water availability and quality and agricultural productivity.

The concept of ecosystem functions, goods and services (MEA, 2005) has experienced increasing attention in the last years as it integrates major ecological processes and communicates their importance to society. Highlighting these values has been done in the BIOSERV-project, where ecosystem functions and services are identified for the region of Neusiedler-See, their potential and their current status. But with a changing climate, basic preconditions of the landscape will alter and hence, 'potential' as well as the 'recent' ecosystem functions are likely to change. These changes will have a big impact on the regions' development, as the natural and economical values are highly interlinked in the area of the Seewinkel due to the special biodiversity situation and nature related tourism.

Based on the consistent description of ecosystem functions and services as a precondition, we are able to focus on valuable assessment of climate change impacts in 2100 , which in turn might be the basis for land use adaptation in the future. If we knew the main climate drivers of related ecosystem functions, we would be able to assess in which direction they are likely to change in the future, and what impact this would have for the regional development. This would enable the formulation of tailor-suited adaptation and mitigation measures for the region.

\subsection{Objectives of the outlined project}

Main aim of the project is the assessment of the sensitivity of ecosystem functions, goods and services to climate change in the region of the Neusiedler See - Seewinkel. Thus, we will focus on

(1) the link of ecosystem functions (EFs) with the spatially explicit regionalized climate data: Oscillation patterns are a characteristic feature of the Seewinkels' climate. These are therefore important drivers of main site parameters of habitats. An important step is therefore to gain insight in this important climate patterns and to investigate how future changes will look like.

(2) the assessment of the 'potential', 'historical' and 'recent' distribution of ecosystem functions in the investigation area as a precondition for the calculation and interpretation of future scenarios. The concept of broader habitat will act as a proxy to investigate the relationships between ecosystem functions and climate parameters. Existing detailed information about structure, trophy, and the environmental variables of Natural Disturbance (DIN), Resource Potential Wetness (RWF), Resource Potential Dryness (RWT) and Resource Potential Nutrient Richness (Wrbka et al., 2003) as well as about current land use type is used for calculation of ecosystem functions.

(3) the assessment of potential impact of modeled climate change on ecosystem functions: Important ecosystem functions like cultivation will respond to changes of climate patterns. Therefore land use systems will adapt to the altered situation. Vegetable production as a land use activity with massive irrigation is one example of a highly sensitive system which is likely to be affected by climate change. Areas which might become less favourable in terms of food production might offer an alternative for the Habitat function as they have a high potential for restoration. 


\subsection{Scientific concept}

The scientific concept of ecosystem functions, goods and services (ESS) has experienced increasing attention in the last years as it provides the means of documenting the importance and benefits of ecosystems and landscape for human society. One of the most relevant publications is the Millennium Ecosystem Assessment (2005) which provides the basic framework for assessing the interactions between ecosystems and humans, how these can be measured, evaluated and strengthened for future human well-being. There, ecosystem function and ecosystem services are defined as follows:

"Ecosystem function: An intrinsic ecosystem characteristic related to the set of conditions and processes whereby an ecosystem maintains its integrity (such as primary productivity, food chain, biogeochemical cycles). Ecosystem functions include such processes as decomposition, production, nutrient cycling, and fluxes of nutrients and energy."

"Ecosystem services: The benefits people obtain from ecosystems. These include provisioning services such as food and water; regulating services such as flood and disease control; cultural services such as spiritual, recreational, and cultural benefits; and supporting services such as nutrient cycling that maintain the conditions for life on Earth. The concept "ecosystem goods and services" is synonymous with ecosystem services."

Several authors have dealt with function and service analysis (de Groot et al., 2002; de Groot, 2006), problems arising with this classification (Egoh et al., 2007; Wallace, 2007) and the implementation via stakeholders (Hein et al., 2006; Goldman et al., 2007, Havstad et al., 2007). Haines-Young and Potschin (2010) provided an assessment framework for linking ecosystems to human well-being, which has been used in several projects, for instance, the TEEB project (TEEB, 2010) (

Figure 1). The proposed diagram makes a distinction between ecological processes and functions as well as the provided services and the outputs considered for humans as benefits. Although the general structure of the suggested framework is widely agreed upon, the distinction between the terms "function", "service" and "benefit" is still under discussion (see Hermann et al., 2011).

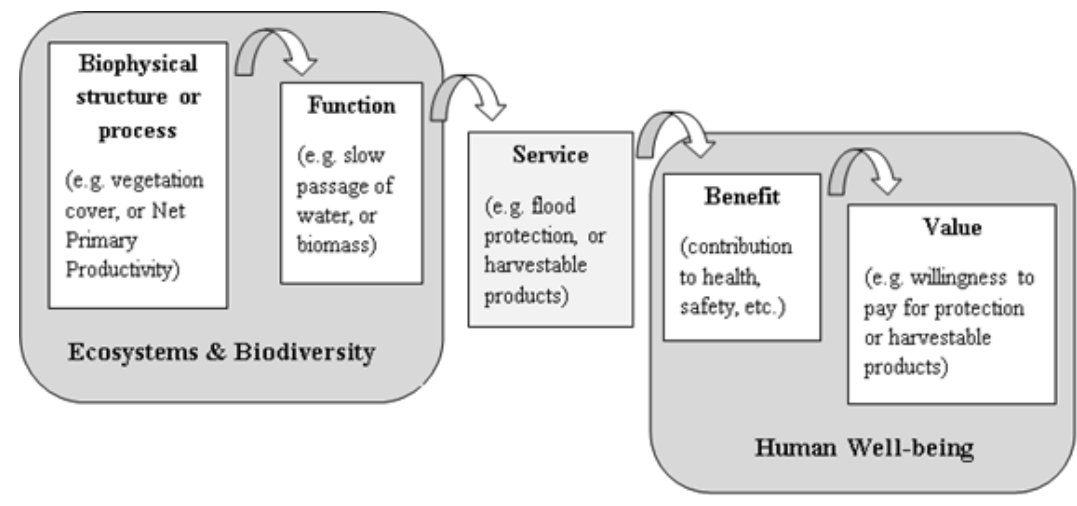

Figure 1: Framework for linking Ecosystems \& Biodiversity to Human Well-being (after Haines-Young and Potschin, 2010).

We made use of and developed this approach in a way to display possibilities for a biosphere reserve in the region of Neusiedler-See in trade-offs with local people and other stakeholders.

In our project we assessed ecosystem functions, which are defined as 'the capacity of natural processes and components to provide goods and services that satisfy human needs, directly or indirectly' (de Groot, 1992). The classification of ecosystem functions and their services is mainly based on de Groot (2006). Ecosystem functions are grouped into five primary categories: 


\section{Regulation functions}

These functions relate to the capacity of cultural landscapes to regulate essential ecological processes and life support systems through biogeochemical cycles. They maintain a "healthy" ecosystem at different scale levels and provide important pre-conditions for all other functions. Whereas a range of regulation functions exist, our project only incorporates those that provide direct and indirect services to humans (such as maintenance of clean water, soil and prevention of soil erosion).

\section{Habitat functions}

Natural as well as cultural ecosystems provide refuge and reproduction habitat to wild plants and animals and thereby contribute to the maintenance of biodiversity (e.g. genetic diversity as evolutionary potential). The availability or condition of this function depends on the physical components of the ecological niche. As the requirements differ for different species groups they can be defined in terms of the carrying capacity and spatial needs (minimum critical habitat size) of the natural habitat type.

\section{Provision functions}

Photosynthesis and nutrient uptake by autotrophic organisms convert energy, carbon dioxide, water and nutrients into a wide range of living biomass. This biomass in turn can be used by humans as food (concerning edible wild plants and animals), raw materials, energy resources and/or genetic resources.

\section{Information functions}

Due to their individual characteristics, natural as well as cultural landscapes provide opportunities for reflection, spiritual enrichment, cognitive development, recreation and aesthetic experiences.

\section{Carrier functions}

These functions only refer to cultural landscapes. As most human activities (e.g. cultivation, habitation, and transportation) require a suitable substrate (soil) or medium (water), the use of these functions implies conversion of the natural system into an either semi-natural or artificial system.

Table 1 gives an overview of the functions and services applied in our project. The first column provides a list of the main functions and their sub-functions and the second column describes the functions in detail. The third column sets examples of specific services consumed at the landscape scale.

Table 1: Functions and related services of cultural ecosystems used in the project CCR (mainly adapted from de Groot et al., 2002 and de Groot, 2006);

\begin{tabular}{|c|c|c|}
\hline Functions & Definition & Services (examples) \\
\hline \multicolumn{3}{|l|}{ Regulation function } \\
\hline Local climate regulation & $\begin{array}{l}\text { Influence of habitat type on } \\
\text { local climate (mainly buffer } \\
\text { function) }\end{array}$ & $\begin{array}{l}\text { Maintenance of a favourable } \\
\text { local climate (e.g. temp., } \\
\text { moisture etc.) for e.g. human } \\
\text { habitation, health, cultivation }\end{array}$ \\
\hline Disturbance prevention & $\begin{array}{l}\text { Influence of landscape } \\
\text { structure on environmental } \\
\text { disturbances }\end{array}$ & $\begin{array}{l}\text { Storm protection and/or flood } \\
\text { prevention (e.g. flood detention } \\
\text { basin, shelter belt) }\end{array}$ \\
\hline Water supply & $\begin{array}{l}\text { Filtering, retention and storage } \\
\text { of fresh water }\end{array}$ & $\begin{array}{l}\text { Provision of water for } \\
\text { consumptive use (e.g. drinking, } \\
\text { irrigation and industrial use) }\end{array}$ \\
\hline Soil retention & Role of vegetation root matrix & Maintenance of arable land; \\
\hline
\end{tabular}




\begin{tabular}{|c|c|c|}
\hline & and soil biota in soil retention & $\begin{array}{l}\text { prevention of damage from } \\
\text { erosion/siltation }\end{array}$ \\
\hline Soil formation & $\begin{array}{l}\text { Weathering of rock, } \\
\text { accumulation of organic matter }\end{array}$ & $\begin{array}{l}\text { Maintenance of natural } \\
\text { productive soils }\end{array}$ \\
\hline Nutrient regulation & $\begin{array}{l}\text { Role of biota in storage (buffer) } \\
\text { and recycling of nutrients (e.g. } \\
\mathrm{N}, \mathrm{P} \text { and S) }\end{array}$ & $\begin{array}{l}\text { Maintenance of healthy and } \\
\text { productive ecosystems }\end{array}$ \\
\hline \multicolumn{3}{|l|}{ Habitat function } \\
\hline Refugium function & $\begin{array}{l}\text { Suitable living space for wild } \\
\text { plants and animals }\end{array}$ & $\begin{array}{l}\text { Maintenance of biodiversity, in } \\
\text { particular }\end{array}$ \\
\hline \multicolumn{3}{|l|}{ Provision function } \\
\hline Food & $\begin{array}{l}\text { Conversion of solar energy into } \\
\text { wild edible plants and animals }\end{array}$ & $\begin{array}{ll}\text { Maintenance of edible wild } \\
\text { plants and fungi } \\
\text { cultivated), game and fish }\end{array}$ \\
\hline Raw materials & $\begin{array}{l}\text { Conversion of solar energy into } \\
\text { biomass }\end{array}$ & $\begin{array}{l}\text { Material for human } \\
\text { constructions (building and } \\
\text { manufacturing), like lumber, } \\
\text { fuel and energy wood }\end{array}$ \\
\hline Genetic resources & $\begin{array}{l}\text { Genetic material and evolution } \\
\text { in wild plants and animals }\end{array}$ & $\begin{array}{l}\text { Improve crop resistance to } \\
\text { pathogens and pests and } \\
\text { maintenance of old cultivated } \\
\text { plants }\end{array}$ \\
\hline \multicolumn{3}{|l|}{ Information function } \\
\hline Science and education & $\begin{array}{l}\text { Variety in nature with scientific } \\
\text { and educational value }\end{array}$ & $\begin{array}{l}\text { Use of nature for scientific } \\
\text { research }\end{array}$ \\
\hline \multicolumn{3}{|l|}{ Carrier function } \\
\hline Cultivation & $\begin{array}{l}\text { Providing suitable substrate for } \\
\text { cultivation (actual available) }\end{array}$ & Cultivated food and fodder \\
\hline
\end{tabular}

Innovative global change assessment and planning may profit from this approach because it would allow an integrative evaluation of vulnerable areas and their contribution to human well-being (Chan et al., 2006; Egoh et al., 2007). The ESS framework extends prior models by encouraging people to reexamine the links between ecosystems and human well-being in a more pragmatic way (Potschin and Haines-Young, 2011). Emphasizing ecological, social and economic dependence on natural assets attract public interest on biodiversity conservation (see Westman, 1977; de Groot, 1987, OdlingSmee, 2005). As the capacity of ecosystems to deliver essential services to society is already under stress, a change of thinking and behaviour in human resource policy is necessary. The additional stresses on ecosystems imposed by climate change in the coming years will require extraordinary adaptation. Several studies have examined ecosystem responses to climate change ranging from future distributions of species and populations (Thomas et al., 2004; Lenoir et al., 2008) including phonological shifts, such as flowering of forbs and migration phenology of songbirds (Cleland et al., 2007; Van Buskirk et al., 2009) over species extinctions within vulnerable habitats to feedbacks at the regional level, for instance albedo effects. In order to adapt to climate change and start to develop mitigation measures in a meaningful way and we need to track the changing status of ecosystems, deepen our understanding of the biological underpinnings for ecosystem service delivery and develop new tools and techniques for maintaining and restoring resilient biological and social systems (Mooney et al., 2009). 


\section{Material and Methods}

\subsection{General characteristics of the region}

The Neusiedler-See Region (Figure 2) is situated between the Alpine region in the west and the Pannonian Region in the east. The closer Neusiedler-See Region is enclosed in the west by the hills of the Leitha-Gebirge and in the south-west of the Wechsel-area. Open and flat land with minor elevations connects the Region in the east to the Pannonian Region, a natural wetland converted in historical times to grassland. However, the shallow Neusiedler-See - with a total area of $321 \mathrm{~km}^{2}$ with $175 \mathrm{~km}^{2}$ reed belt and $146 \mathrm{~km}^{2}$ open water - is dominantly supplied with water from the western part of the catchment by the river Wulka. During the last centuries the lake disappeared several times because of drought events, the severe drought appeared from 1865 to 1870 (Österreichisch - Ungarische Gewässerkommission 1996). Former hydro-geological interdependences of the lake with the wetlands in the Seewinkel have changed because of the construction of the artificial draining Einser-Kanal, connecting the lake with the river Rábca in Hungary. Since 1965 the lake level is artificially regulated at an average sea level of $\mathbf{1 1 5 . 4 9}$ meters by a sluice in the EinserKanal.

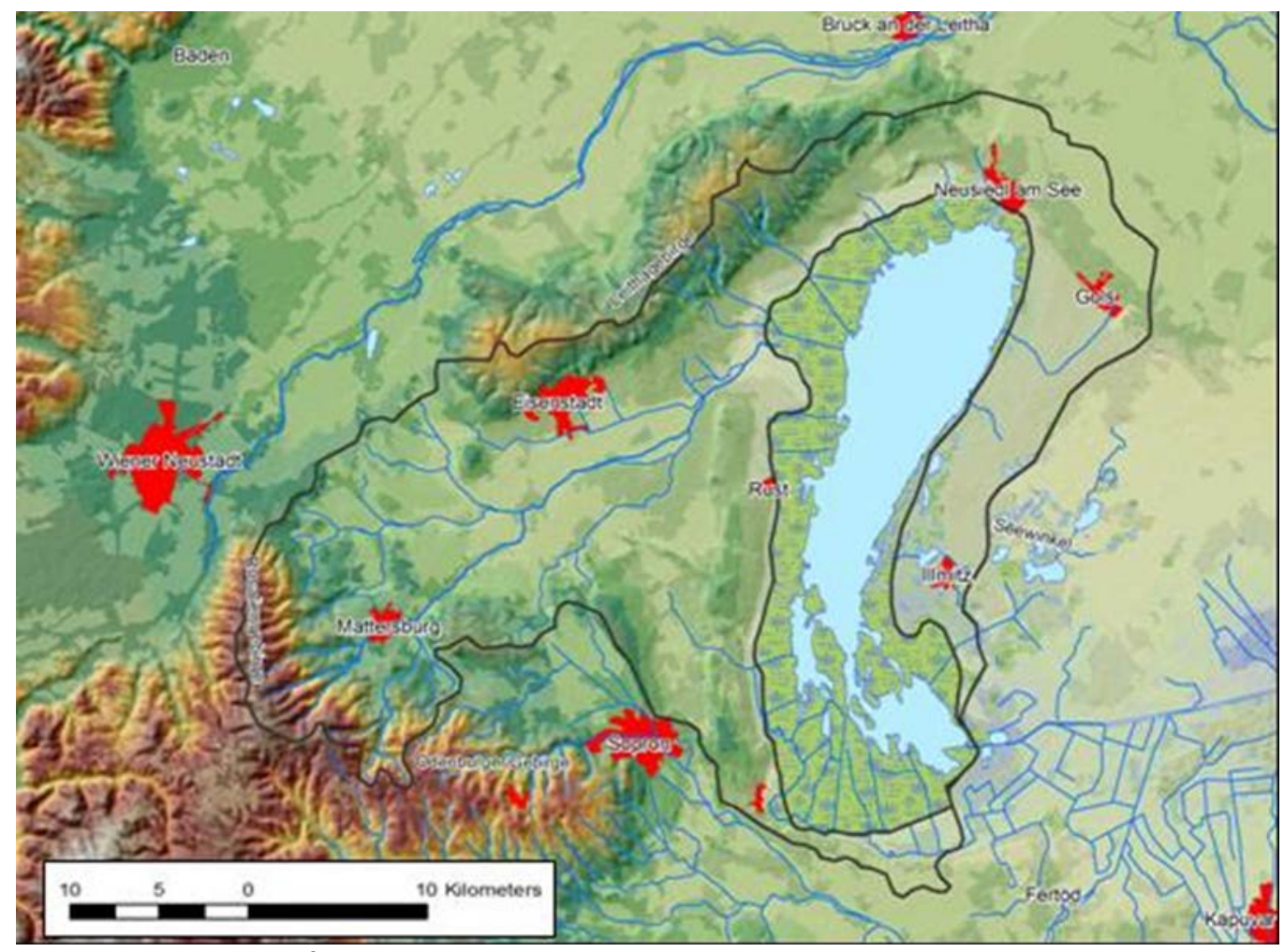

Figure 2: General map of the Neusiedler See region

More sensitive to dry conditions are the still existing small and shallow water bodies in the Seewinkel, named "Lacken". Most of them become dry during summer months because of the increased evapo-transpiration driven by combined effects of temperature, solar radiation and wind. Salination of the water bodies is a consequence of the high evapo-transpiration rates, but also crucial for the ecological function of the small water bodies Krachler 2007 and microbiological dynamics (Kirschner et al., 2002).

Climatic conditions of the Neusiedler-See region are strongly influenced by the particular geographical conditions. Low annual precipitation of approximately $600 \mathrm{~mm}$ and differences of $40^{\circ} \mathrm{C}$ summer temperature maxima and $-20^{\circ} \mathrm{C}$ winter temperature minima are characteristics of a continental climate. However, the climate is also influenced by Atlantic conditions due to the prevailing winds from north-west. Average monthly temperatures had their lowest value of $-0.5^{\circ} \mathrm{C}$ in January and their maximum of $20.4^{\circ} \mathrm{C}$ in July during the thirty year period between 1971 and 2000 . 
Average monthly precipitation sums are at lowest in February $(28.7 \mathrm{~mm})$ and at highest values between $61.4 \mathrm{~mm}$ and $64.9 \mathrm{~mm}$ during May until August (Figure 3 ).
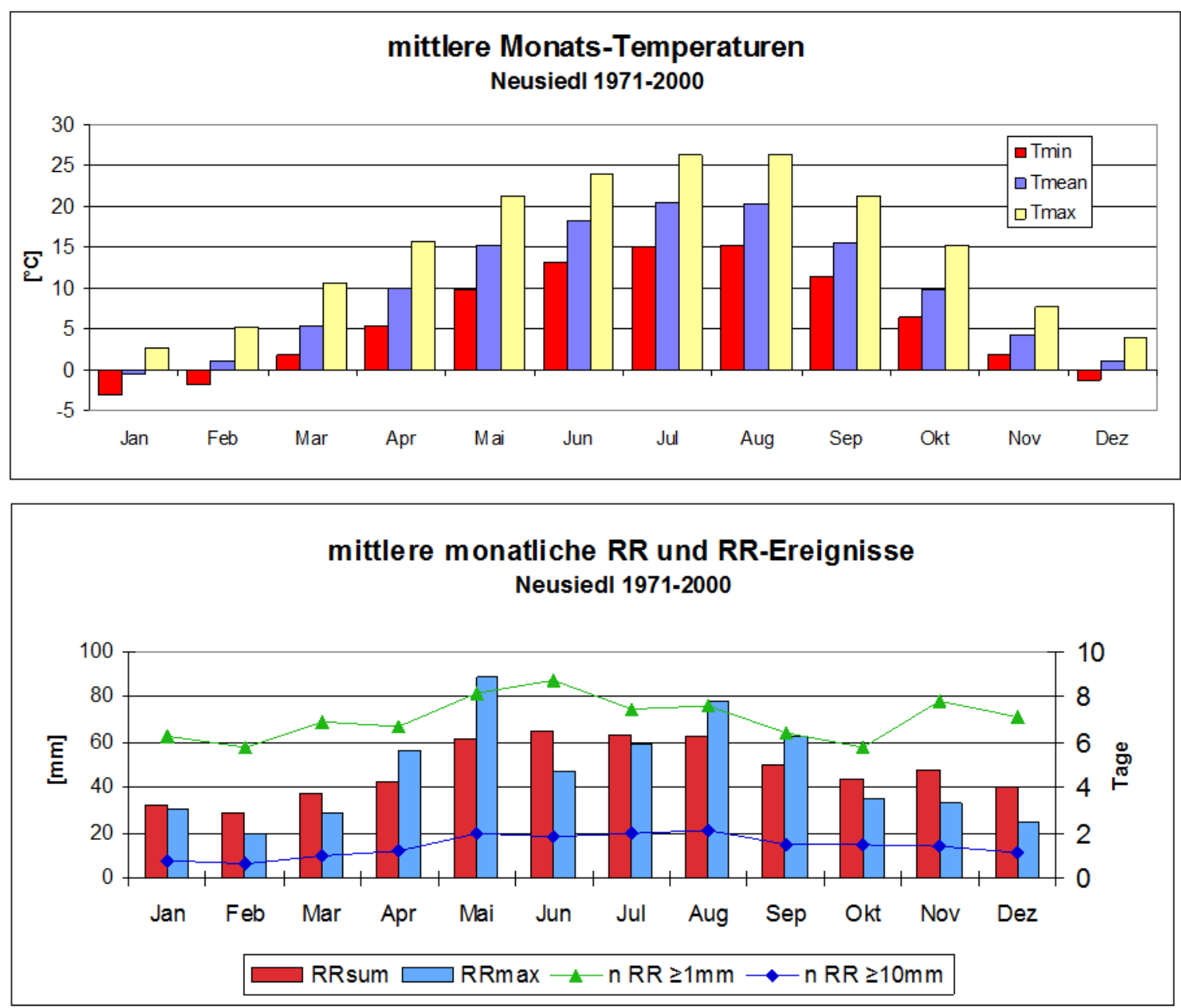

Figure 3: Average temperature and precipitation characteristics of the climate Station Neusiedl for the period 1971 to 2000. Data source: http://www.zamg.ac.at/fix/klima/oe71-00/klima2000/klimadaten_oesterreich_1971_frame1.htm

Wind is a characteristic feature of the climate in the Neusiedler-See-Region, only $5.2 \%$ calms are observed in the annual average at the observation station Neusiedl. Monthly averages of calms are below from December until July and above the annual average from August to November (Figure 4). Dominant wind directions are northwest and north over the whole year, followed by southeast and south (Figure 5). 


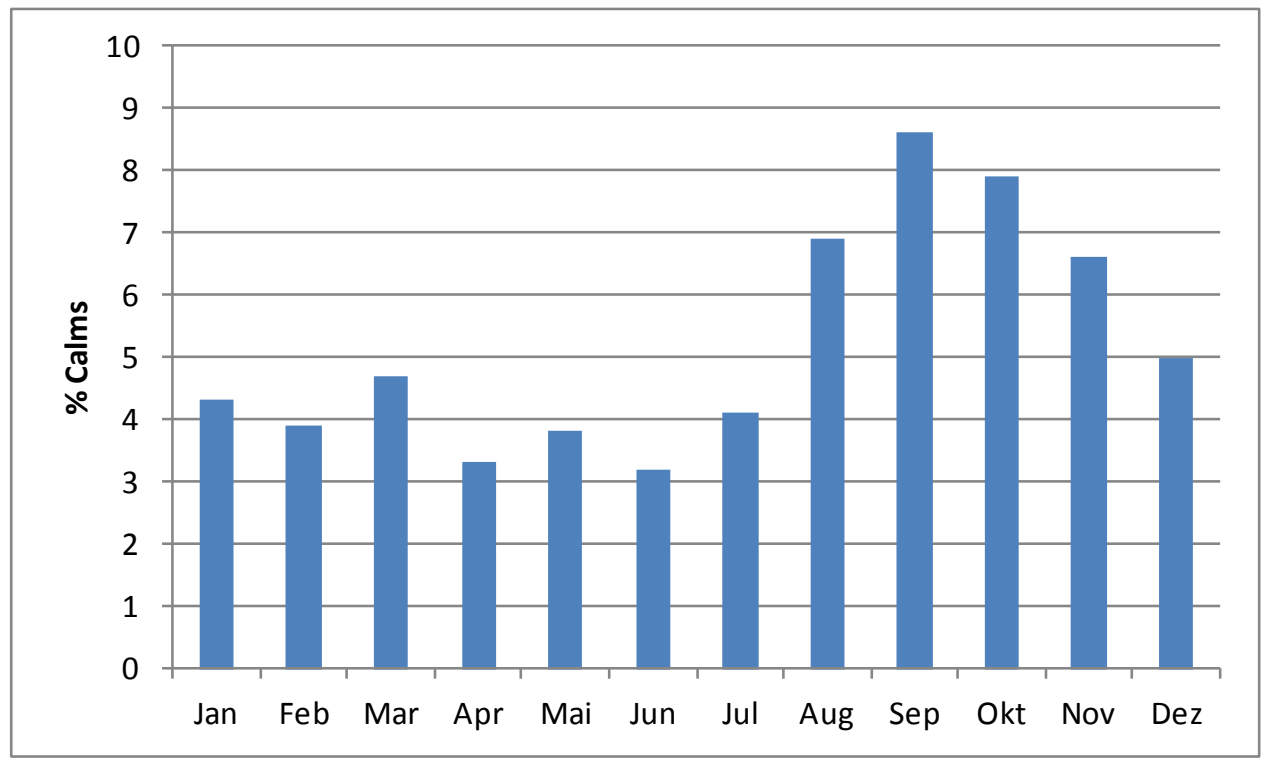

Figure 4: Monthly averages of calms in per cents observed at the climate Station Neusiedl for the period 1971 to 2000. Data source: http://www.zamg.ac.at/fix/klima/oe71-00/klima2000/klimadaten_oesterreich_1971_frame1.htm.

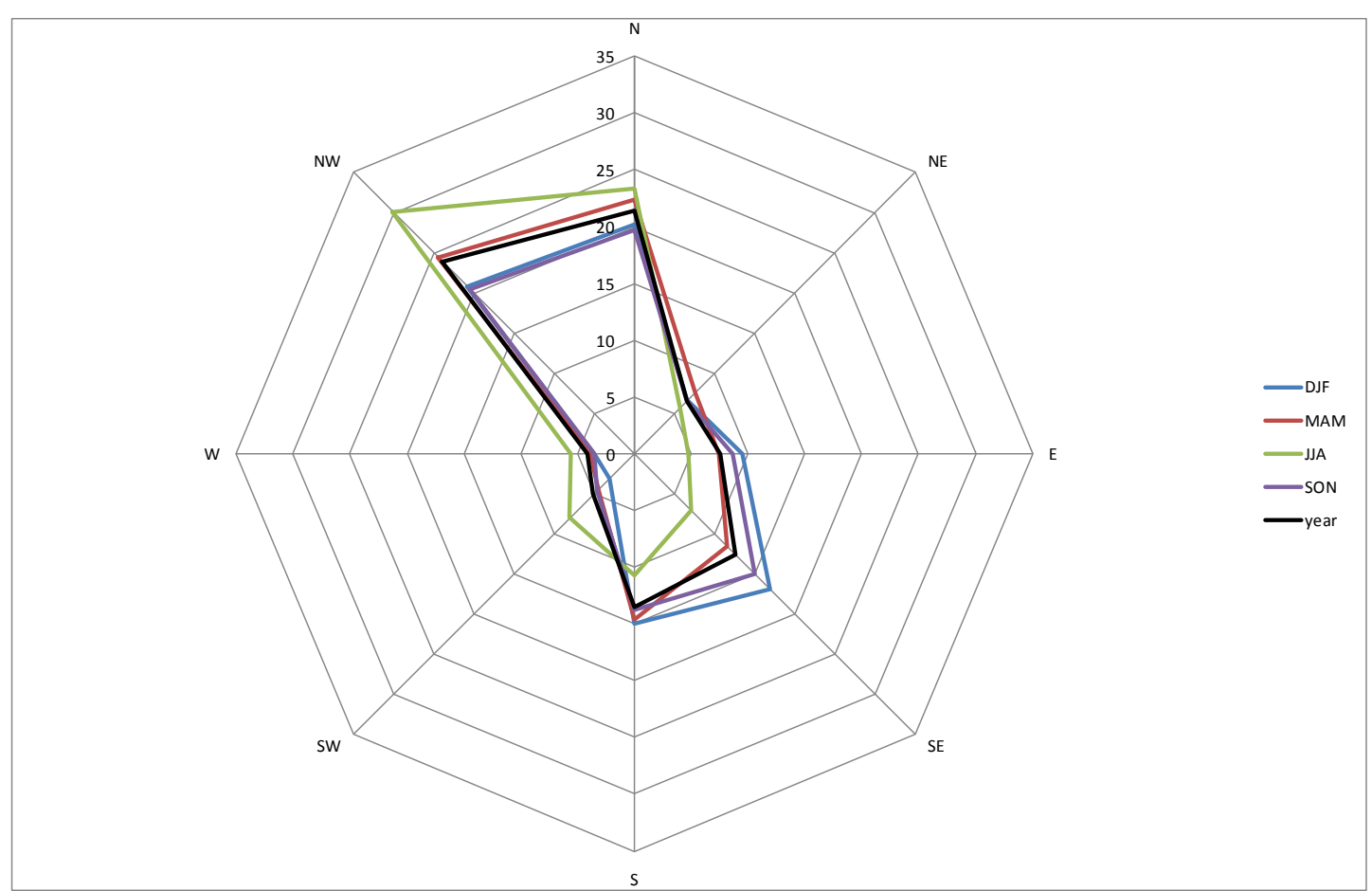

Figure 5: Relative shares (in per cents) of wind directions in three month and annual averages at the climate Station Neusiedl for the period 1971 to 2000. Data source: http://www.zamg.ac.at/fix/klima/oe7100/klima2000/klimadaten_oesterreich_1971_frame1.htm.

Highest average wind speeds are observed in spring with $3.2 \mathrm{~m} / \mathrm{sec}$, lowest in autumn with $2.7 \mathrm{~m} / \mathrm{sec}$ (Figure 6). The annual average is $3.0 \mathrm{~m} / \mathrm{sec}$, observed over the period $1971-2000$. 


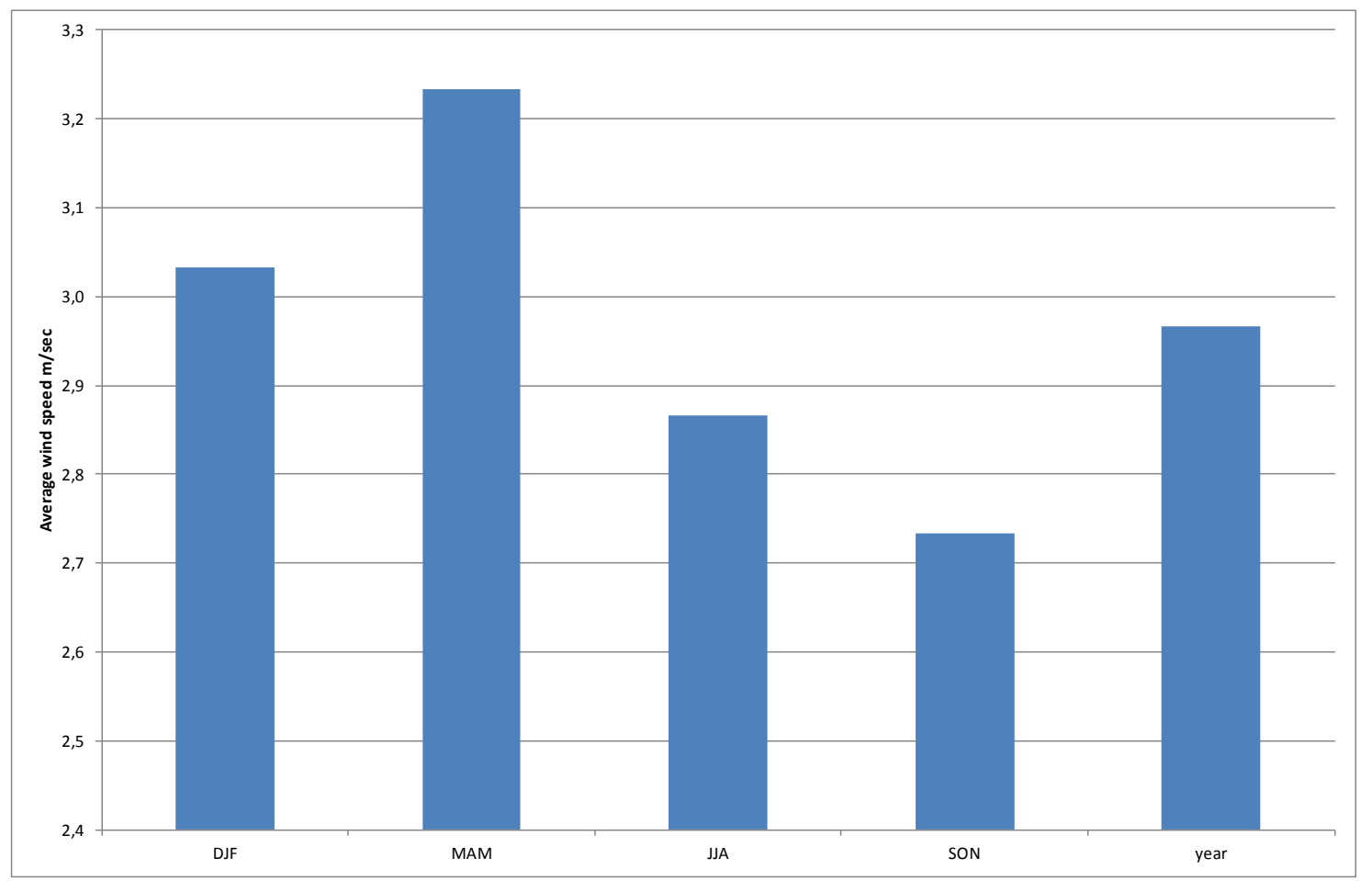

Figure 6: Three month and annual wind speed averages at the climate Station Neusiedl for the period 1971 to 2000. Data source: http://www.zamg.ac.at/fix/klima/oe71-00/klima2000/klimadaten_oesterreich_1971_frame1.htm. 


\subsection{Project specific approach}

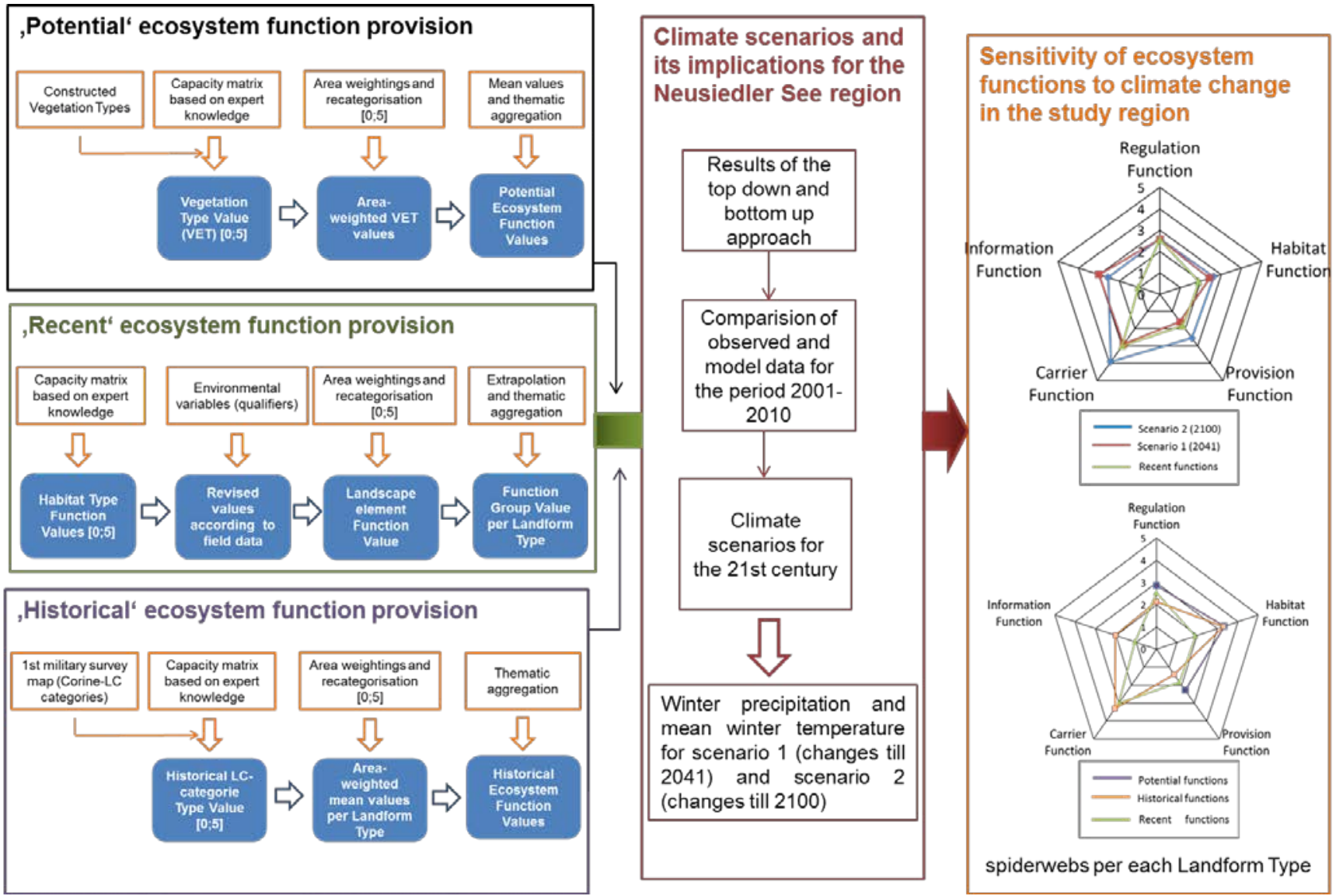

Figure 7: Methodological approach for the assessment of the sensitivity of ecosystem functions to climate change in the study region Neusiedler-See; Corine-LC: Corine-Landcover.

The project can be divided into three big workpackages, each again separated into several working tasks. One workpackage addresses the assessment of the 'potential', 'historical' and 'recent' ecosystem function provision within the study area. Each Landform Type (see Figure 47) is characterized by the allocation of the different function groups (Regulation, Habitat, Provision, Carrier and Information). The changes in the provision of the different functions were illustrated by spiderwebs ('potential', 'historical' and 'recent' distribution of the functions). In another workpackage the climate scenarios recognized as drivers for changes in the ecosystem function provision were calculated. Within the third workpackage we assessed the function responses to climate change effects. Two scenarios were described: ecosystem function changes till 2041 and changes till 2100.

\subsection{Climate scenarios and its implications for the Neusiedler-See region}

\subsubsection{Method and data sources}

Dynamic properties of climate can only be identified on time series of data and not on average values. A big challenge in calculation of climate scenarios for small regions is to close the gap between spatial scales of global climate scenarios and the scale of interest, because of changing relevance of individual factors for climate dynamics at different scales and limited data availability. To solve the task a combination of a top down and a bottom up approaches were selected for the calculation and interpretation of the climate scenarios. The top down approach is based on 
methodical developments made at AIT during former projects. It provides climate scenarios at a spatial resolution of $10 \times 10 \mathrm{~km}$ up to the year 2100 for selected global climate change scenarios. The bottom up approach is based on measured local time series of weather data, provided by the biological research Institute Neusiedlersee. For comparisons between both approaches different spatial resolution of data from both approaches and different spatial and temporal dimension of dynamic processes had to be considered. This is in particular important for the interpretation of precipitation which can be caused by large scale events as also by small scale thunderstorm events. No attempt was made to identify relations between observed wind events at small scales and calculated large scale wind processes, because of high uncertainties in long term wind scenarios.

\section{Methods and data of the top down approach}

Background data and scenario calculations

Climate scenarios are based on the GCM "ECHAM 5", developed at the Max Planck Institute for Meteorology, the most recent version of the ECHAM models series. The dynamic model comprises several physical parameters, including

- short- and longwave radiation and their interactions with chemical composition of the atmosphere, aerosol and cloud particles;

- stratiform cloud schemes;

- cumulus convection;

- subgrid scale orography effects taking into account momentum transfer accomplished orographic gravity waves and the drag exerted by mountains, blocking air flow close to the ground level;

- horizontal diffusion;

- surface fluxes and vertical diffusion;

- land surface processes, including e.g. surface temperature regimes, energetic of water dynamics and albedo;

- land surface parameters, including e.g. background albedo, roughness length, leaf area index and water folding capacities of major ecosystem types.

Anthropogenic emission drivers of the climate scenarios are the IPCC scenarios A1B and B1, representing the central and the most optimistic expectations of the whole bandwidth of all emission scenarios (Figure 8). Based on these scenarios the global temperature will increase until 2100 between 1.5 and 2 degrees (Figure 9).

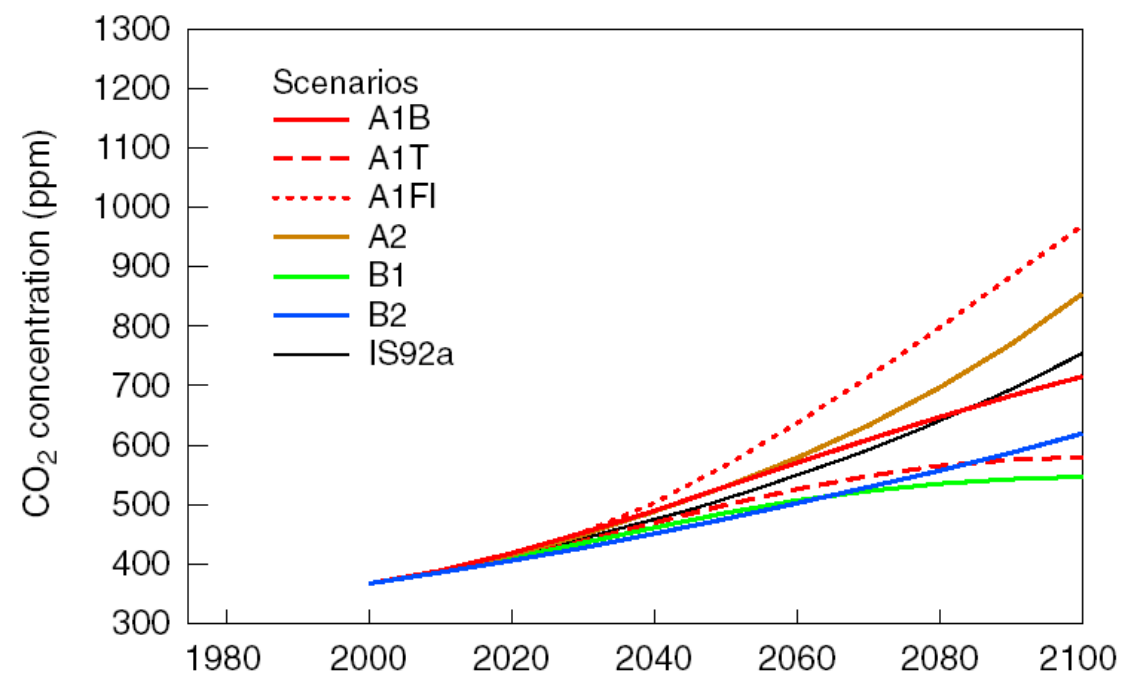

Figure 8: Overview about IPCC scenarios. 


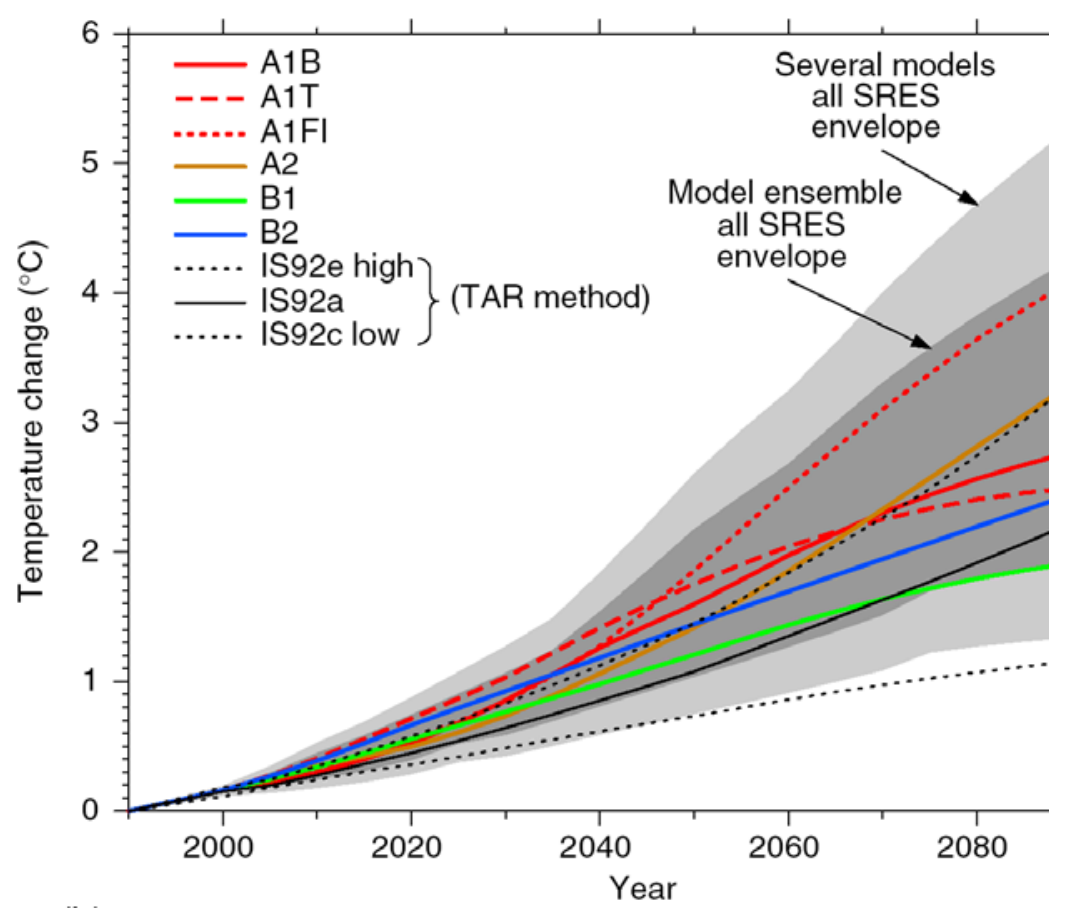

Figure 9: Increases of the global temperature according to different IPCC scenarios.

As Regional Climate Model the COSMO-CLM (CCLM) with a horizontal resolution of $18 \times 18 \mathrm{~km}$ is applied. The model is used and further developed by the ConsOrtium for Small scale MOdeling of several European National weather services and the climate limited area modelling community (http://www.cosmo-model.org/content/default.htm). CCLM is supplied with additional datasets to improve the spatial resolution of the climate scenarios:

- The GLOBE dataset from the National Geophysical Datacenter contains e.g. parameters of the geometric hight of the earth surface, standard deviation of subgrid scale of orographical height and mean slope of subgrid scale orography in a resolution of 30 arc seconds.

- The Global Landcover 2000 Database of the Joint Research Center of the European commission provides parameters of the land cover, surface roughness, ground fraction covered by vegetation during the vegetation period and the rest of the year, ground fraction covered by evergreen und deciduous forest, leaf area index during the vegetation period and the rest of the year, root depth, plant resistance, long wave surface emissivity with a resolution of $1 \times 1 \mathrm{~km}$. For Europe the CORINE Land Cover dataset of the EU with a resolution of $250 \times 250 \mathrm{~m}$ is used.

- The Normalized Differential Vegetation Index (NDVI) from the NASA, comprising annual maximum of normalized differential vegetation index, monthly normalized differential vegetation index and the proportion of actual value to normalized vegetation index.

- The Digital Soil Map of the World from the FAO.

- The climatology of the $2 \mathrm{~m}$ temperature supplied by the Climate Research Unit of the University of East Anglia for the baseline period from 1961 to 1990 in a resolution of 0.5 degrees.

Climate scenarios can be calculated until 2100 in the temporal perspective with spatial resolutions of $10 \times 10 \mathrm{~km}$ for Austria and the Alpine area and $18 \times 18 \mathrm{~km}$ Europe.

\section{Methods and data of the bottom-up approach}

Measured weather data from three different places in the Seewinkel - area were provided by the Biologische Station Neusiedlersee for the time period $1984-2010$. The original data were edited at 
the AIT to achieve reliable data sets for further calculations. Additional data were used from the long term climate monitoring site Neusiedl and the long term lake monitoring site Rust. Data sets from the last mentioned station were used as substitutes to analyse relationships between precipitation and surface water dynamics.

\section{Comparison of both approaches}

Results of both approaches were compared for the period 1984 - 2010 to identify weakness and strengths of the scenario model for the description of climate conditions at high resolutions. Additionally to provide a sound basis for the interpretation of scenario results at the regional level. Hence, the methods were focussed on comparisons of the presentation of particular dynamic aspects between both results, in particular for precipitation events.

\section{Main results of the bottom up approach}

\section{Precipitation}

Analysis of the precipitation data was focussed on the identification of temporal patterns at different scales. A first analysis of annual as also over summer and winter half year precipitation sums over the period $1984-2010$ provides first insights into annual variations (Figure 10). The annual dynamics of the precipitation sums of the full year and the summer half year are very similar in contrast to the values for the winter half year. Big differences can be identified between precipitation sums of different years. The biggest difference of annual precipitation were observed the dry year 1990 and the wet year 1996, for the summer half year between the years 1992 and 1996, and for the winter half year between the years 1990 and 1995. It becomes also evident that the sum of summer precipitations is in general higher than for winter precipitations with few exceptions.

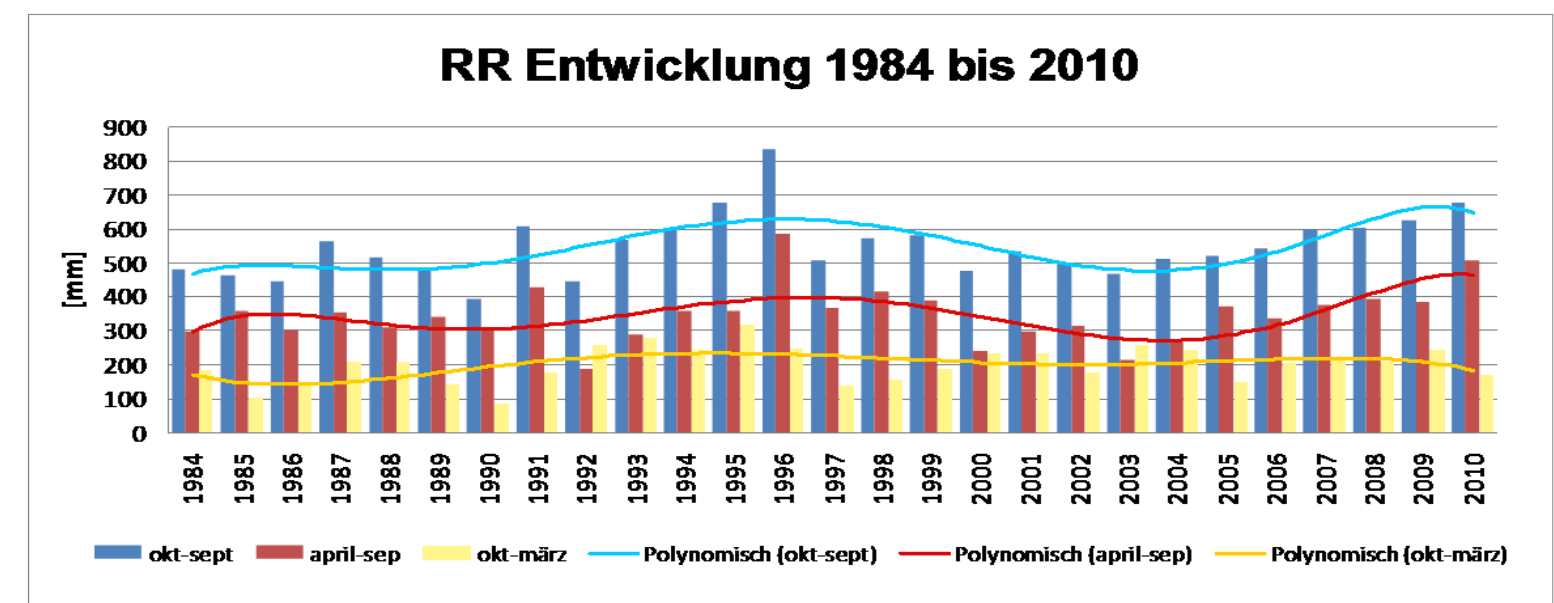

Figure 10: Temporal variability of annual precipitation sums (oct-sep) together with precipitation sums of the summer (april-sep) and winter (okt-märz) half year precipitation sums over the period 1984-2010 in the Seewinkel Region. Data source: Biologische Station Neusiedlersee.

More details about temporal dynamics can be identified by analyses of three month precipitation sums (Figure 11). Highest values were observed for the summer season, followed by spring, autumn, and winter precipitation in descendant order. 

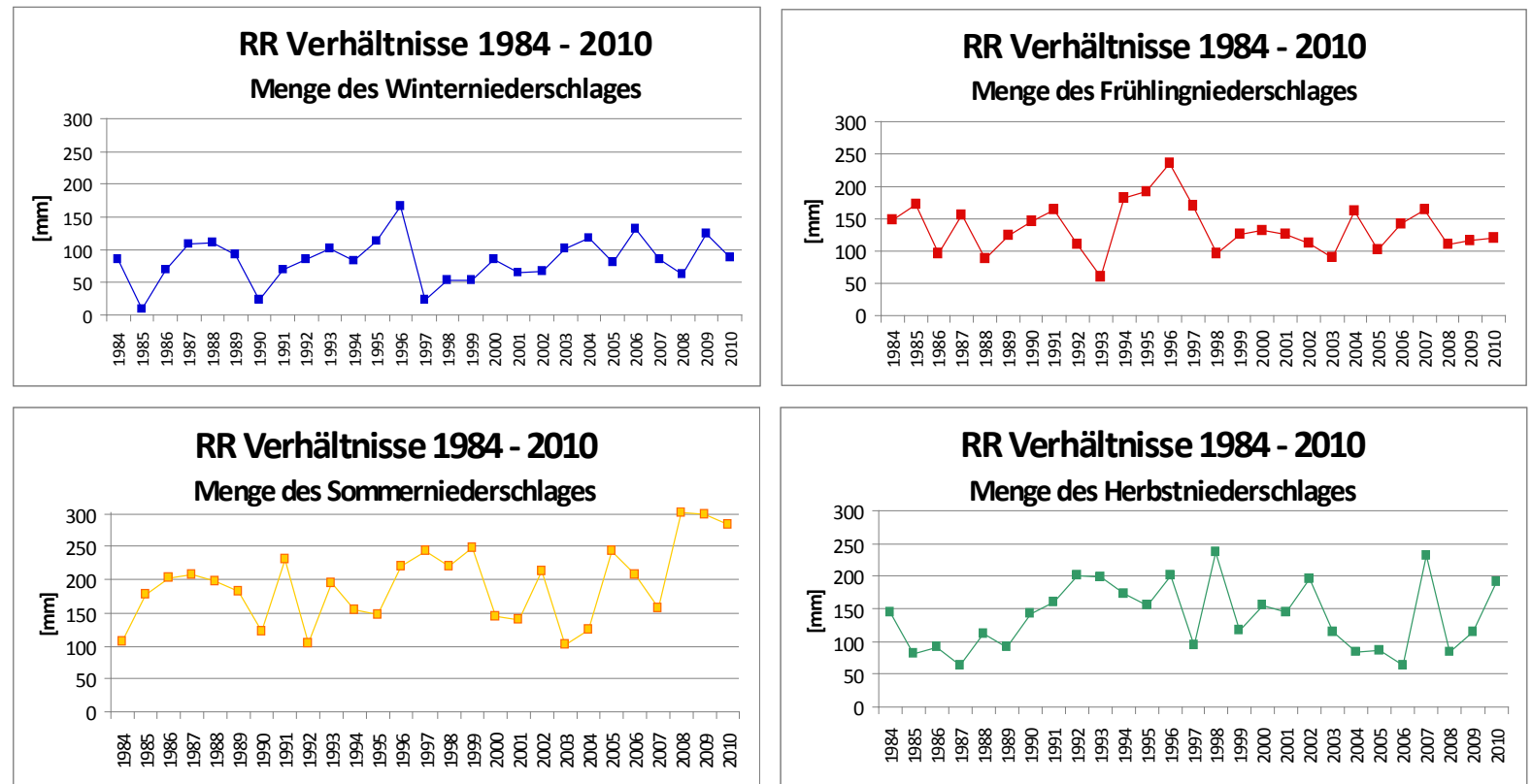

Figure 11: Dynamics of the seasonal precipitation sums over the period 1984-2010 in the Seewinkel Region. Data source: Biologische Station Neusiedlersee.

The order of seasonal precipitation magnitudes can also be found by direct comparisons of five year moving averages among the four seasons (Figure 12). The dominance of summer precipitation persists even at the shorter time interval, except for the period 1990 to 1994 . In the contrary the lowest precipitation sums are evident for the months December until February. Spring and autumn precipitation values are in general in between summer and winter values.

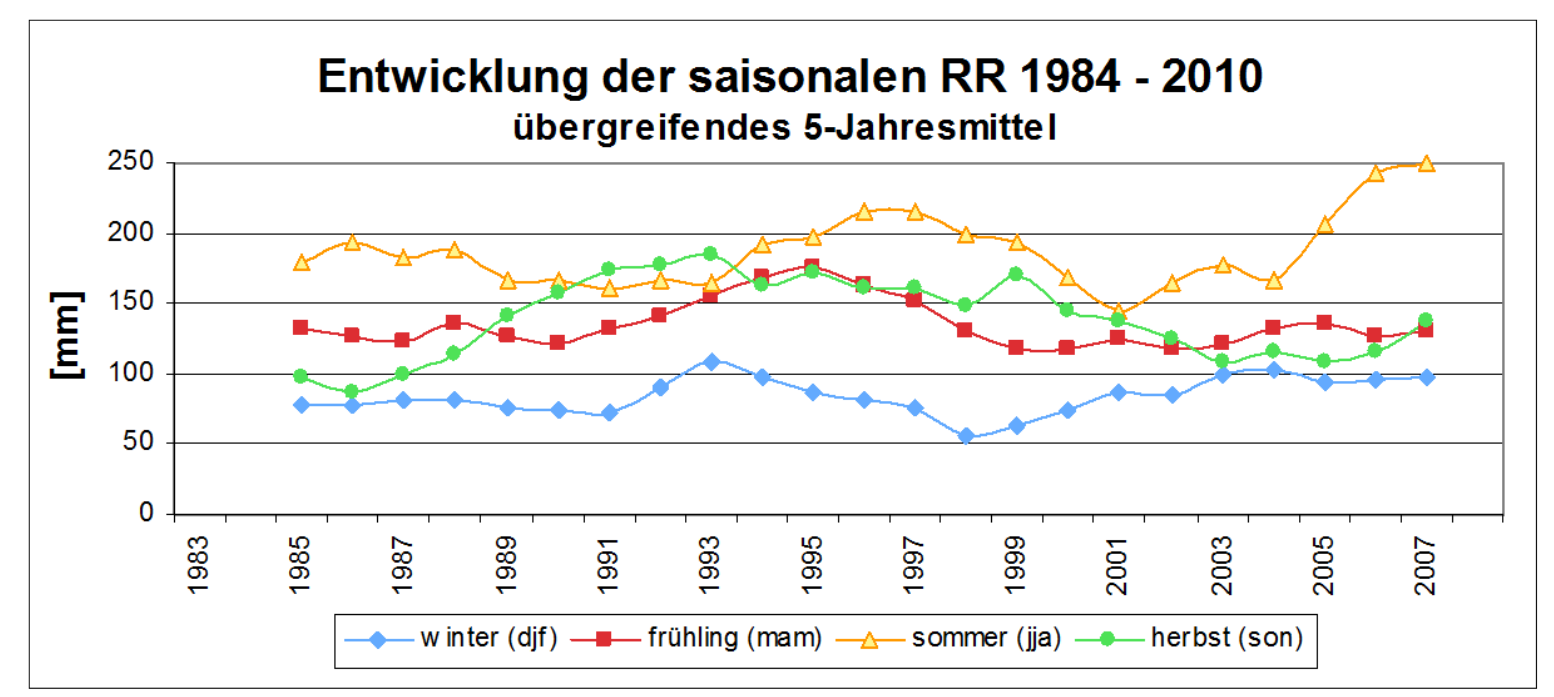

Figure 12: Three-month precipitation sums for winter (djf), spring (mam), summer (jja) and autumn (son) presented by fife year moving averages for the period 1983-2010 in the Seewinkel Region. Data source: Biologische Station Neusiedlersee.

The relevance of the seasonal precipitation for the annual precipitation becomes evident by the presentation in percents (Figure 13). Summer precipitation contributes in general to annual precipitation in the range between 25 and 50 percents, winter precipitation less than 25 percents. Spring and autumn precipitation contribute in general around the level of 25 percents. 

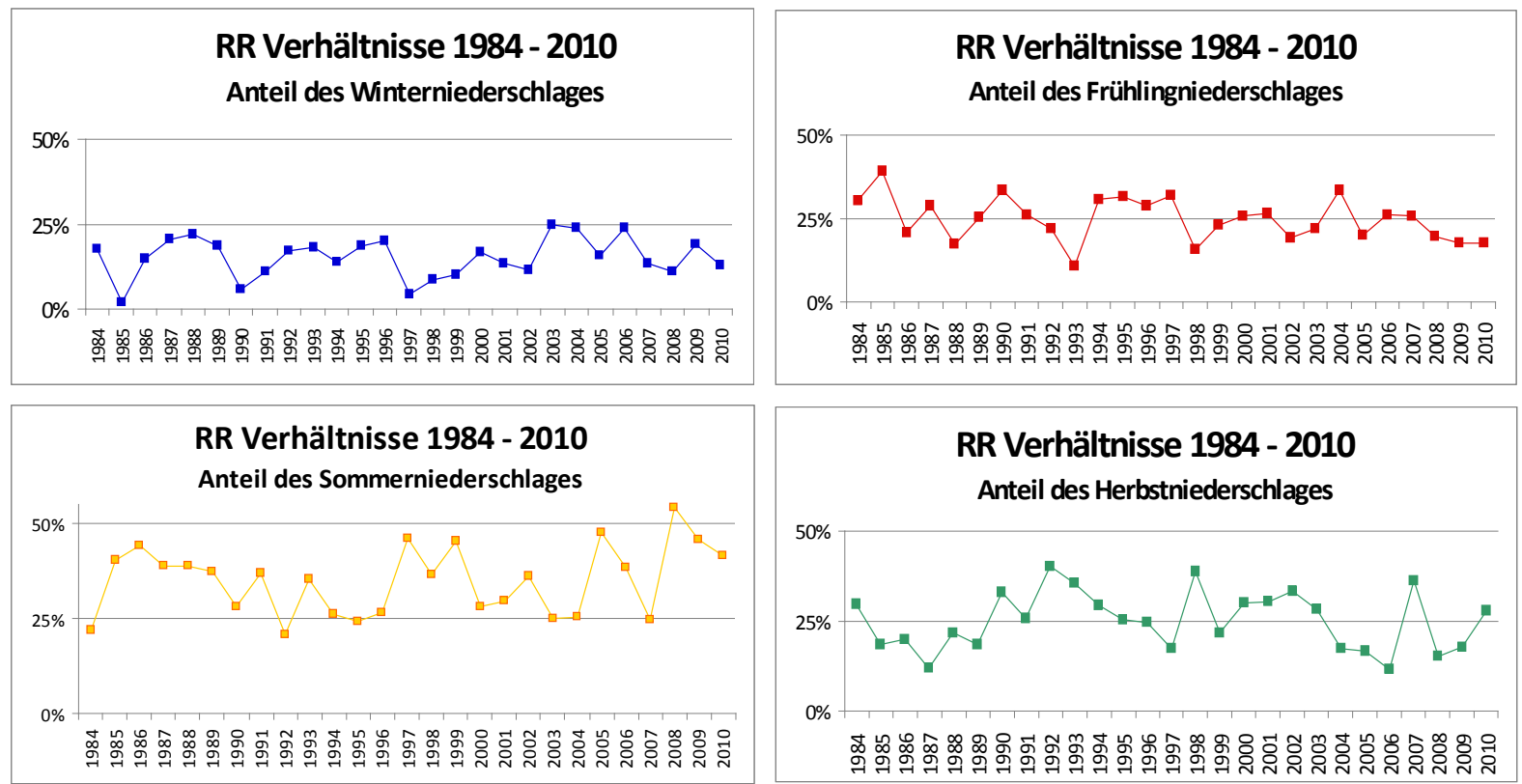

Figure 13: Dynamics of the seasonal contributions to the annual precipitation for the period 1983-2010 in the Seewinkel Region. Data source: Biologische Station Neusiedlersee.

\section{Extreme precipitation events}

The occurrence of extreme precipitation events was analyzed by the application of two thresholds for daily precipitation sums. The lower threshold was defined as $10 \mathrm{~mm}$ precipitation per day and the higher threshold as $20 \mathrm{~mm}$ per day to identify days with heavy rainfall (Figure 14 and Figure 15). Annual changes of days and contributions of rainfalls above both thresholds are similar to the dynamics of total rainfall (Figure 10).

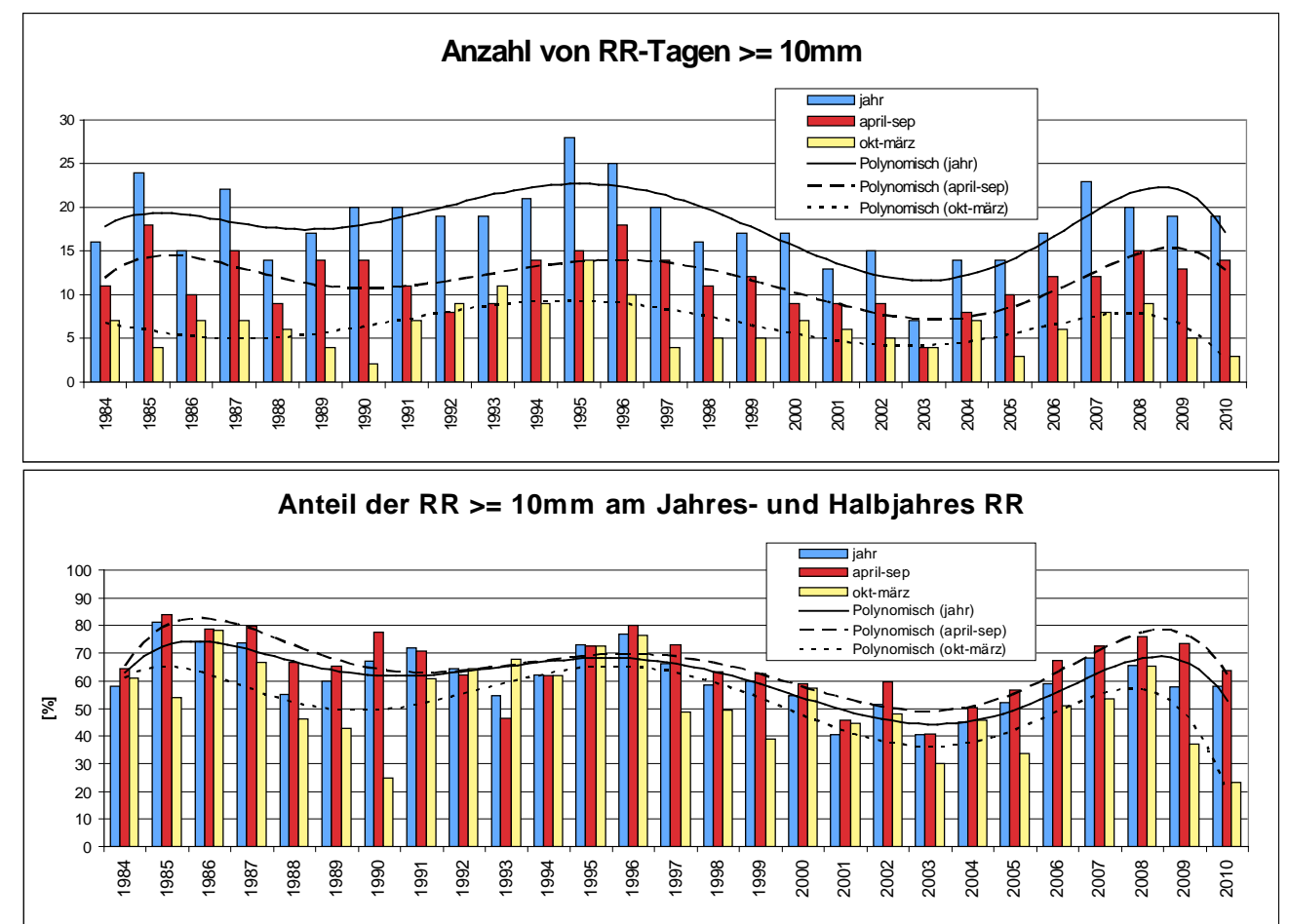

Figure 14: Number of days with precipitation values achieving or exceeding the threshold of $10 \mathrm{~mm}$ (upper diagram), and the contribution of these precipitation to the annual and half year precipitation for the period 1983-2010 in the Seewinkel Region. Data source: Biologische Station Neusiedlersee. 

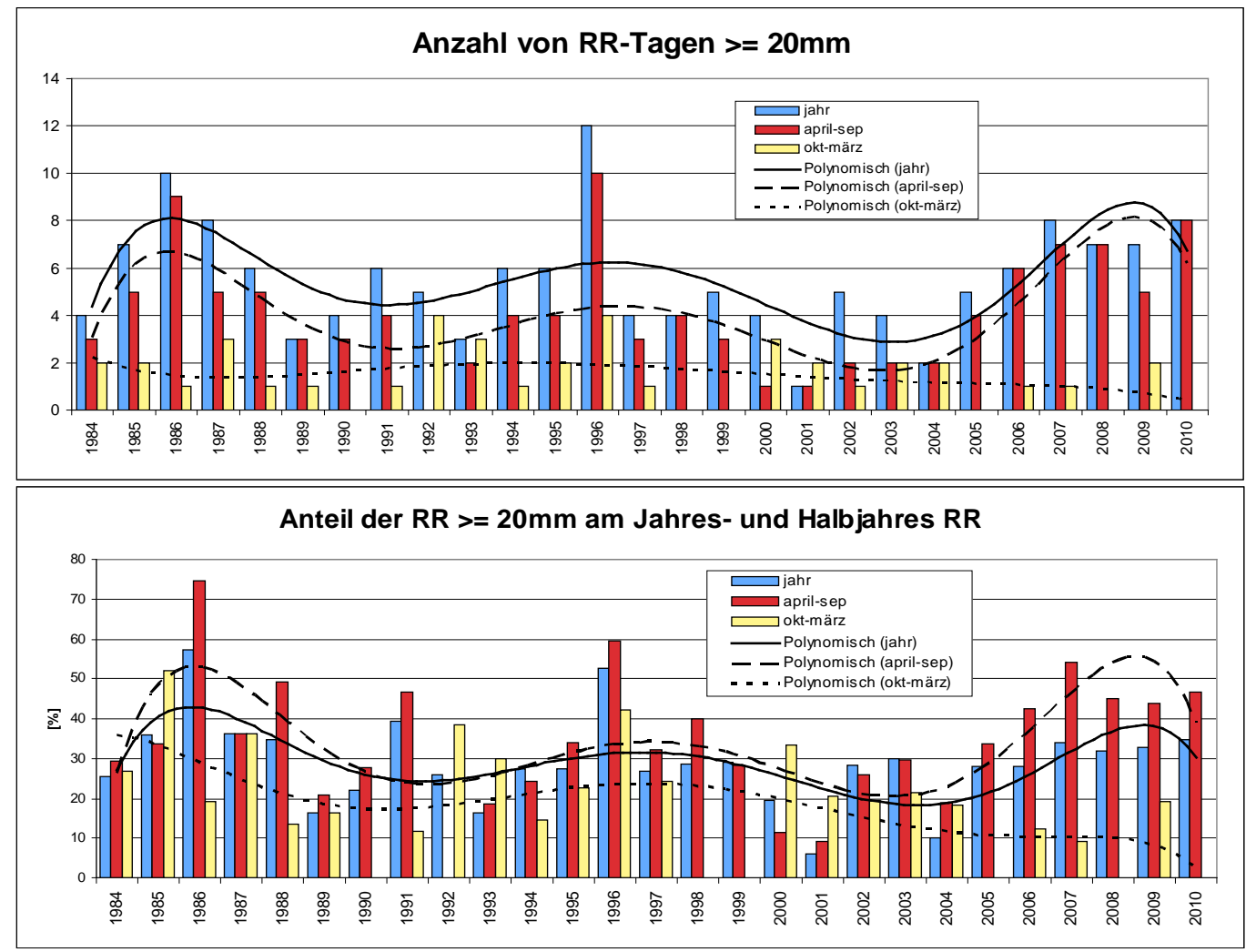

Figure 15: Number of days with precipitation values achieving or exceeding the threshold of $20 \mathrm{~mm}$ (upper diagram), and the contribution of these precipitation to the annual and half year precipitation for the period 1983-2010 in the Seewinkel Region. Data source: Biologische Station Neusiedlersee.

Two questions can be raised because of the similarities of temporal dynamics. The first question concerns the relevance of heavy rainfall for seasonal precipitation, the second concerns temporal trends of heavy rainfall. In the annual presentation of the contributions to the seasonal precipitation a remarkable difference can be found for the time periods before 2002 and from 2002 until 2010. The rainfall of days with minimum sums of $20 \mathrm{~mm}$ contributes to all seasons in most years. In contrary no contribution can be observed for the winter season since 2002, contributions to autumn rainfall occurred during this period only in four years. Of relevance are the contributions of days with heavy rain in particular for the summer season. These changes can also be identified on the mean season values for the decades (Figure 17). Remarkable is the decrease of days without rain over the three decades.

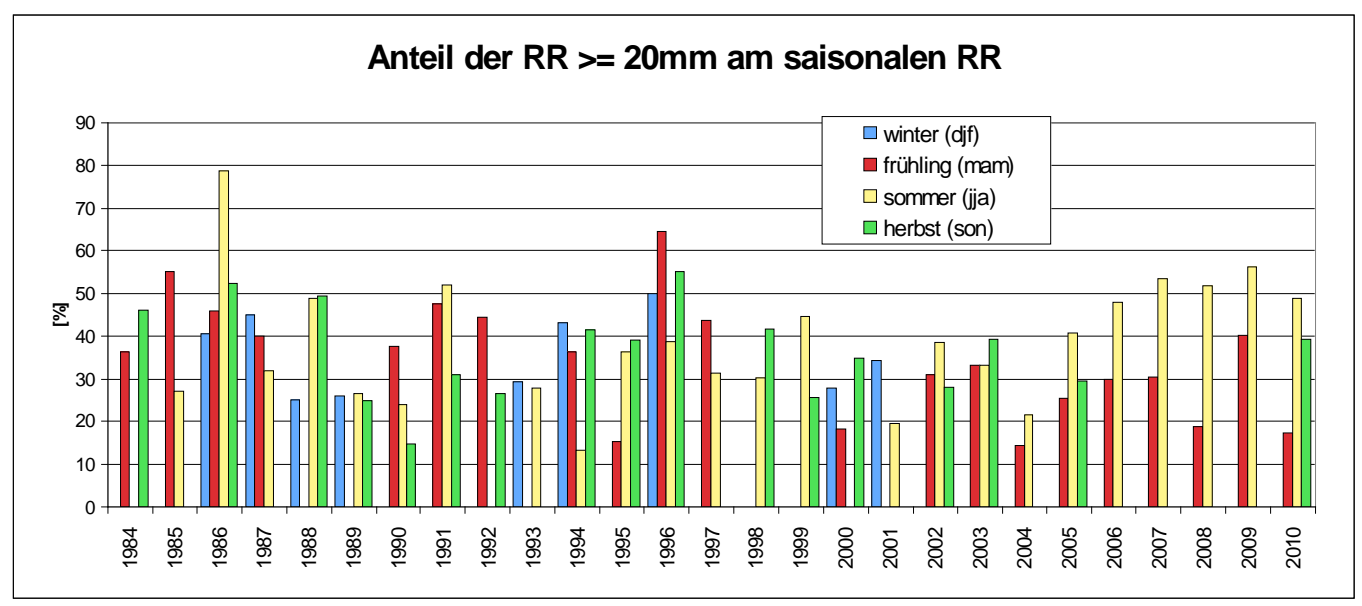

Figure 16: Relative contributions of the precipitation on days with minimum precipitation sums of $20 \mathrm{~mm}$ on total seasonal precipitations in the Seewinkel Region. Data source: Biologische Station Neusiedlersee. 

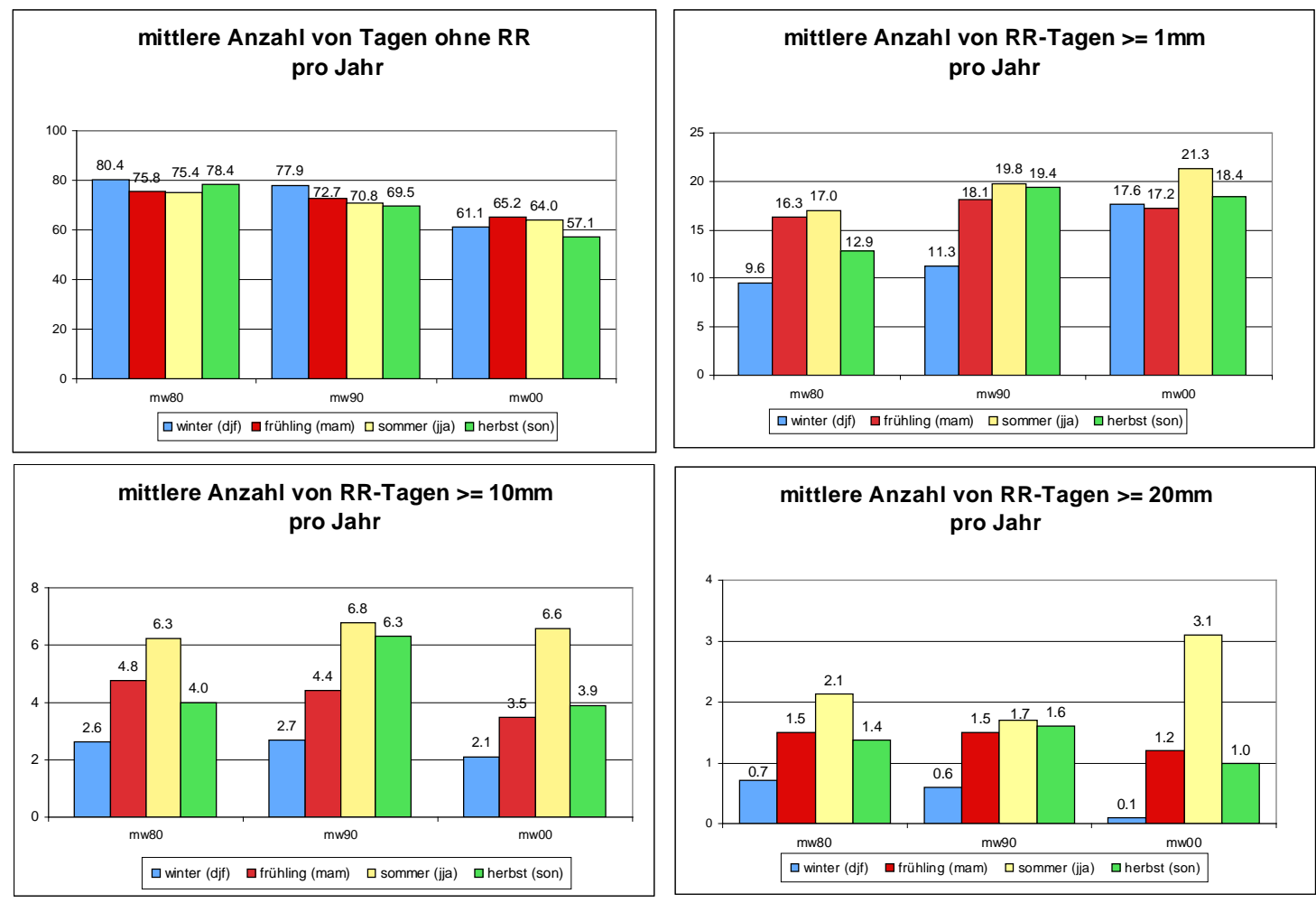

Figure 17: Comparisons of average seasonal values of days without rain, days with minimum precipitation sums of $1 \mathrm{~mm}$, $10 \mathrm{~mm}$ and $20 \mathrm{~mm}$ of the decades 1980-1989, 1990-1999, and 2000-2009 in the Seewinkel Region. Data source: Biologische Station Neusiedlersee.

Of particular interest for ecological studies and for land use management is the temporal development of heavy rainfall intensities. A comparison of the mean seasonal values of rainfall intensities between the three decades provides no information about potential trends (Figure 18). Highest average rainfall intensities were observed during the 1990th with a peak event with $79 \mathrm{~mm}$ in May 1991.

From the comparison of precipitation data of the four monitoring stations it can also be concluded that heavy rainfall events are local phenomena, even in open areas like the Seewinkel (Figure 19). This is important for the definition of requirements for the calculation of climate scenarios. Because of the minimum spatial resolution of the scenario model it is not possible to consider local phenomena like heavy rainfall events in the calculations. In the best case it is possible to provide spatial average precipitation data per singular model cell of 10 to 10 kilometers.

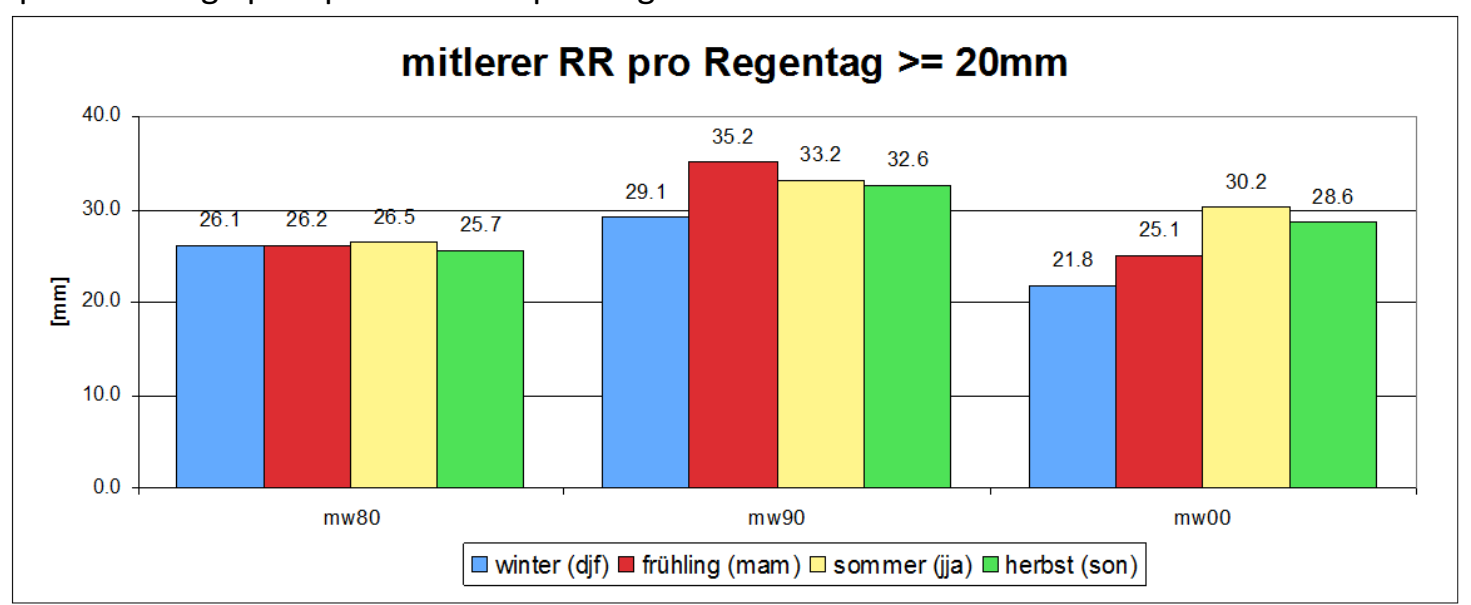

Figure 18: Comparisons of the average seasonal rainfall intensity for days with a minimum precipitation of $20 \mathrm{~mm}$ of the decades 1980-1989, 1990-1999, and 2000-2009 in the Seewinkel Region. Data source: Biologische Station Neusiedlersee. 


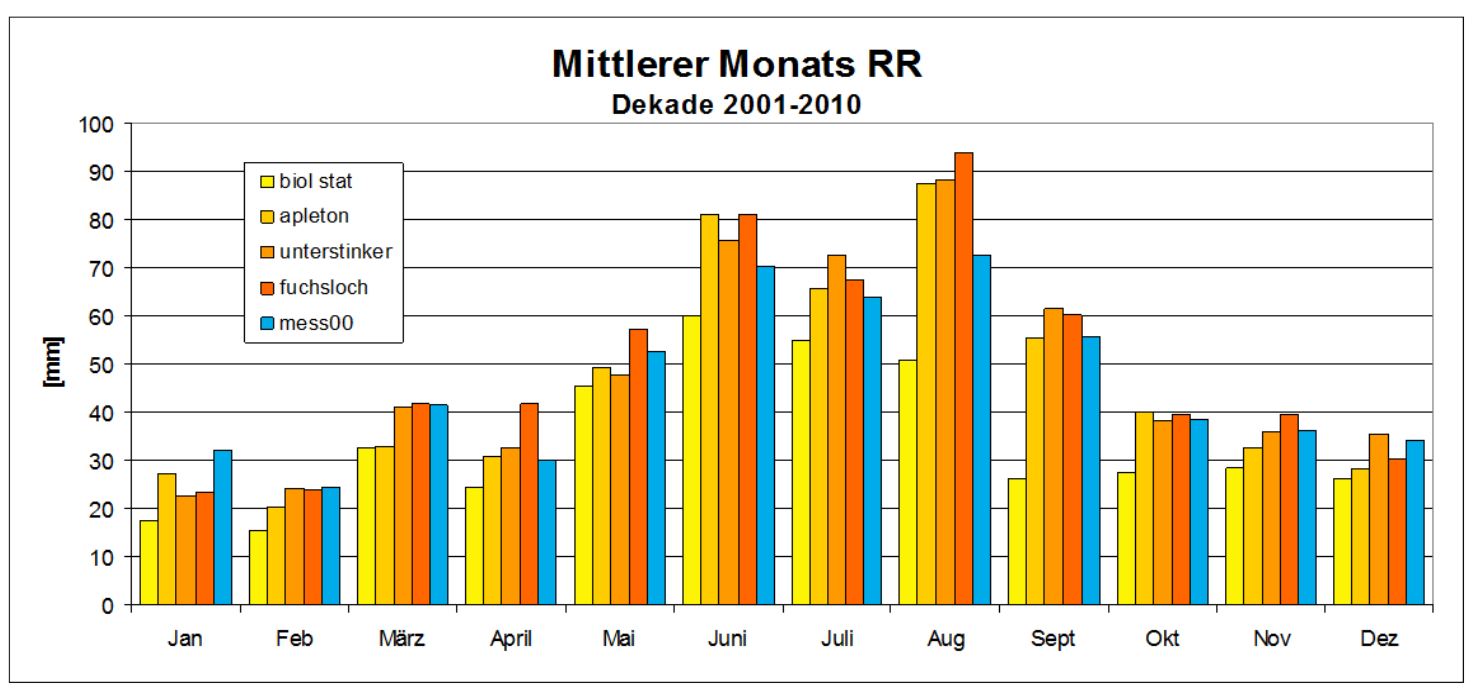

Figure 19: Average monthly precipitation intensities at four monitoring stations in the Seewinkel for the period 20012010. Data source: Biologische Station Neusiedlersee.

\subsubsection{Comparison of observed data and model data for the period 2001-2010}

\section{Objectives and purpose of the comparison}

The objectives of the comparison were the identification of systematic differences between measured and modelled data to provide a support for the interpretation of scenario results. To avoid random influences of spatial distributions model data from a set of six grid cells were compared with average values of the four monitoring sites (Figure 20).

The main reason for this approach was the relatively short time period of available measured data, in particular for temperature with a data set for only ten years. The second reason was the relatively small area covered by the monitoring stations. A model calibration based on such data sets bears a high risk to introduce peculiarities of the short observation time or local conditions into model calculation, causing a bias in the transient scenario calculations.

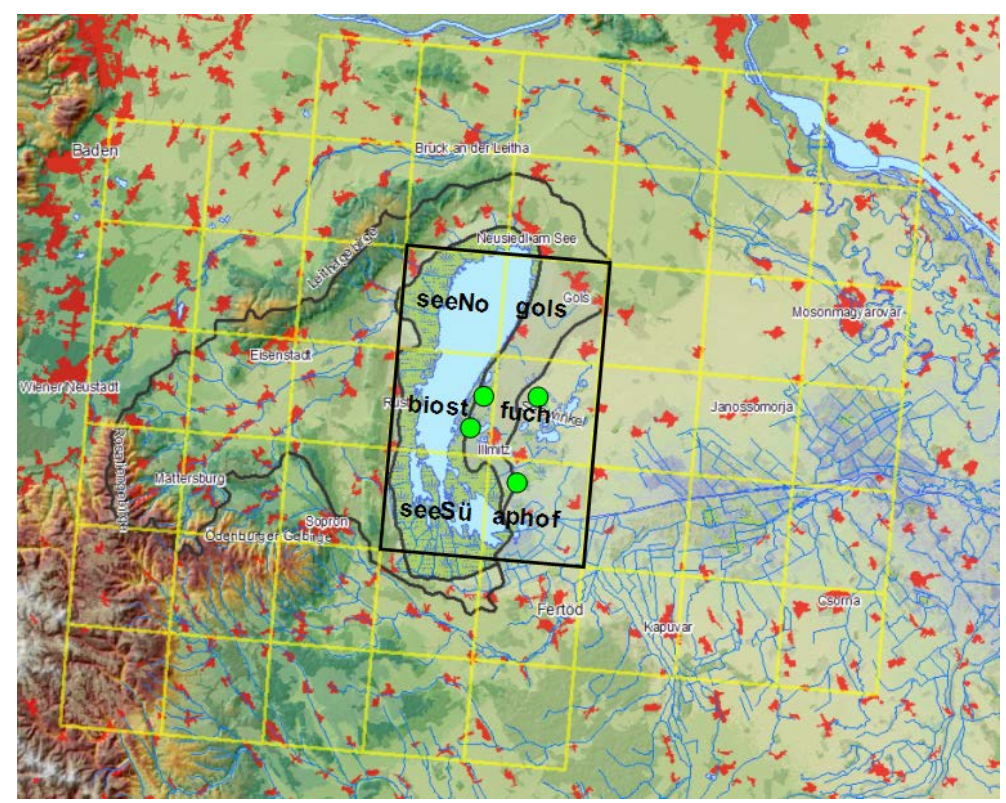

Figure 20: Map of the spatial grid of the scenario model (yellow lines), the spatial distribution of monitoring sites (green dots), and area of model data used for comparisons (black frame). 
At first the data were compared at annual and seasonal temporal resolutions (Figure 21). The model provides at temporal resolutions of one or a half year slight lower temperatures than measured. The differences became larger for spring and summer at seasonal resolutions, but smaller for winter and autumn. No systematic differences can be found for the precipitation, because the model predicts less precipitation for summer seasons, but higher precipitation for autumn and winter seasons. The differences for spring seasons can be neglected.
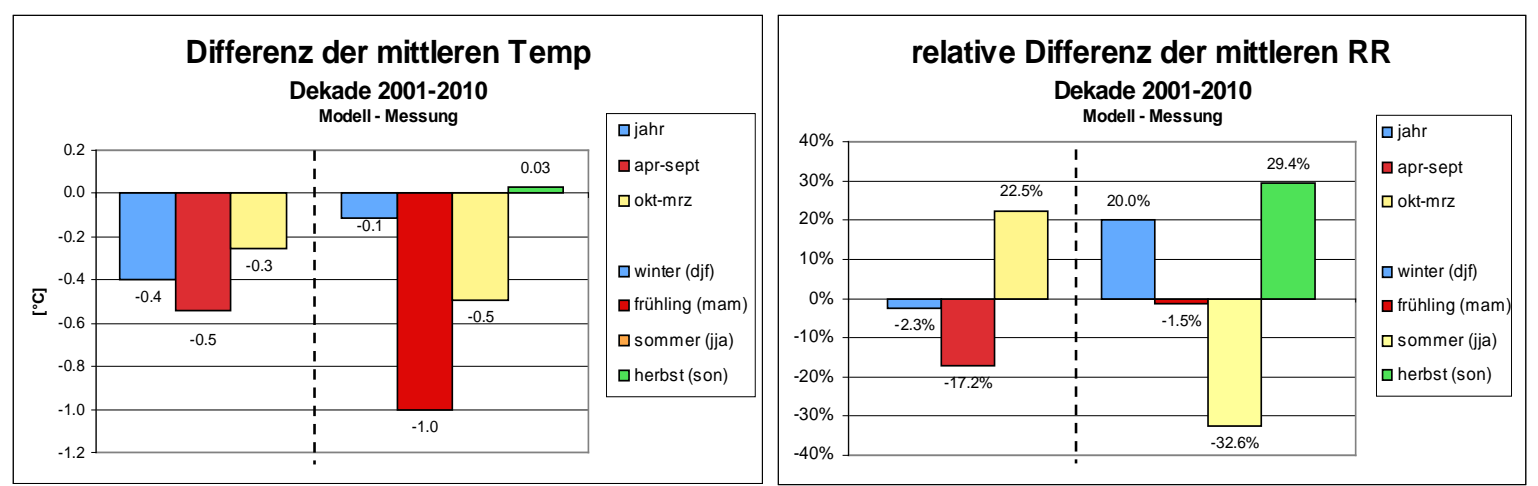

Figure 21: Differences between modeled values and measured values for temperature and precipitation at annual and half year resolution, and seasonal averages over the decade 2001-2002 for the Seewinkel Region. Data sources: Biologische Station Neusiedlersee, and own model calculations.

The variability of differences increases at temporal resolutions of one month. For temperature the largest difference can be found for May with an underestimation of $1.5^{\circ} \mathrm{C}$ by the model. In contrary the temperatures were overestimated for September by $1^{\circ} \mathrm{C}$ (Figure 22).



Figure 22: Differences between modeled values and measured values for temperature of monthly averages over the decade 2001-2002 for the Seewinkel Region. Data sources: Biologische Station Neusiedlersee, and own model calculations.

A higher variability of differences can also be found for the precipitation (Figure 23). The model underestimates the measured values by $24.5 \mathrm{~mm}$ or $38 \%$ in July and overestimates by $26.8 \mathrm{~mm}$ or $73 \%$ in November. Underestimation by model calculations prevails dominantly for summer months, and overestimation for late autumn and early winter. Over- and underestimation occurs between February and April.

The results are a confirmation of our restrictions to use observed data from a relatively short time period for the calibration of long term models. This becomes in particular evident at higher temporal 
resolutions, where the variability of natural dynamics of temperature and precipitation can be larger than the selected resolution. This is in particular important at the margins of analytical time periods. For illustration, if a heavy rainfall occurs in the last days of one month or during the first days of the subsequent month provides very different observation values at monthly resolution. Such variability cannot be considered in transient models because of limited capacities for the consideration of variability in model calculation. By the comparisons of measured and modelled data without model calibration it can also demonstrated that it makes no sense to expect similar temporal resolutions for scenarios as for observations. This fact may be disappointing at the first view, but it has to be considered that there are also big gaps in the spatial resolution of monitoring, which is of high relevance at boundaries between different climate regimes. Modelled spatial variability of temperature and precipitation are presented in Figure 24 and Figure 25 for annual values as also for pre-vegetation and vegetation periods.

However, it raises the awareness to deal carefully with uncertainties in interpretation of phenomena of complex systems like climate. Any mechanistic interpretation of scenario data would distract from the challenges to identify potential trends and uncertainties and to transform the insights into real mitigation measures.
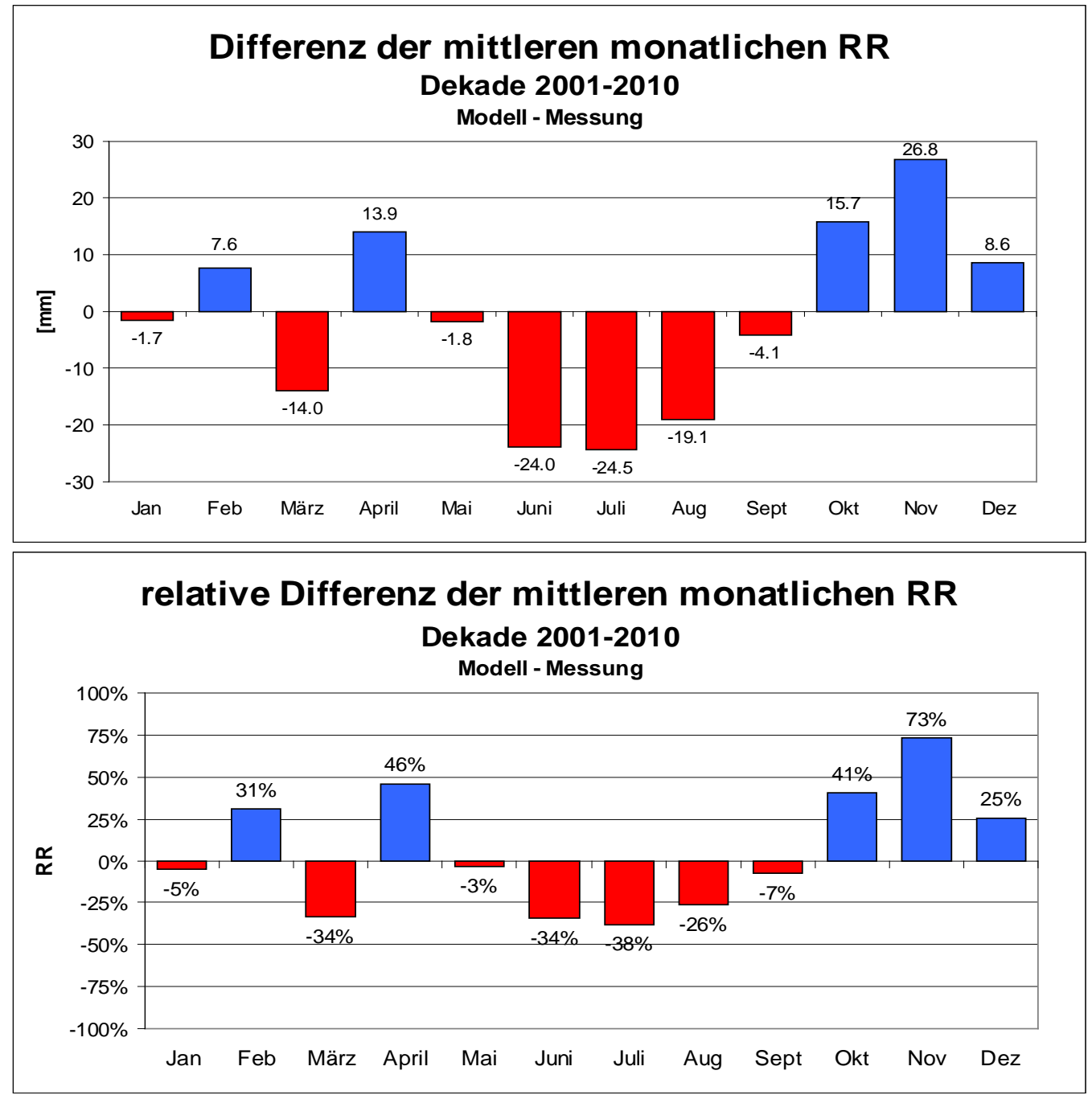

Figure 23: Differences in absolute values and pre cents between modeled values and measured values for precipitation of monthly averages over the decade 2001-2002 for the Seewinkel Region. Data sources: Biologische Station Neusiedlersee, and own model calculations. 
T preveg_00
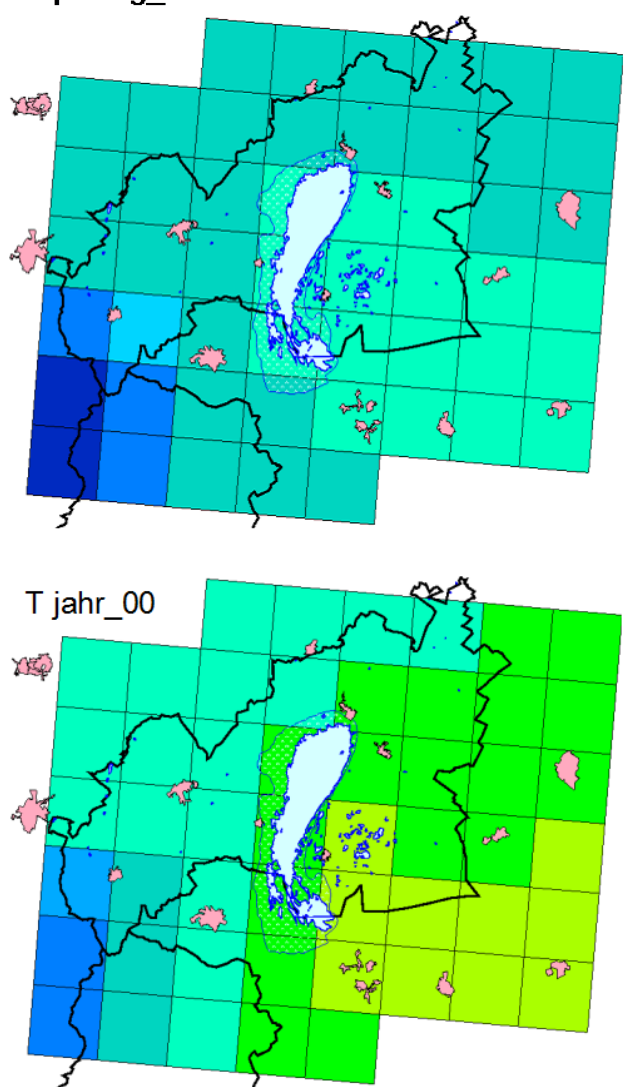

T veg_00

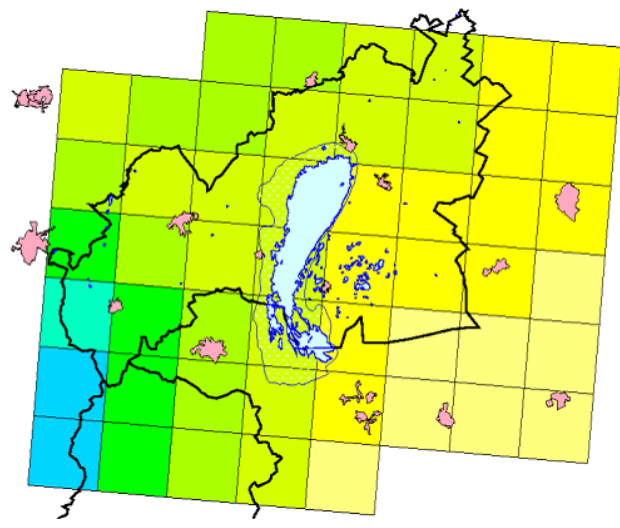

Figure 24: Modeled spatial variability of temperature means for the whole year and the pre-vegetation and vegetation period in the Neusiedler-See region for the period 2001-2010. Data source: own calculations.

RR preveg 00
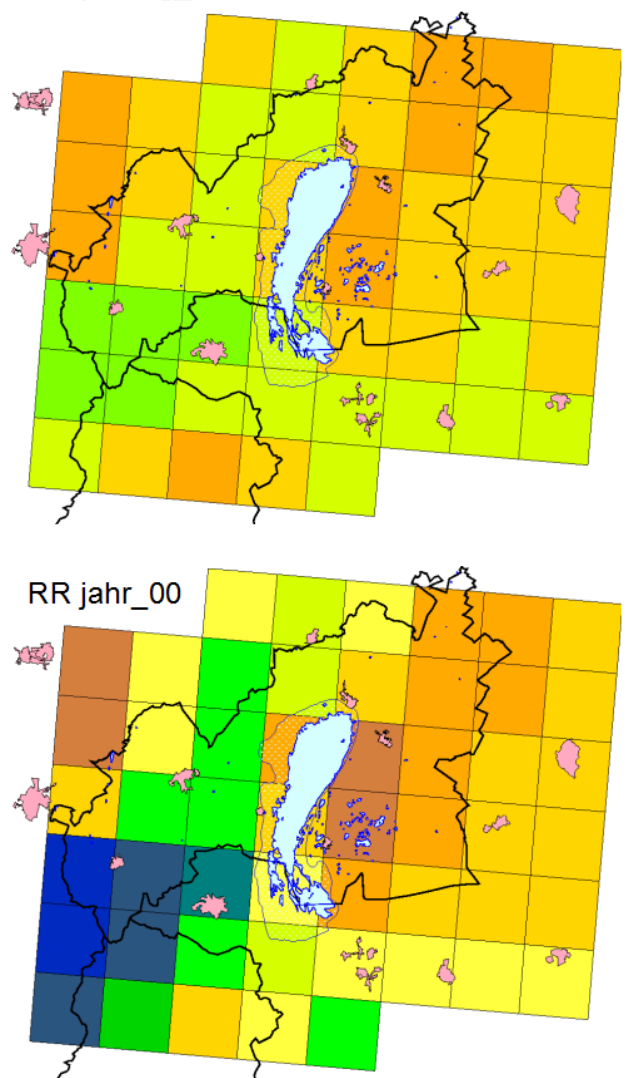

RR veg_00

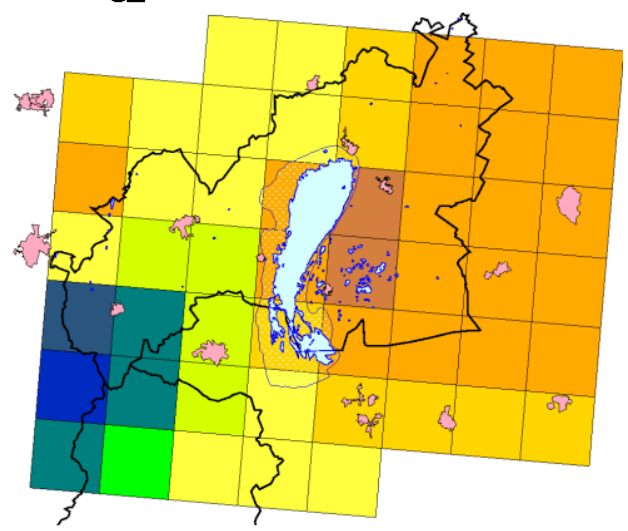

\begin{tabular}{|c|c|}
\hline$R R$ preveg (okt-mrz) & $R R$ veg (apr-sep) \\
\hline$\square 200-250$ & $\square 250-275$ \\
\hline $250-275$ & $275-300$ \\
\hline $275-300$ & $300-325$ \\
\hline $300-325$ & $325-350$ \\
\hline & $\begin{array}{l}350-375 \\
375-400\end{array}$ \\
\hline RR jahr & $400-425$ \\
\hline $500-525$ & $425-450$ \\
\hline $525-550$ & $450-475$ \\
\hline $\begin{array}{l}550-575 \\
575-600\end{array}$ & $475-500$ \\
\hline $\begin{array}{l}575-600 \\
600-625\end{array}$ & \\
\hline $625-650$ & \\
\hline $650-675$ & \\
\hline $675-700$ & \\
\hline $\begin{array}{l}700-750 \\
750-800\end{array}$ & \\
\hline & \\
\hline
\end{tabular}

Figure 25: Modeled spatial variability of precipitation means for the whole year and the pre-vegetation and vegetation period in the Neusiedler-See region for the period 2001-2010. Data source: own calculations. 


\subsubsection{Climate scenarios for the 21st century}

Starting point for the investigation of the future climate of the region was the modeled Decade 20012010. Figure 26 shows the temporal evolution of the mean annual and semi-annual temperatures and precipitation for the six cells that define the study area (Figure 20). In the following Figure 27, the differences of the future decades - concerning precipitation the absolute as well as the relative are plotted against the comparative decade.
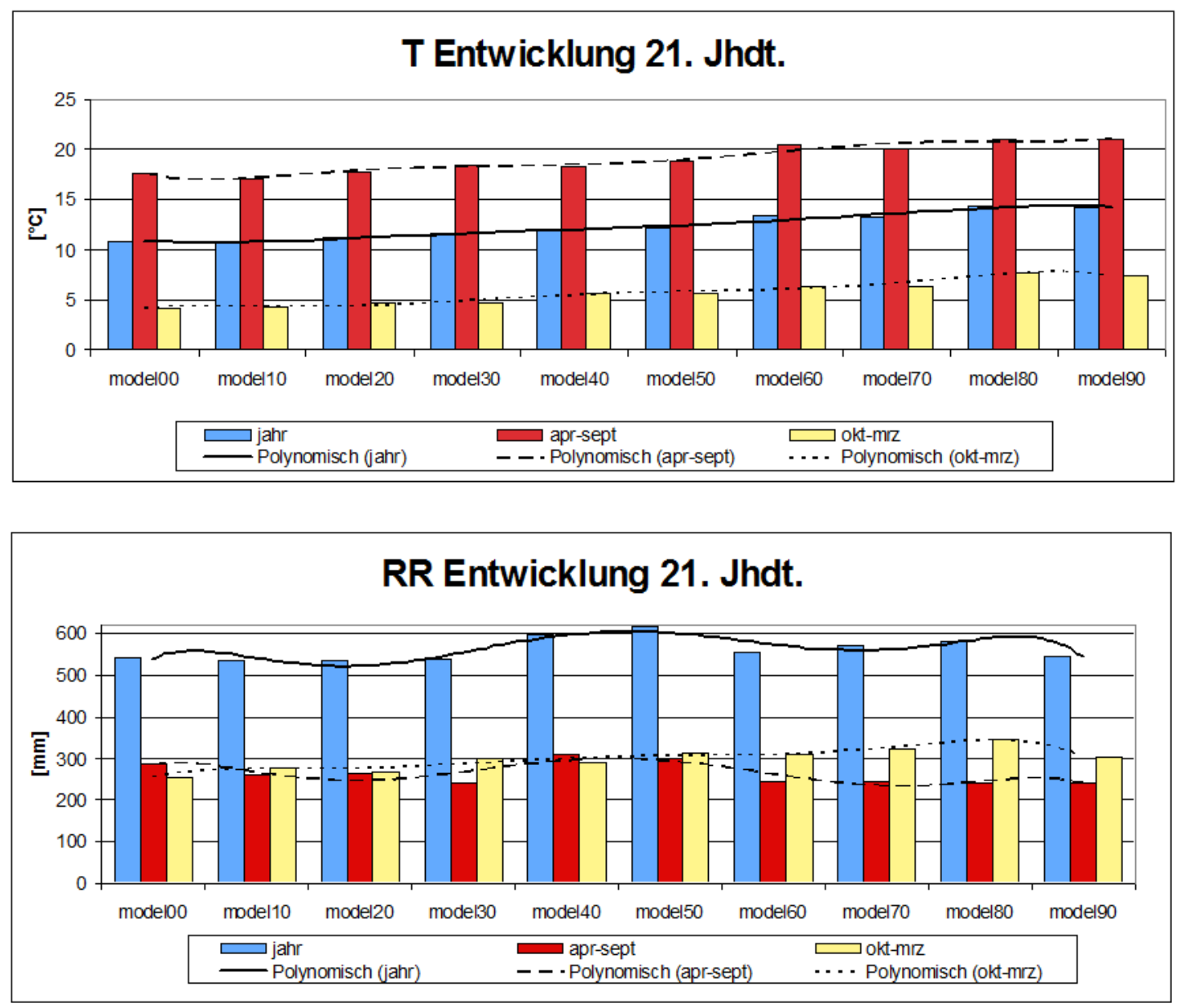

Figure 26: Temporal evolution of the mean temperature and precipitation in the 21st Century, calculated for each decade

While a more or less a continuous increase can be seen in temperature (with a certain stagnation of summer temperature between the 2030ies and the 2050ies), an oscillation occurs again in precipitation. The highest annual precipitations would occur here in the middle of the century. In addition, again a slight time shift in the half-year precipitations can be seen. While precipitations before the vegetation period will already be higher in the next decade, precipitations during the vegetation period decline at first and only from the 2040ies on rise again to comparable levels only to decrease again from the 2060ies onwards. Both together lead to the high annual totals in the 2040ies and 2050ies. However, from the 2060ies on the development is widening. Thus, precipitations from October to March will continue to rise until the 2080ies, but those during the vegetation period will decline significantly.

The future trends become even more apparent in depicting the differences to the comparative period in Figure 27. 

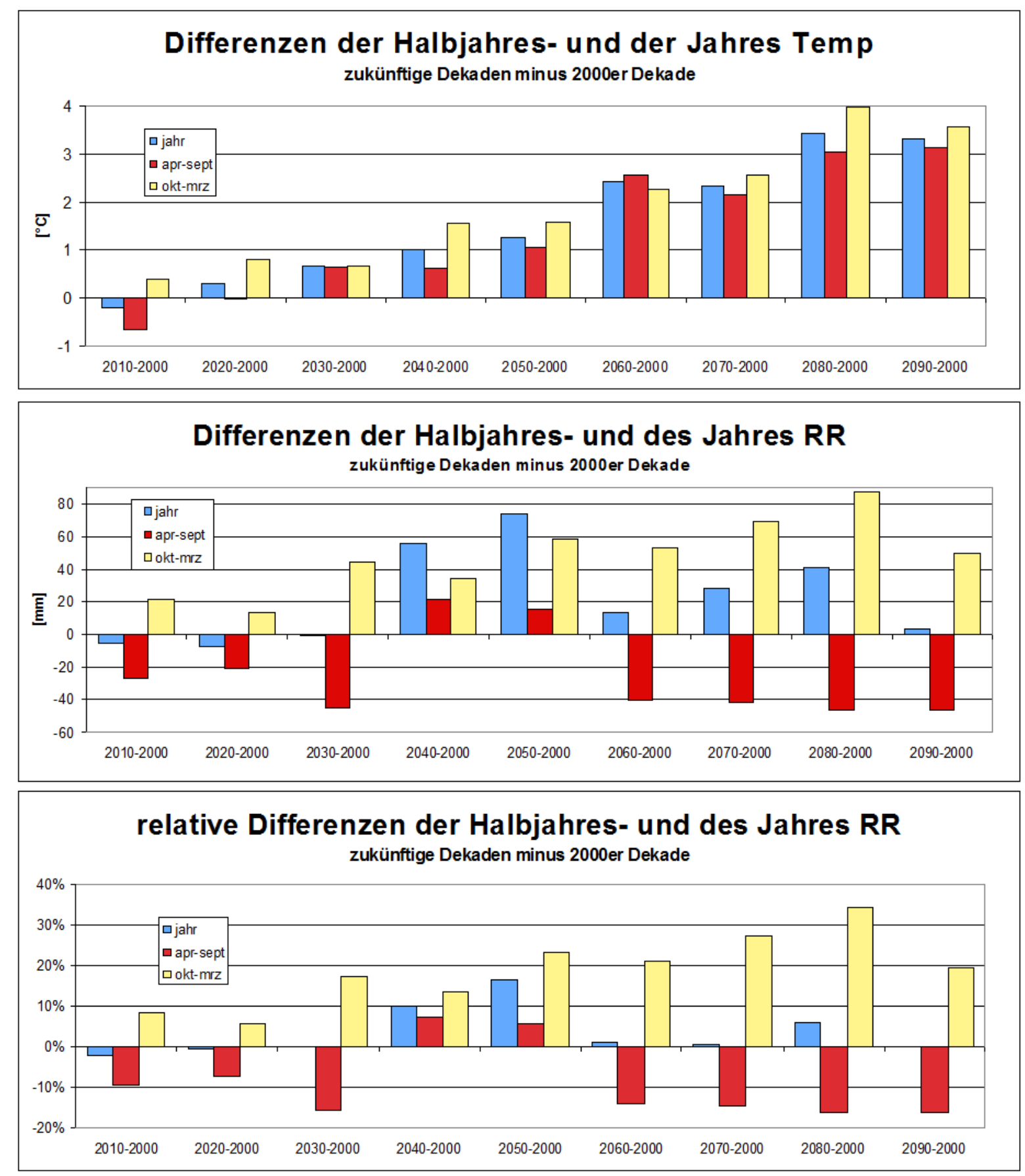

Figure 27: Comparison of the future average temperatures and precipitations for each decade with the reference Decade 2001-2010.

Although the temperature throughout the vegetation period initially decreases by $-0.7^{\circ} \mathrm{C}$ in the next decade (and thereby also slightly throughout the year) and also remains at about the level of the 2010s in the 2020ies, from the decade 2031-2040 onwards it first rises slightly and from the 2060ies onwards the increase gets relatively strong. In general, the increase can be divided into four intervals: In the 2010s and 2020ies a slight decrease followed by an increase to current values; during the 2030ies and 2050ies an increase up to $+1^{\circ} \mathrm{C}$; in the 2060ies and 2070ies an increase to just above $+2^{\circ} \mathrm{C}$; in the last two decades an increase to more than $+3^{\circ} \mathrm{C}$. The highest value with $+3.4^{\circ} \mathrm{C}$ results in the 2080ies mainly due to the extremely elevated winter season temperatures.

When looking at precipitation the temporal oscillation can be seen even more clearly. While differences in precipitation in the winter season vary quite considerably, but always remain positive, precipitations during the vegetation period decrease significantly $(-45 \mathrm{~mm}$ and $-16 \%$ respectively) up 
to the 2030s. In the middle of the century, the amount of precipitation will be slightly higher than in the 2010s, only to drop again (strongly) in the subsequent decades. Seen throughout the year this results in a slight decrease, in the two middle decades the increases add up to a significant growth, while the increase in the winter season's precipitations in spite of decrease in rainfall during the vegetation period leads to a slight increase in the last decades. Only in the very last decade increase and decrease largely cancel each other out. All in all, it seems that the precipitation regime is getting reversed in comparison to the 2000s: The winter precipitations are gaining in importance compared to those of the vegetation period. However, it has to be considered that the reference decade with its exceptionally high summer rainfall (often up to September) was not a typical one compared to the previous decades (see the previous chapter).

Looking at the different seasons more closely the increase in temperature is even more visible especially winter temperatures rise sharply, from the mid-century on the temperatures of the other seasons do as well. The least change can be found in spring. Looking at precipitation shows that from the middle of the century onwards especially precipitations in spring will rise sharply, as will those of the three winter months from the 2070ies on. The precipitations in autumn will hardly change and those in summer will decrease sharply from the 2050ies on. Whether this is due to an actual decline in summer thunderstorms or only to the apparent problems of the model to resolve those, cannot be said.
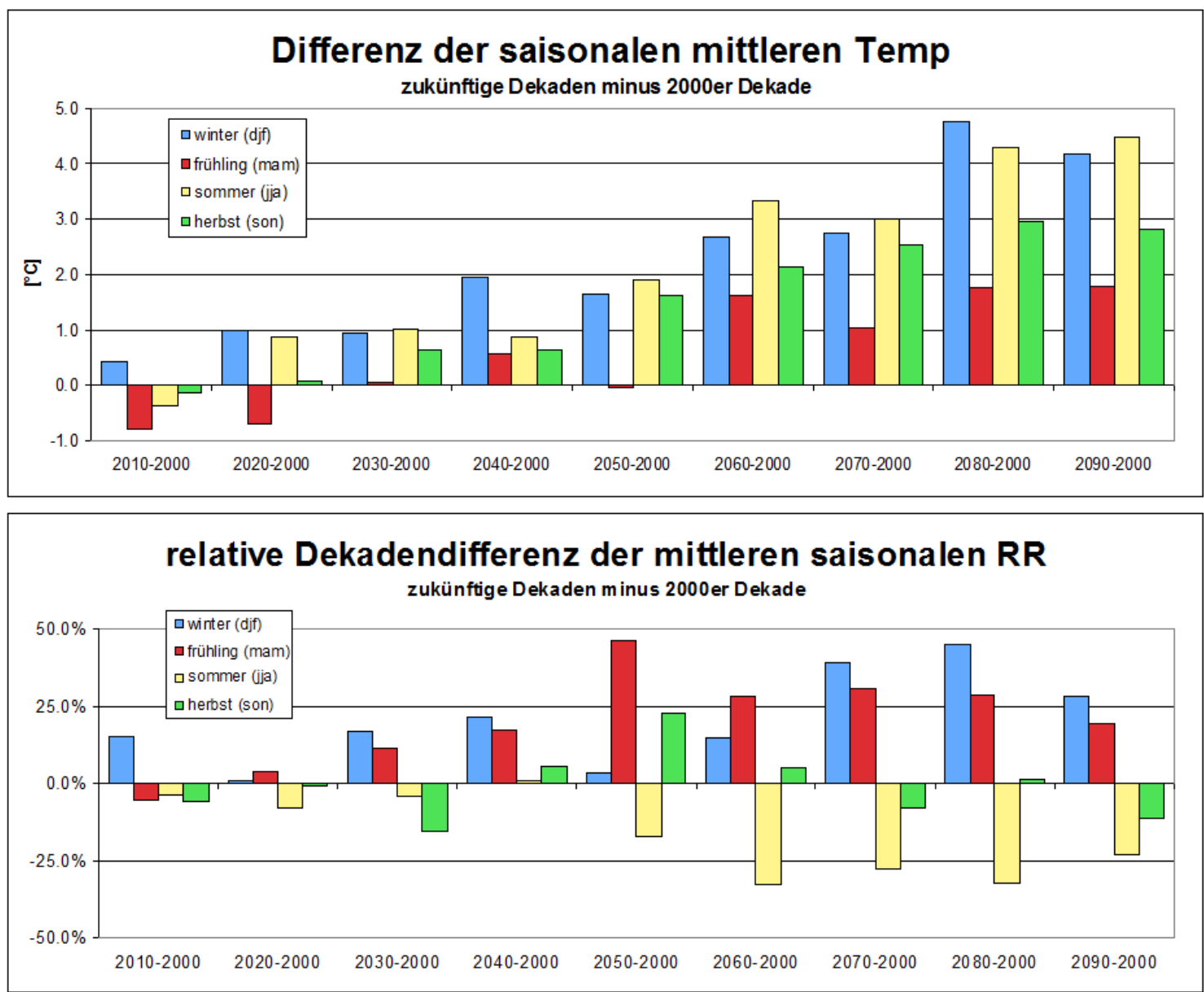

Figure 28: Comparison of the future average seasonal temperatures and precipitations for each decade with the reference Decade 2001-2010.

In the following figures the results of all decade models are compared to each other for a better illustration. The temperature figures also show the measured values of the comparative decade, the precipitation figures also show the values of the 90ies decade. In addition, the monthly developments are presented as well. As mentioned above, this should be treated with increased 
caution. Specific explanations of the monthly values are not given for reasons mentioned above. In the figure series Figure 33 all temperatures and precipitation totals are finally summarized again.

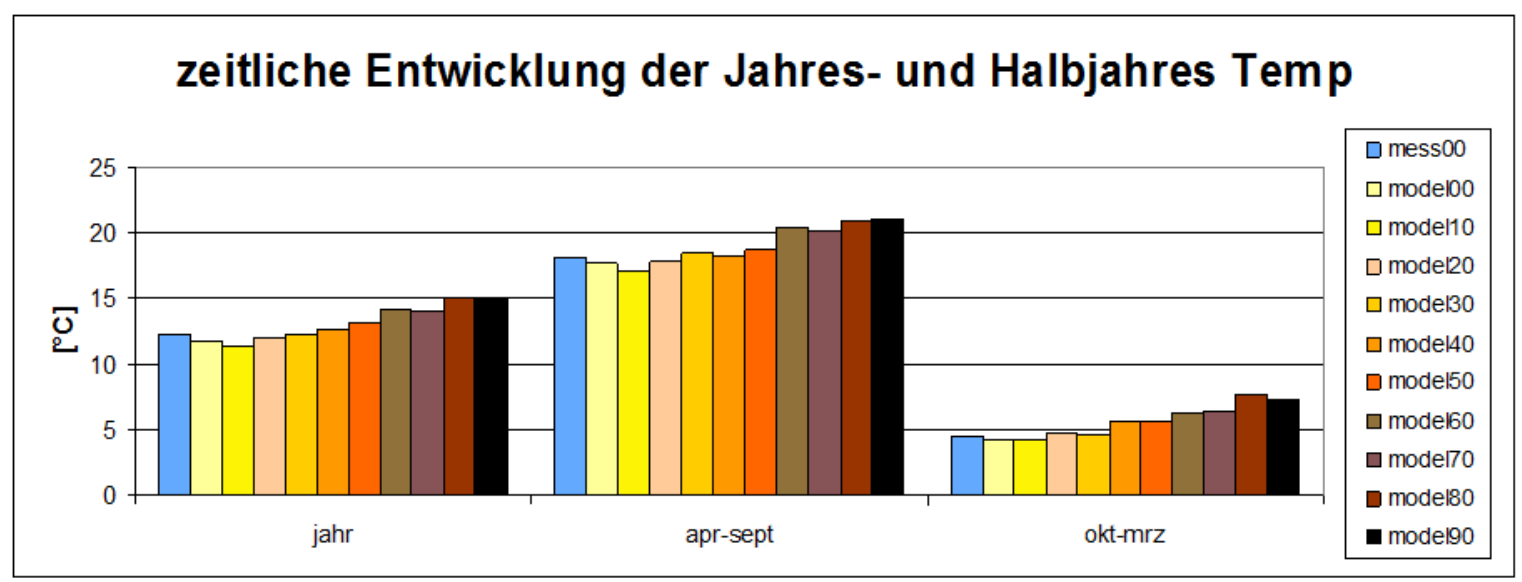

Figure 29: Comparison of mean annual and semi-annual temperatures, by decades
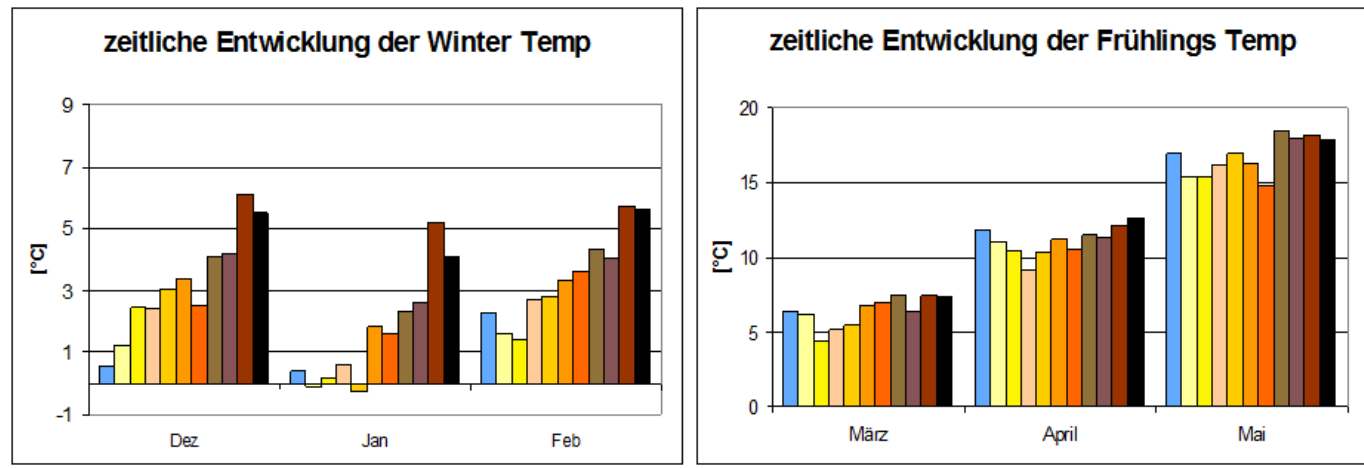

zeitliche Entwicklung der Sommer Temp
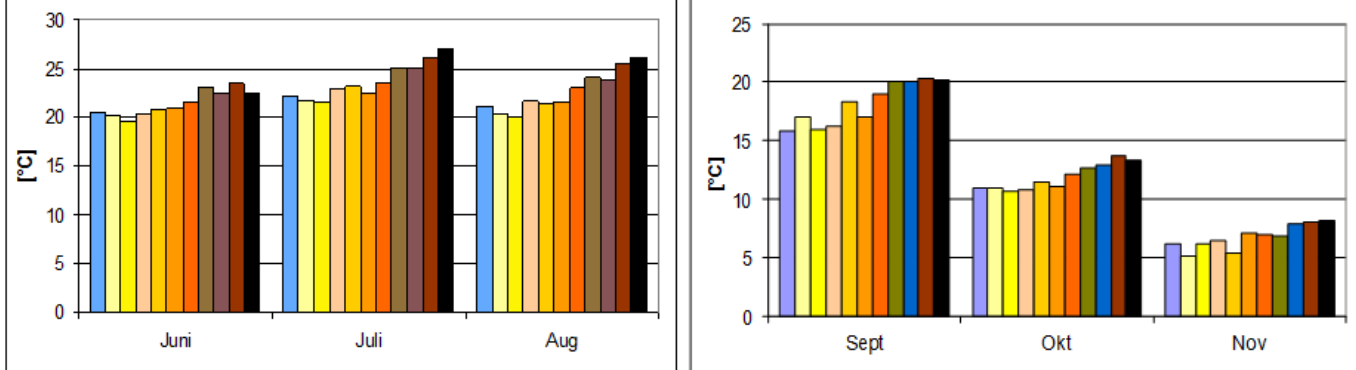

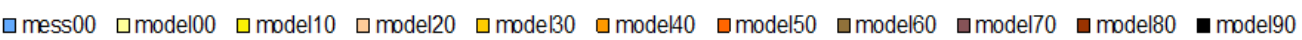

Figure 30: Comparison of mean monthly temperatures, by decades 


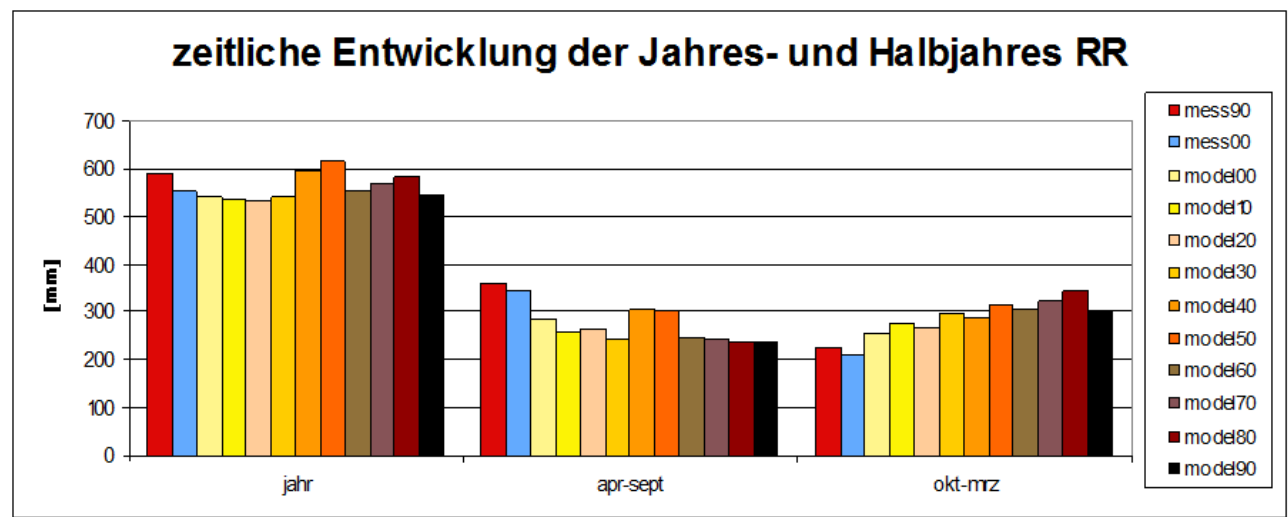

Figure 31: Comparison of mean annual and semi-annual precipitation, by decades
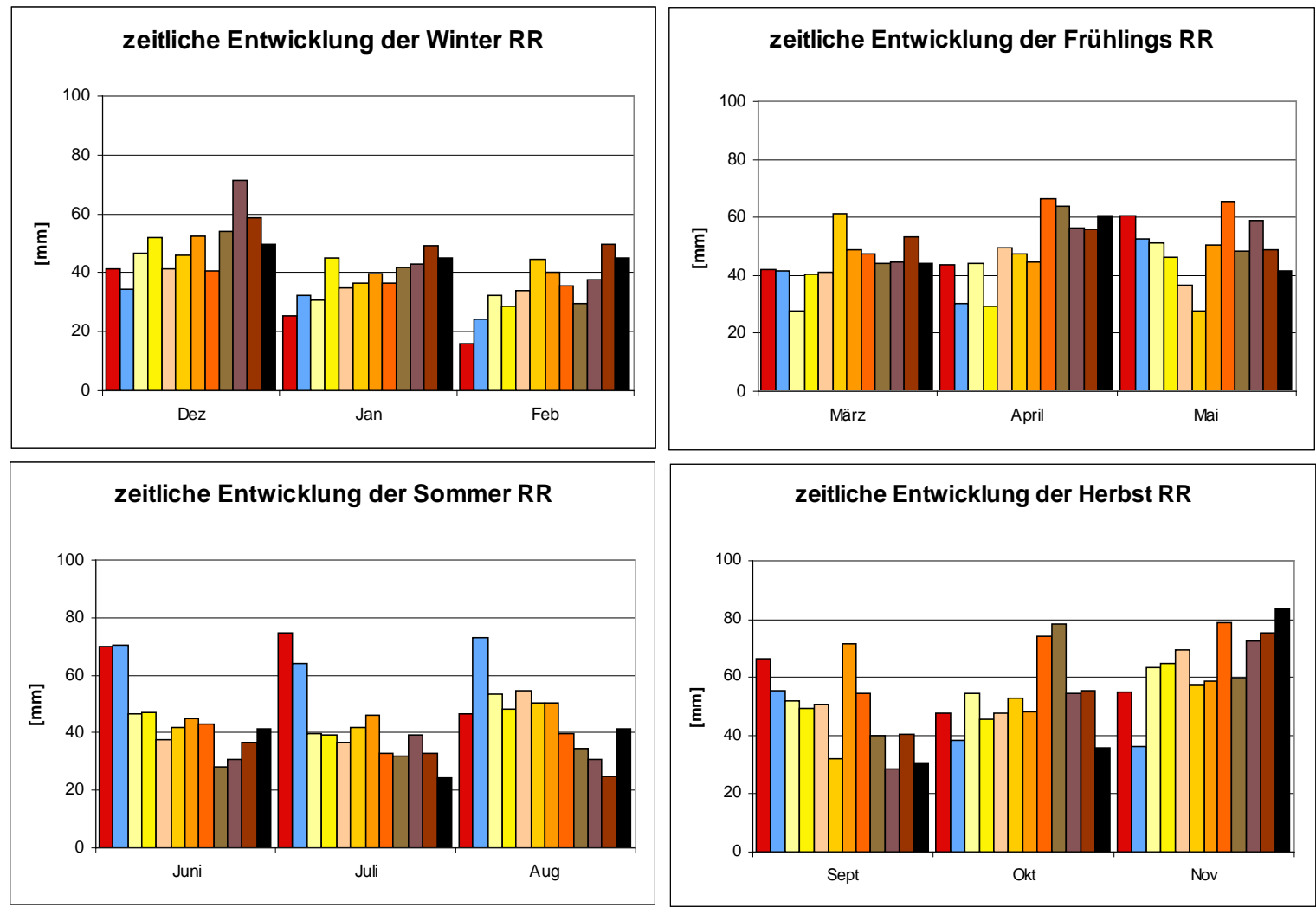

$\square$ mess90 $\square$ mess00 $\square$ model00 $\square$ model10 $\square$ model20 $\square$ model30 $\square$ model40 $\square$ model50 $\square$ model60 $\square$ model70 $\square$ model80 $\square$ model90

Figure 32: Comparison of mean monthly precipitation, by decades 

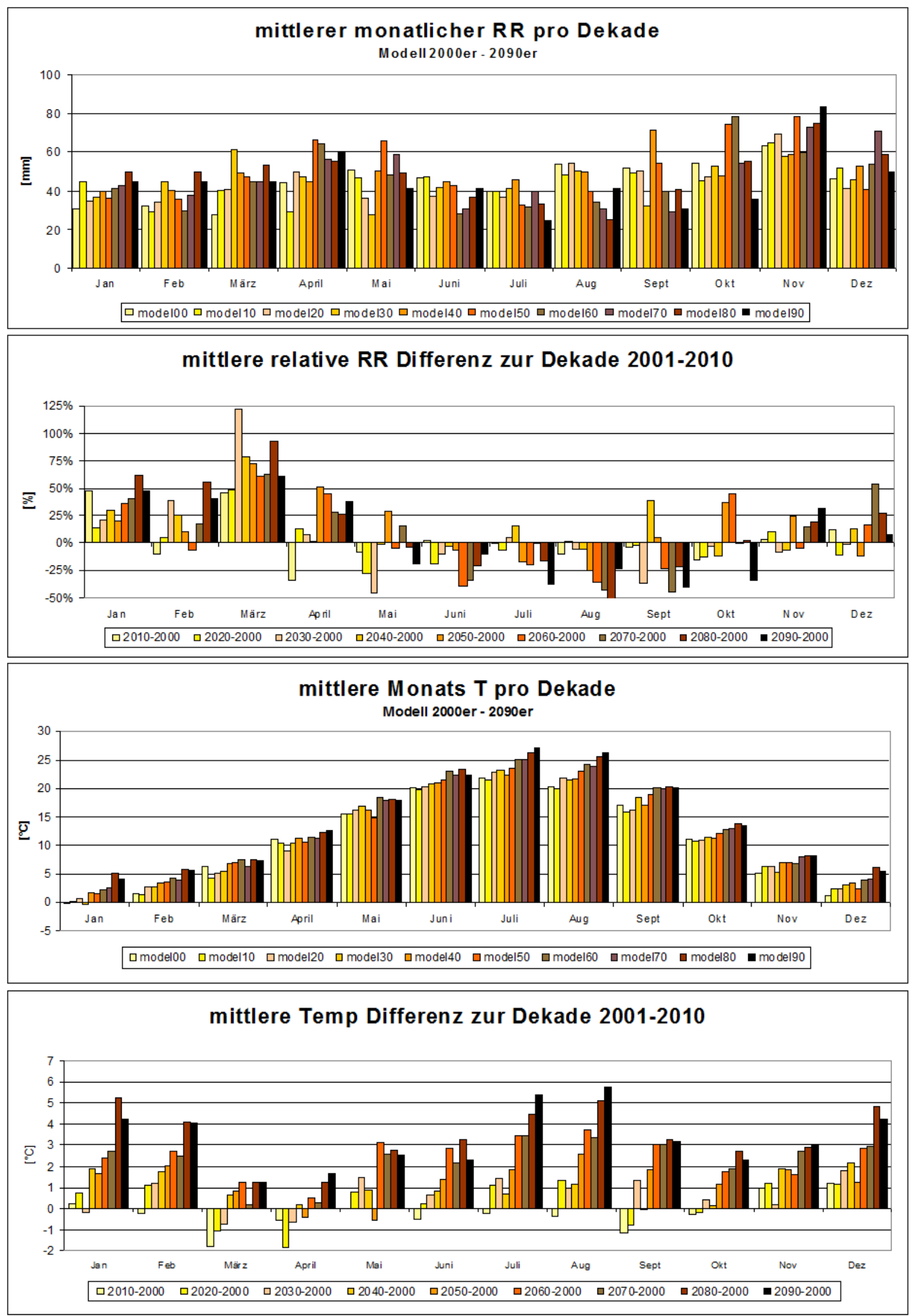

Figure 33: Comparison of mean monthly precipitation and temperature as well as the differences compared to the reference Decade 2001-2010 


\section{Analysis of the west-east gradient}

In addition to what's already been said it was interesting to clarify as to what extent other conditions arise in neighboring cells. To answer this question, a west-east sector was selected, with 7 grid cells covering the entire east-west extent of the study area. Figure 34 shows their location and their abbreviations, and the two subsequent Figure 35 and Figure 36 show the occurring gradients and the expected changes in the coming decades.

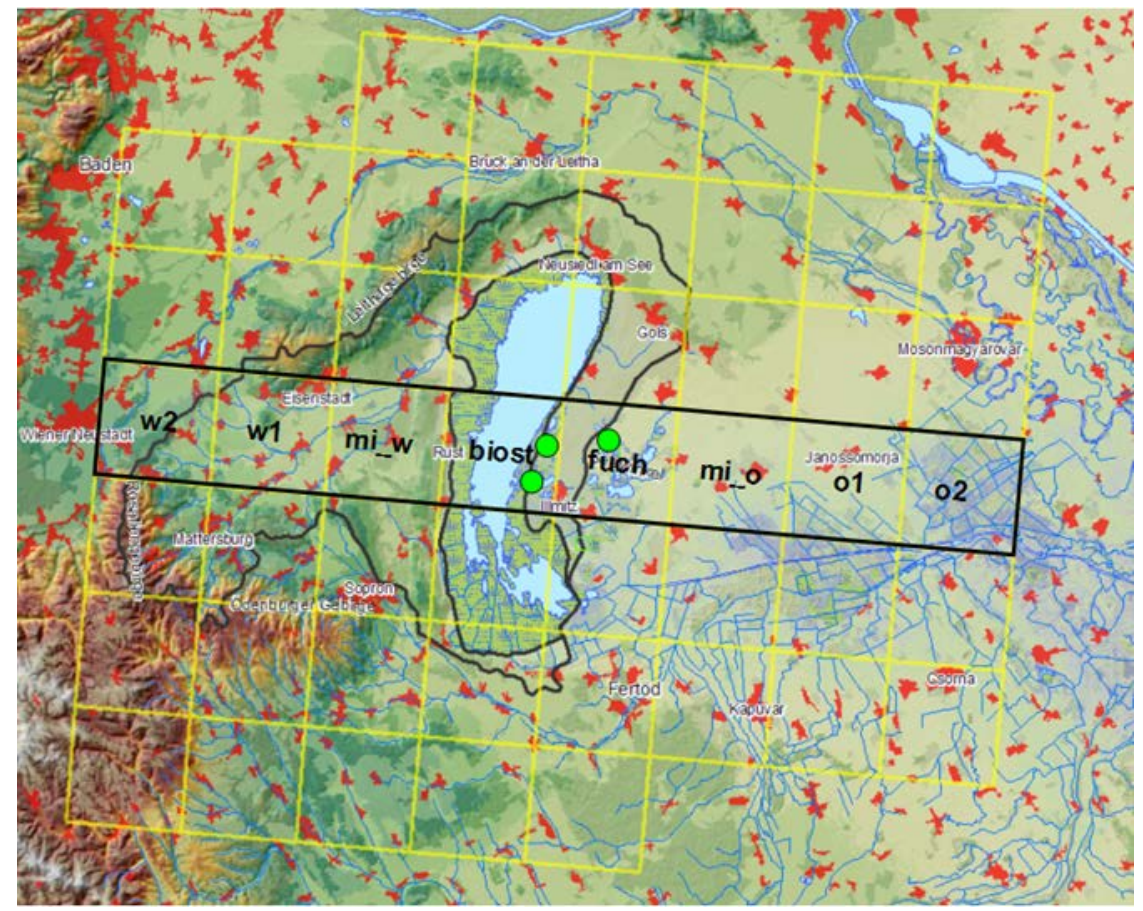

Figure 34: Location and designation of cells for space analysis 'West-East gradient'
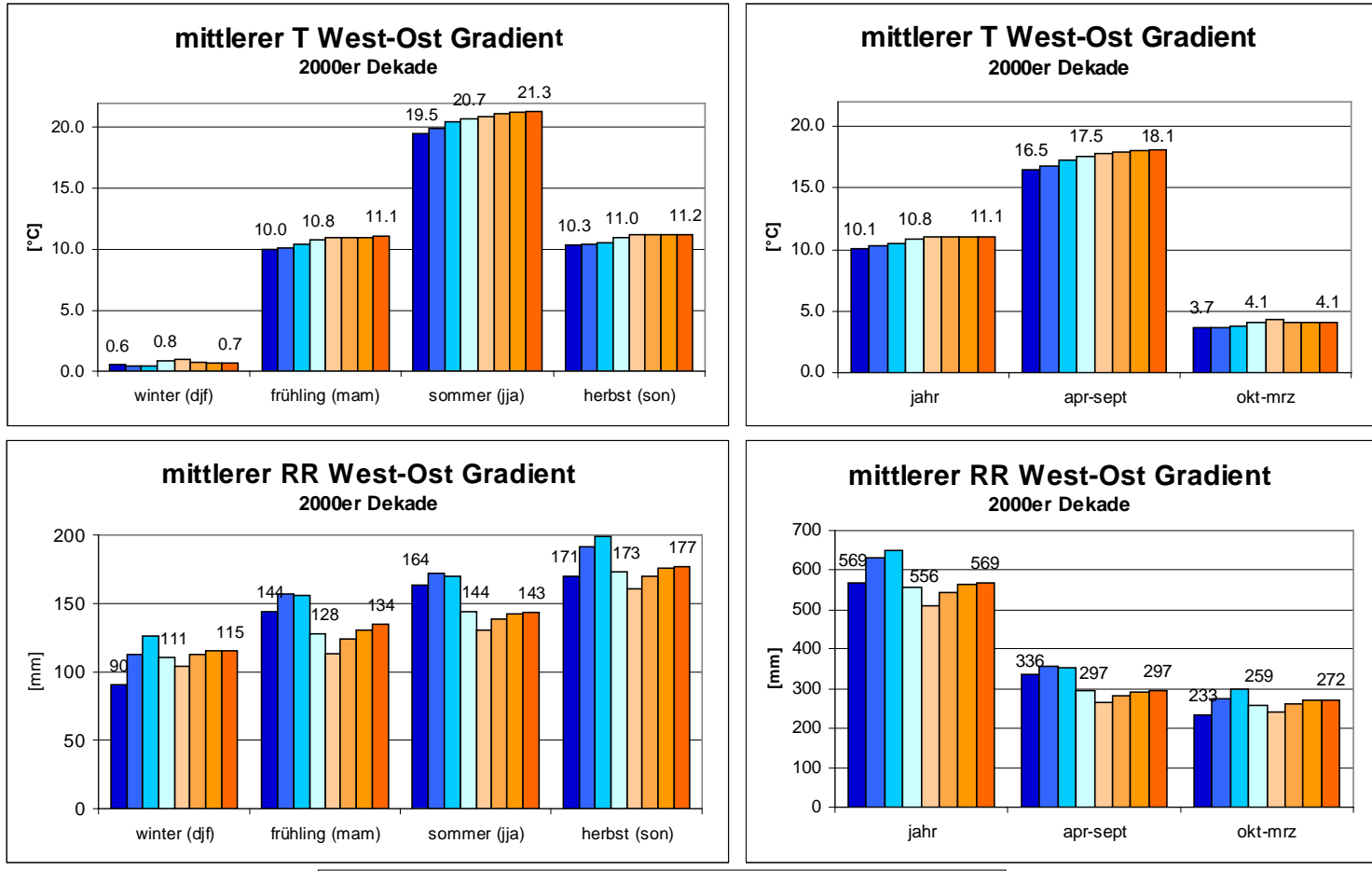

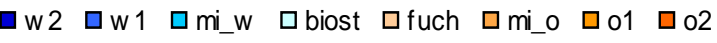

Figure 35: West-east gradient of mean temperature and precipitation 
Looking at the temperature, the figures show a quite to be expected gradient due to the increasing continentality, especially in the summer months. However, it is quite surprising that this gradient does not occur in winter as well. Yet, it seems that this gradient may be somewhat less pronounced in future decades. Precipitation, however, shows an even more surprising phenomenon: Just east of Lake Neusiedl a local minimum occurs, east of the lake precipitation increases again. In the future, precipitation seems to decrease especially on the west side of the lake, so to say in the catchment area of the Wulka. Compare the following illustrations to the spatial representations in the Appendix.

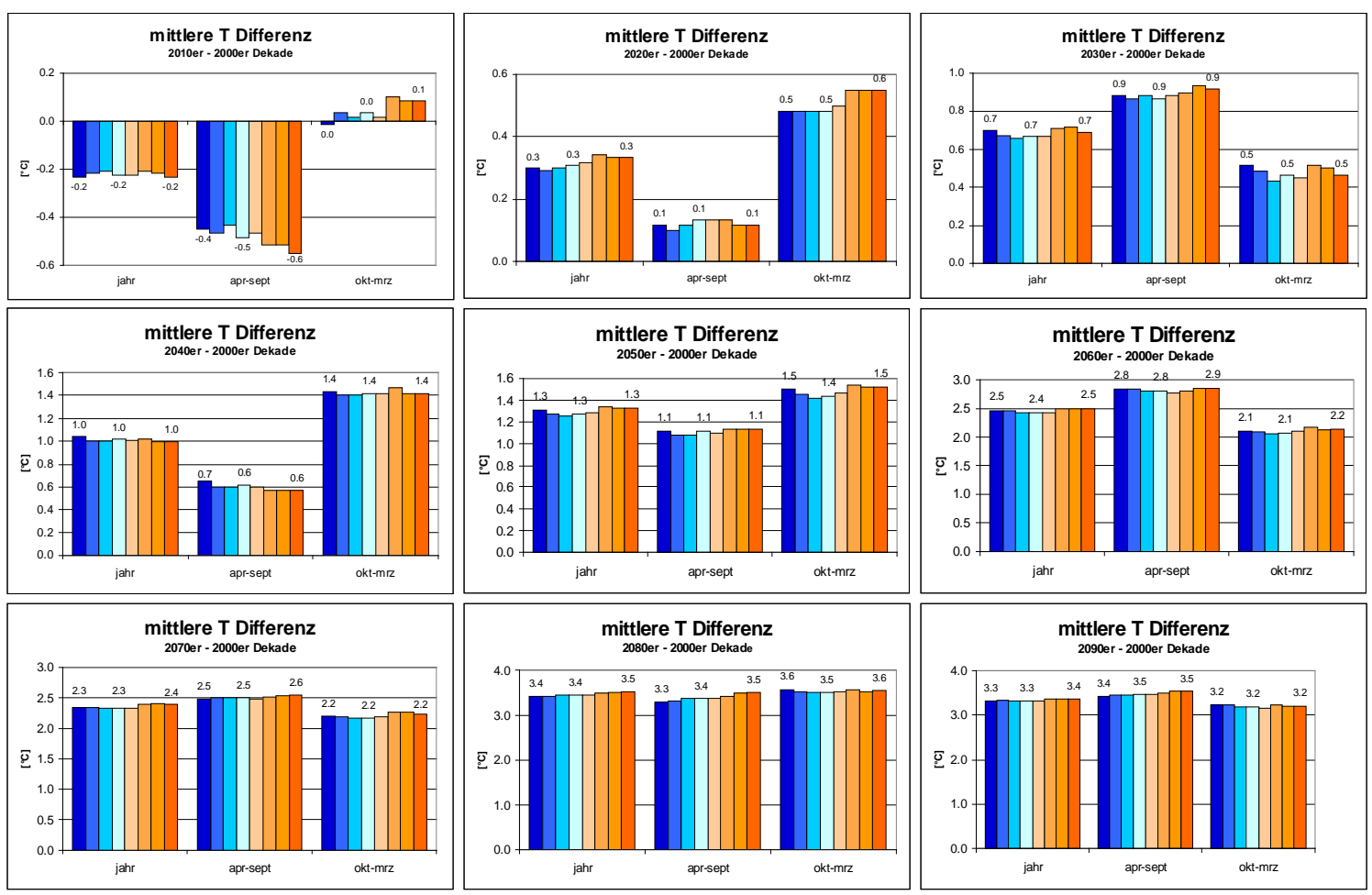

घw2 $\square$ w1 $\square$ mi_w $\square$ biost $\square$ fuch $\square$ mi_o $\square 01 \square 02$
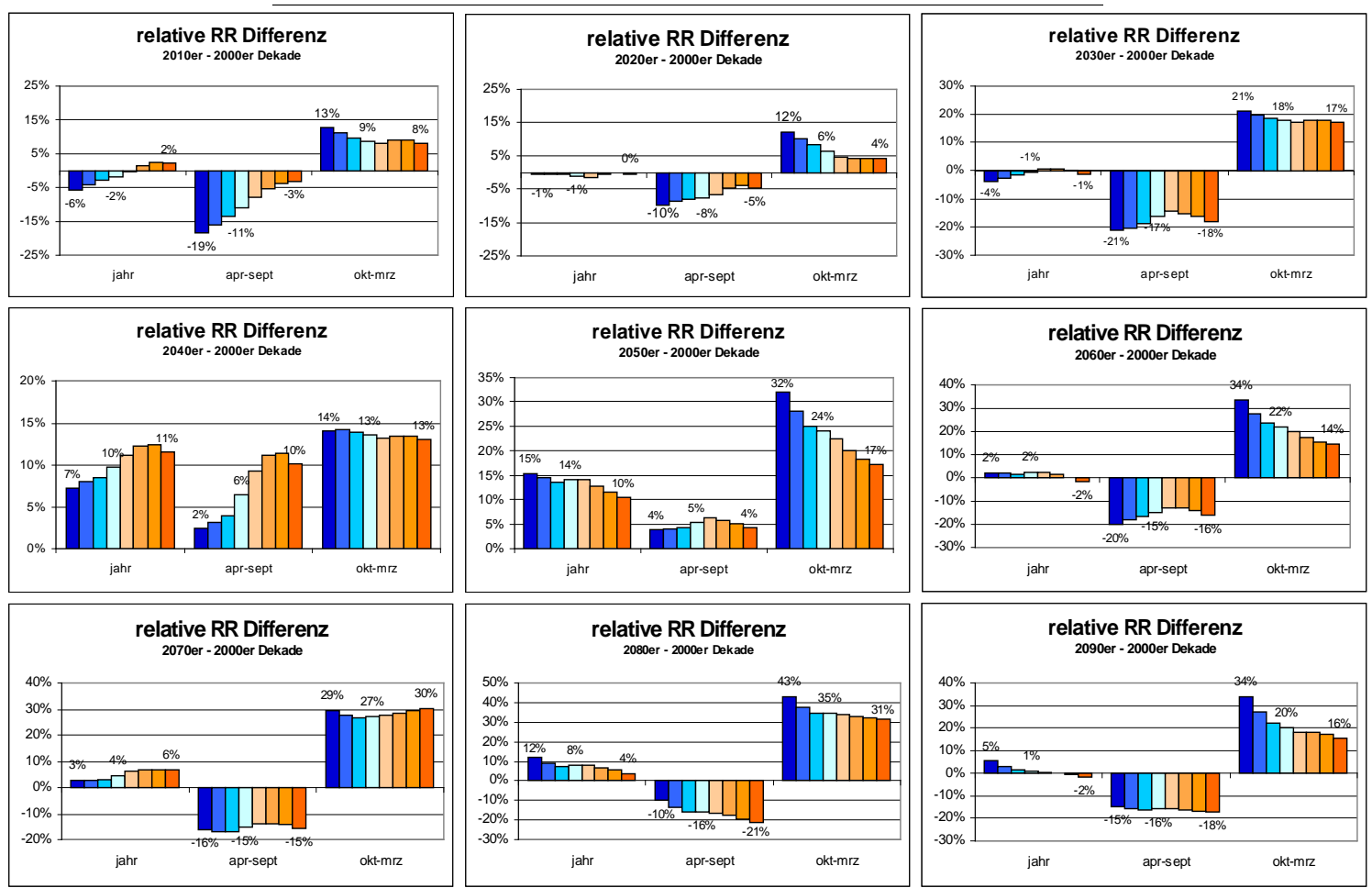

Figure 36: Temporal development of the west-east gradient of mean temperature and precipitation 
An estimate of future climate solely from changes in temperature and precipitation is only conditionally possible. For this reason, derived parameters such as heating degree days, ice days, frost days, summer days, tropical days, heat waves and droughts and their length are often used. In this work particularly the last two parameters were examined more closely.

In practice, as a definition of a heat wave the one after Kysely (2004) proved most suitable in the Central European context: a "heat wave" is detected when the maximum temperature exceeds $30^{\circ} \mathrm{C}$ at least 3 days in a row and lasts as long, as the average maximum temperature over the whole period remains above $30^{\circ} \mathrm{C}$ and on no day the maximum temperature drops under $25^{\circ} \mathrm{C}$. Such heat waves occur in the Eastern Alps not every year, but could still be observed repeatedly in the past decades, and also from historical data series an increase in frequency and duration can be observed. The reference to episodes (of at least 3 days duration) rather than to hot days allows, inter alia, meteorological robust statements for future decades.

Figure 37 shows the expected number of heat wave days and the maximum length of such a period respectively, as well as their changes over the reference period. As can be clearly seen, such events will increasingly occur especially from the middle of the century on. In addition, the length of these heat waves increases dramatically. But in the next three to four decades the impact of climate change still stays limited to some extent.

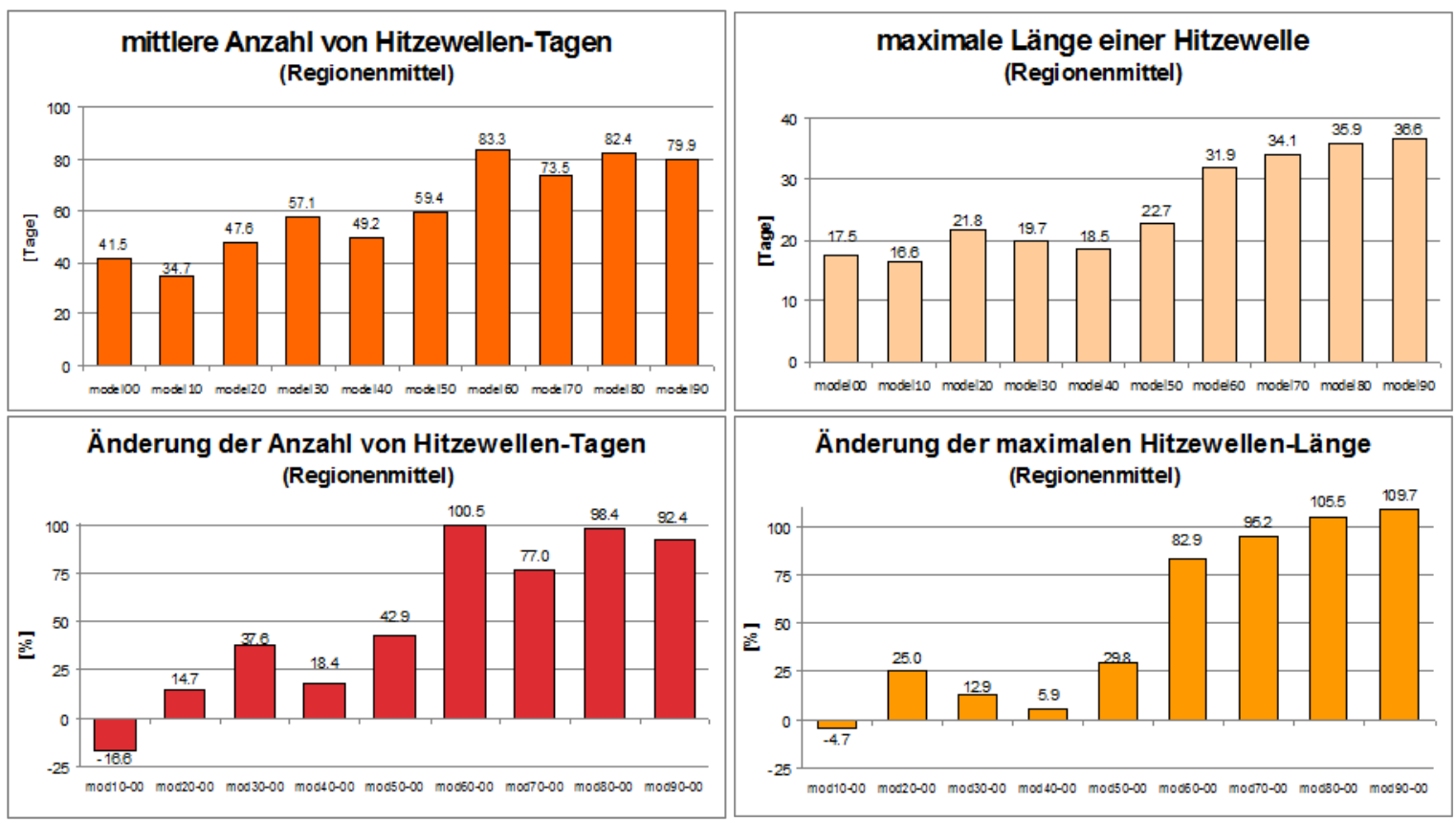

Figure 37: Mean number of heat wave days and maximum length of a heat wave occurring in each decade (top); relative changes compared with the reference Decade 2001-2010 (bottom).

Dry periods are defined as consecutive days with precipitation $<1 \mathrm{~mm}$. The threshold of one millimeter is intended to filter out those events that aren't actually caused by rain, but where dew or comparative effects lead to very low levels. The illustrations Figure 38 to Figure 42 show the expected seasonal dry days or dry periods of varying lengths and their changes over the reference period. As can easily be seen, dry days increase (partly) significantly in spring and summer while in autumn and winter declines are rather predominant. Although e.g. dry periods lasting more than 10 days occur only once or twice per decade, the comparison with the reference period shows that by the end of the century an increase by up to $80 \%$ can be expected, so nearly double the number! 


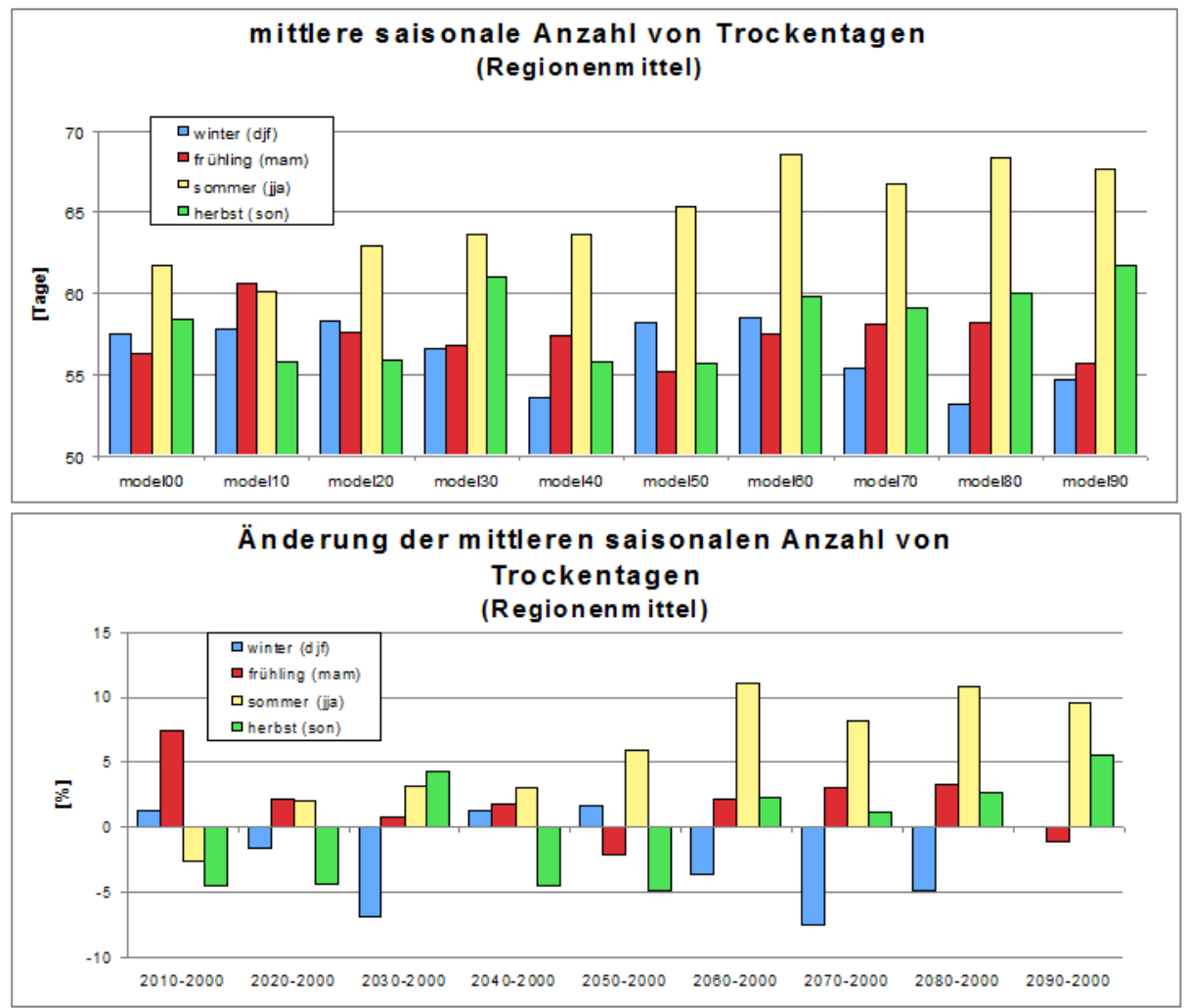

Figure 38: Mean seasonal number of dry days and their relative change in each decade
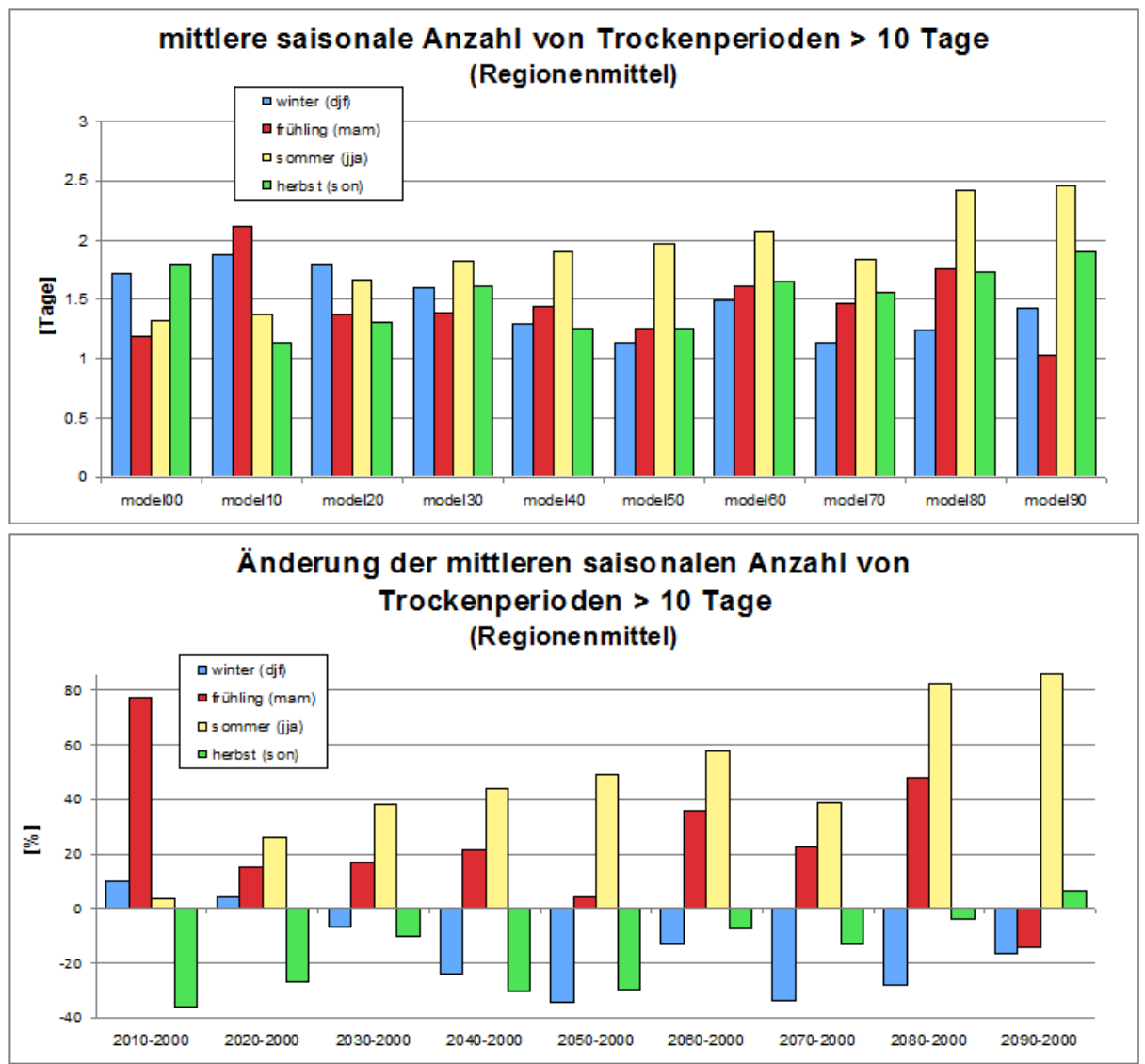

Figure 39: Mean number of seasonal dry periods longer than 10 days and their relative change in each decade 

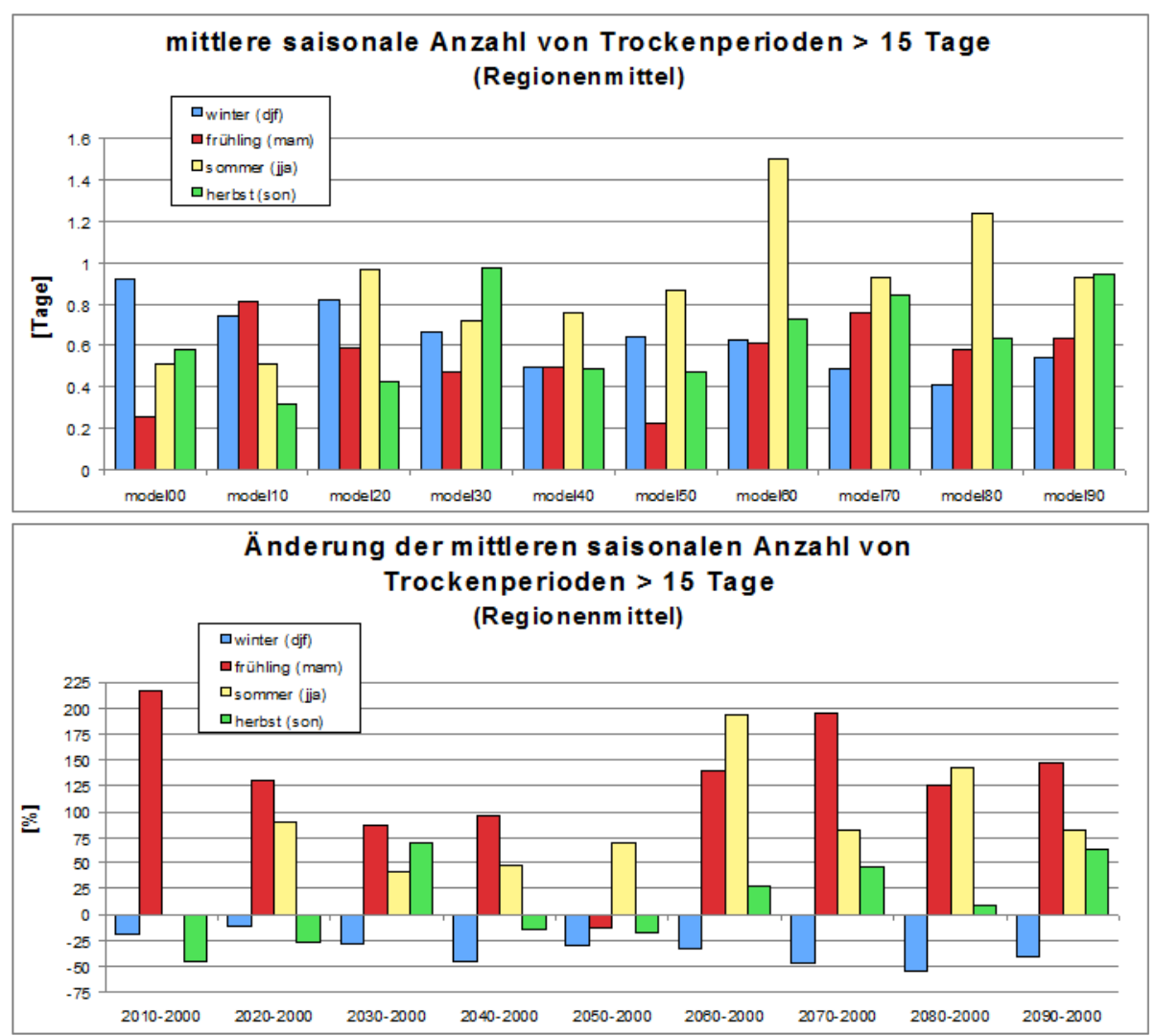

Figure 40: Mean number of seasonal dry periods longer than 15 days and their relative change in each decade
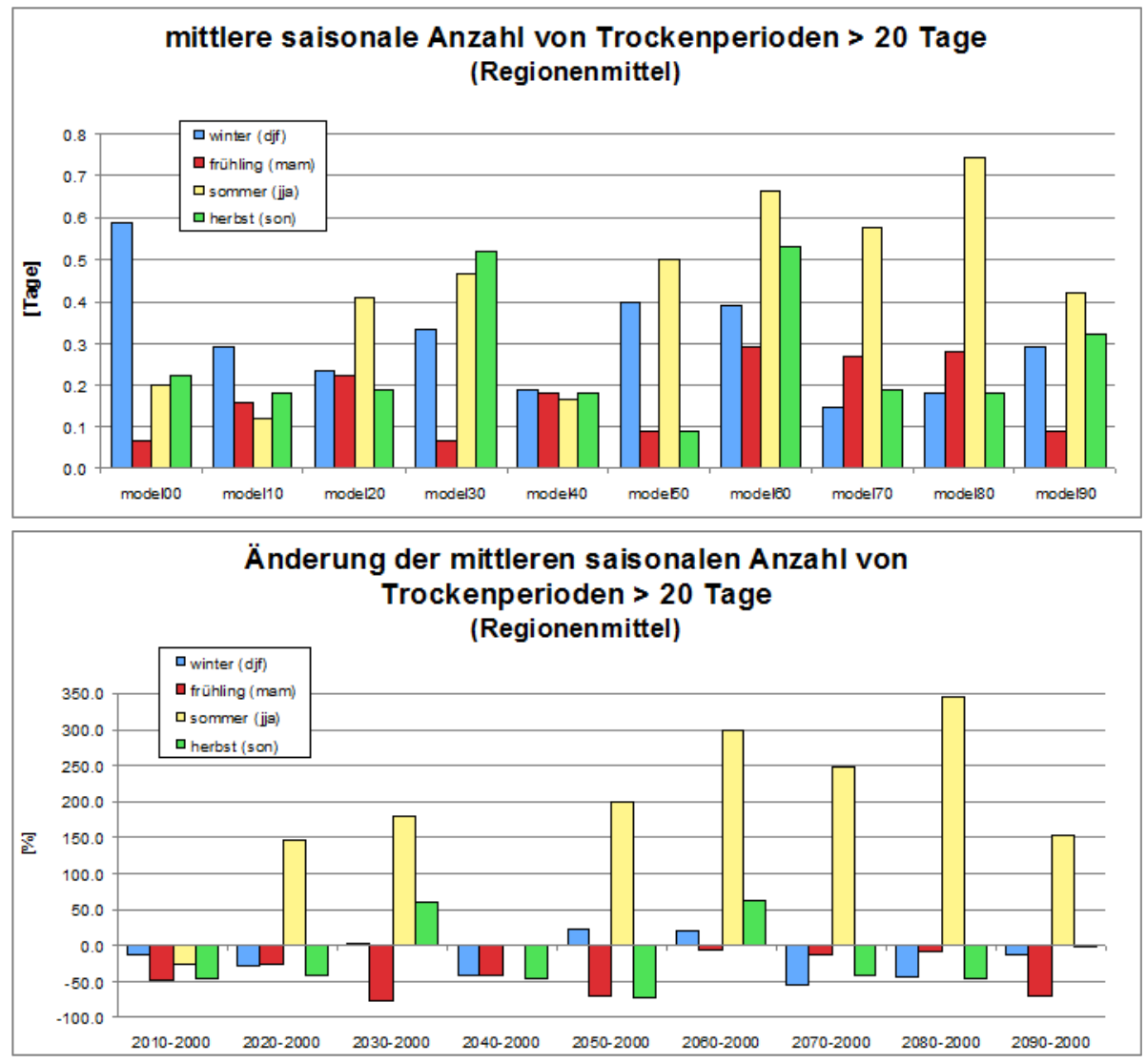

Figure 41: Mean number of seasonal dry periods longer than 20 days and their relative change in each decade 


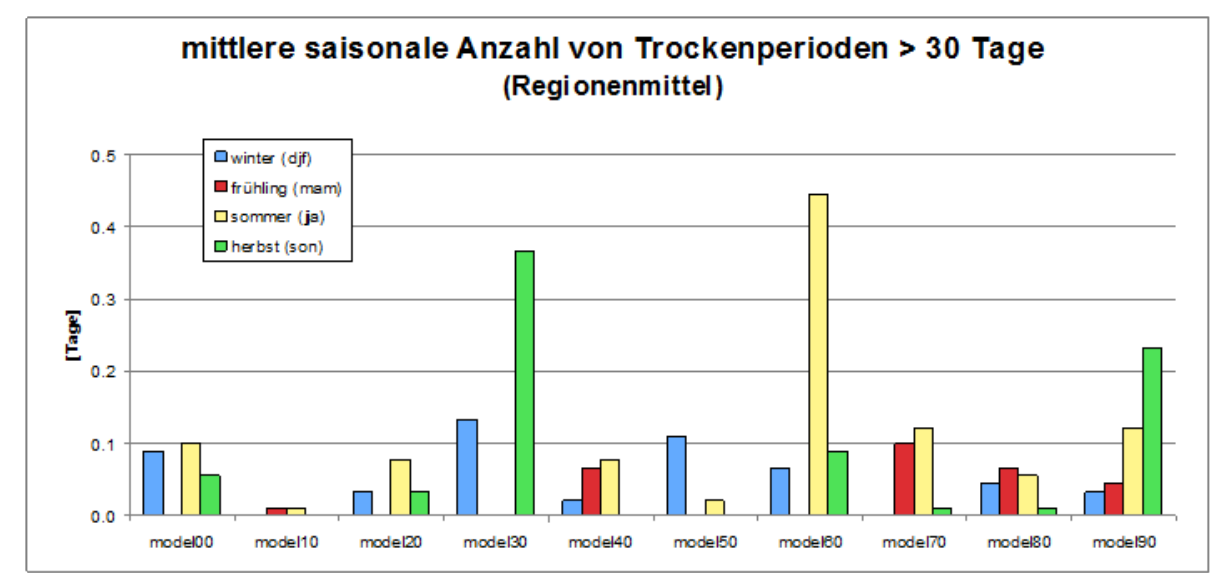

Figure 42: Mean number of seasonal dry periods longer than $\mathbf{3 0}$ days in each decade

Clearly, the number of dry periods with increasing length decreases drastically. Periods lasting more than two weeks on average only occur once a year or rarer, such lasting up to three weeks only occur about every five years. But also here, the comparison to the reference period leads us to expect that they will occur up to twice as often in the future.

Extremely long dry periods (e.g. more than 30 days as shown in Figure 42) are already so rare that looking at a relative change makes little more sense (which is why only the mean number is presented), but the two "outliers" Autumn 2030s and summer 2060s years shall indicate the existing hazards. There is always the possibility that in these decades such long dry periods particularly accumulate and certainly can occur more than once per decade. It is clear that such long dry periods will have extreme effects on the flora and fauna of the region, especially on the sensitive natural puddles and ponds.

\subsubsection{Summary and Conclusions}

As shown on the preceding pages, significant climate changes really are to be expected for the area of Lake Neusiedl and the Seewinkel. Figure 43 and Figure 44 show a summary of the expected mean scenario values of precipitation and temperature on annual, semi-annual and seasonal basis. 

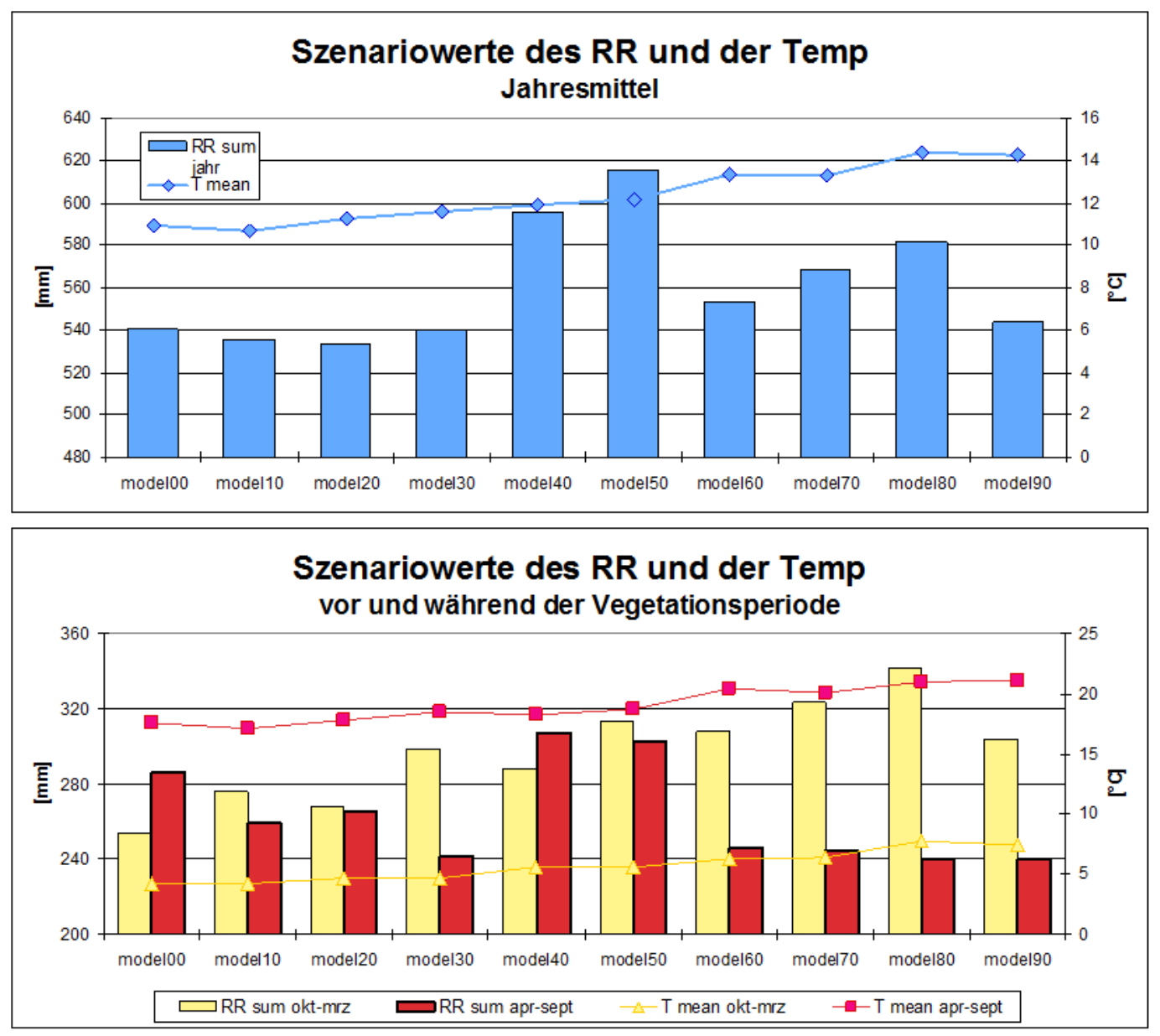

Figure 43: Summary of the scenario results for mean temperature and precipitation values during and outside of the growing season for each decade.

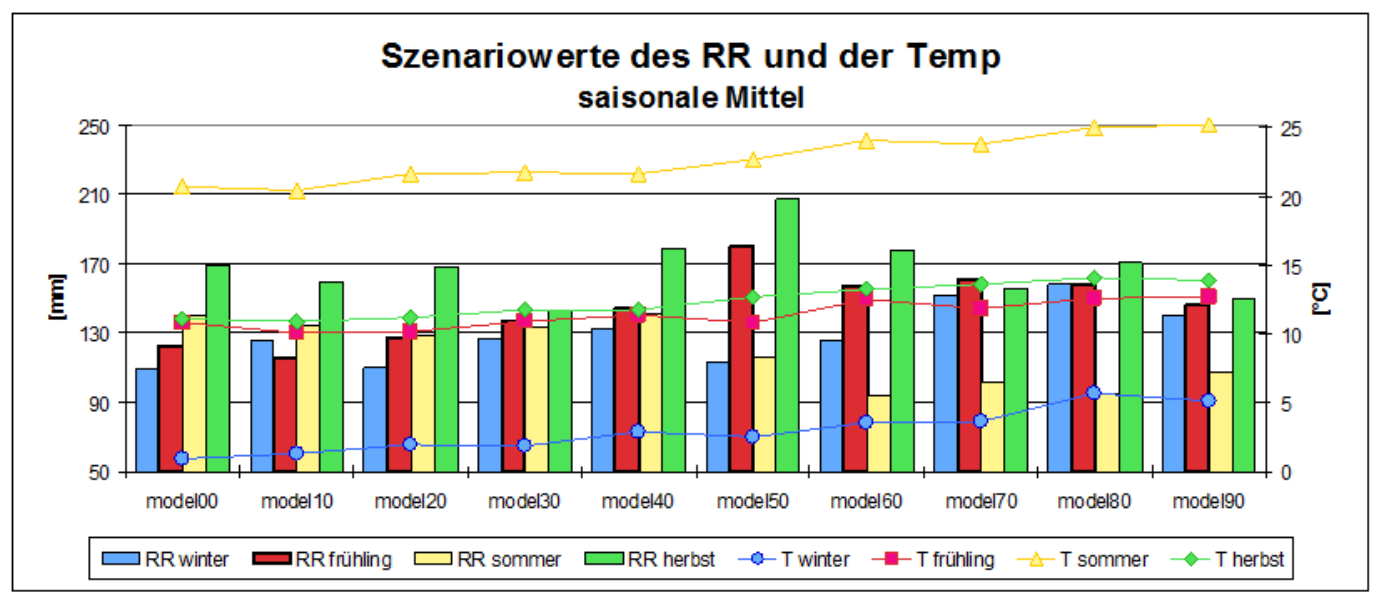

Figure 44: Summary of the scenario results for mean temperature and precipitation values during the different seasons of the decades.

Summing up, the scenario results lead us to expect a continuous increase in average temperatures concerning all seasons by the end of the century. However, the development of total precipitation does not follow a consistent trend. Until the middle of the century slight decreases in precipitation totals show. For the forties and fifties the scenario calculations show increased precipitation totals which are mainly distributed over the spring and autumn months. By the end of the century, the calculations show different trends of annual precipitation, but significant decreases of total precipitation during the vegetation periods, especially during the summer months. 
But it must be noted that there are some uncertainties due to the present data situation. On the one hand, detailed (and necessary) sensitivity analyzes and plausibility tests would have been helpful and on the other hand a comparative model run would have been desirable. The existing base data also only allowed for a single Decade comparison level: an approach that may already lead to possibly incorrect interpretations in particular in climatological studies on a monthly basis.

In how far temperature and precipitation during recurrent weather situations (reference is made in this context to meteorological singularities, such as the "Ice Saints", the "Sheep's Cold" or regularly occurring "Christmas Thaw") shift in time and thus fall into other months or seasons, could not be clarified here. The question whether such singularities actually shift, or if they just seemingly occur due to model simplifications (e.g. the increase or decrease of thunderstorms) would also be of great interest.

Finally, it must also be noted that the underlying global emissions scenario requires the consistent implementation of measures to reduce greenhouse gas emissions. However, the observation of the actual global trends so far suggests that effective mitigation measures are at least delayed and only poorly implemented. In scientific literature the impacts of higher greenhouse gas emissions on the global climate are increasingly discussed (Anderson et al., 2011; Fung et al., 2011; Sanderson et al., 2011). Extreme scenarios assuming that all fossil fuels are burned to depletion of known reserves let a rise in the average global temperature by $5,1^{\circ} \mathrm{K}$ by the end of this century and the continuation of the temperature rise over several centuries to be expected (Sanderson et al., 2011). 


\subsection{Assessment of 'potential' ecosystem functions within the Neusiedler-See region}

\subsubsection{Introduction}

The functions of a landscape which can be used by stakeholders are to the most dependent on the geo-ecological potential provided by the landscape. These given structures are providing the frame in which people / society is able to use the services which are provided by their landscape. By this, we follow the hierarchical concept of "primary - secondary - tertiary landscape structure" (O'Neill et al., 1986; Ružicka \& Miklos, 1990), an approach that tries to systematically assign any landscape attribute to the biophysical (= primary landscape structure, referred to as "PLS"), the land-management / socio-economic (= secondary landscape structure, referred to as "SLS") and the planning / policy (= tertiary landscape structure/TLS) domain. In this concept, parameters like climate, topography and bedrock are the main drivers of land cover which cannot be altered very easily and are therefore assigned as PLS.

Based on this concept we therefore want to extract the 'potential' ecosystem functions which are in principle described by the PLS parameters.

Addressing the issue of the potential of the landscape is very much driven by the reference scale which needs to be set. One way would be to look at former time points and compare land use systems and related land consumption (amongst others Prinz et al., 2010; Frondini et al., 2011). This implies that former land use was oriented at the potential of the landscapes. Another way (and maybe even more straightforward) is to exclude land use at all and try to derive the potential of the landscape regardless any human activity.

Cambridge Dictionary Online defines 'Potential' as "someone's or something's ability to develop, achieve or succeed" (http://dictionary.cambridge.org).

Adapting the definition of ecosystem functions (de Groot, 1992) therefore to ...

'Potential' Ecosystem functions: "the ability of the landscape to achieve the sustainable provision of goods and services that satisfy human needs, directly and indirectly".

...we want to address the question to what extent the landscapes in the project region are able to provide certain ecosystem functions and compare this potential as reference with the 'recent' ecosystem functions derived as described in detail in the aforementioned chapters.

Not all ecosystem functions and services have a possible reference, f.ex. What would be the potential for tourism facilities or what is the potential of aesthetic information? Due to this reason, we will select those functions that can be assessed by the potential land cover, i.e. that kind of cover which would establish on specific site conditions without human interaction. Zampieri and Lionello (2010) stressed with their work the fact that Land Cover Types are closely connected to vegetation types, as vegetation together with urban areas, lakes, glaciers and ice caps are the characterising key elements of the land surface.

We aim at mapping ecologically homogeneous units each of them populated by a specific vegetation type and to present a map of Constructed Vegetation in the region of Neusiedler See. Based on this map, we want to further develop the assessment of the 'potential' ecosystem functions to use them as reference lines for specific 'recent' ecosystem functions. 


\subsubsection{Methods}

\section{Vegetation types}

In principle, we took existing vegetation maps of the region for gathering information on potential vegetation communities of the area in question. The most important maps are from Niklfeld (1970/1989) and Bohn et al. (2000/2003). Both maps work on a rather large scale: $1: 2000000$ and $1: 2500000$ respectively. Thus, the spatial resolution is rather poor and not applicable for our objectives, we want to provide a better resolution on a smaller scale. Still, both maps gave us valuable information of the vegetation communities which are most likely to occur in the project region.

Based on Bohn et al. (2000/2003) and Willner and Grabherr (2007), specific site conditions for each vegetation type were extracted. In general, the region is characterised by a strong control of standing and ground water leading to the development of azonal communities. Only where the influence of water is only of minor importance, zonal communities can grow. We modified the list of vegetation types by introducing also the vegetation type of beech forest, as submontane conditions exist in the Sopron Mountains.

We translated the site conditions into selection criteria of geodata. We used data on soil (polygon data), geology (polygon data) and a digital elevation model (raster data with a pixel size of $70 \mathrm{~m}$ ). Climate variation is strongly correlated to topography and thus not directly implemented into the niche descriptions. In GIS, we processed all geodata-layer with "identity" and cleaned the resulting shape. Thus, we were able to provide a consistent attribute list separated for the Austrian and the Hungarian part, since geodata where partly different. Additionally, we included the information on streams and rivers into the map by buffering running waterbodies by 10 meters and included into the "identity" process. Minimum mapping unit was $400 \mathrm{~m}^{2}$. The different attributes of the geodata were assigned in a hierarchical way (first azonal, then zonal communities) to the individual vegetation types via attribute selection eventually ending up with a map of "Constructed Vegetation Types". Only the vegetation type "alluvial forest" was treated also by a spatial selection of all alluvial soil polygons within the search radius of $250 \mathrm{~m}$ of running waterbodies and assigned.

\section{'Potential' Ecosystem functions}

In this study, we want to assess the ecosystem functions which are directly related to land cover or vegetation type. Thus, we concentrate on the following functions:

- Regulation functions ('local climate regulation', 'disturbance prevention', 'water regulation', 'water supply', 'soil retention', 'soil formation', 'nutrient regulation', 'pollination')

- Habitat functions ('refugium', 'nursery')

- Provision functions ('food', 'genetic resources', 'medicinal resources')

The vegetation types were linked by expert knowledge about the different types' capacities to provide various ecosystem functions. Therefore, a capacity matrix was created (

Table 2). Whereas on the $x$-axis selected ecosystem functions are placed, on the $y$-axis the 12 land cover and vegetation types are placed marking the capacity for providing the function at the intersections. The so-called vegetation type value (VET) ranges from 0 to 5 . The higher the value, the higher the general relationship between habitat type and function: 
Table 2: Capacity matrix of different vegetation types for providing individual ecosystem functions. $0=$ no relevant link between vegetation type and specific function, $1=$ low relevant link, $2=$ relevant link, $3=$ medium relevant link, $4=$ high relevant link, 5 = very high relevant link (adapted from Burkhard et al., 2009).

\begin{tabular}{|c|c|c|c|c|c|c|c|c|c|c|c|c|c|c|c|c|c|c|}
\hline vegtype & & & 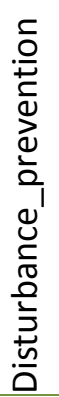 & 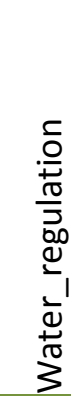 & & 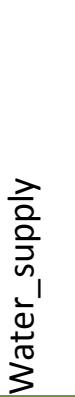 & 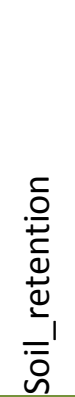 & 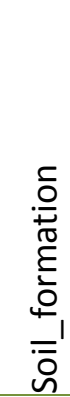 & & 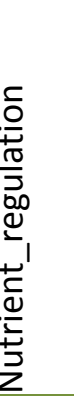 & 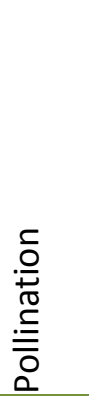 & 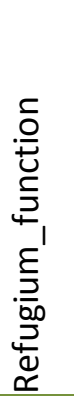 & 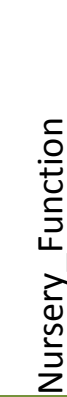 & & $\begin{array}{l}\text { ס } \\
\text { ¿ } \\
1\end{array}$ & 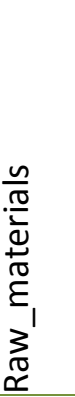 & 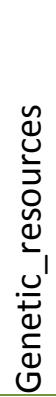 & \\
\hline alluvial & 5 & 5 & & 5 & 4 & 5 & 5 & 5 & 5 & 3 & 5 & & 4 & 2 & 4 & 2 & & 3 \\
\hline anthropogen & 2 & 2 & & 1 & 0 & 1 & . & 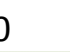 & 1 & 1 & 1 & & 0 & 0 & 0 & 0 & & 0 \\
\hline beech & 5 & 5 & & 5 & 3 & 5 & 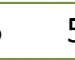 & 5 & 5 & 2 & 5 & & 5 & 3 & 5 & 2 & & 3 \\
\hline bitter+sessile oak & 5 & 5 & & 5 & 3 & 5 & & 5 & 5 & 2 & 5 & & 5 & 3 & 4 & 2 & & 3 \\
\hline downy oak & 3 & 3 & & 4 & 2 & 4 & & 4 & 5 & 2 & 4 & & 3 & 3 & 3 & 2 & & 3 \\
\hline fens & 3 & 4 & & 5 & 4 & 3 & & 5 & 5 & 2 & 5 & & 3 & 1 & 3 & 0 & & 2 \\
\hline forest steppe & 1 & 2 & & 3 & 1 & 3 & & 3 & 4 & 2 & 4 & & 2 & 3 & 2 & 2 & & 3 \\
\hline halophytic & 0 & 2 & & 3 & 0 & 3 & & 3 & 3 & 2 & 5 & & 2 & 1 & 0 & 0 & & 0 \\
\hline oak-hornbeam & 5 & 4 & & 5 & 3 & 5 & & 5 & 5 & 2 & 5 & & 5 & 3 & 5 & 2 & & 3 \\
\hline reedbed & 5 & 5 & & 5 & 1 & 2 & & 2 & 5 & 1 & 5 & & 5 & 5 & 4 & 1 & & 1 \\
\hline rivers & 4 & 4 & & 4 & 5 & 0 & & 0 & 4 & 1 & 4 & & 4 & 3 & 0 & 0 & & 0 \\
\hline waterbodies & 5 & 4 & & 5 & 1 & 0 & ) & 0 & 4 & 1 & 4 & & 3 & 4 & 0 & 1 & & 0 \\
\hline
\end{tabular}

For receiving the final 'potential' ecosystem functions values, we calculated the area-weighted mean of the VET-values within each Landform. Finally, we took the mean value of the sub-functions within each main function in order to plot the main 'potential' functions Provision, Regulation and Habitat onto a 3-axes spider web diagram.

\subsubsection{Results and Discussion}

In general, the different vegetation communities did separate very well. The quick look on the map of Constructed Vegetation seems rather plausible, also in comparison with the small maps of Bohn et al. $(2000 / 2003)$ and Niklfeld (1970/1989). We want to stress the point, that the construction is reproducible and transparent, only based on geodata having in mind the shortcomings of the geodata, mainly (i) differences in resolution and scale and (ii) incomplete coverage. When necessary the definition of the selection criteria and the hierarchical sequence can be adapted and refined.

The distribution of the different Constructed Vegetation Types varied enormously among the landforms as also the Landforms as such already are of different size.

Based on the capacity matrix and the location of the vegetation types, a picture of the distribution of the individual subfunctions can also be drawn. Examples are shown in Figure 45, where the differences among sub-functions become clear. 
a.

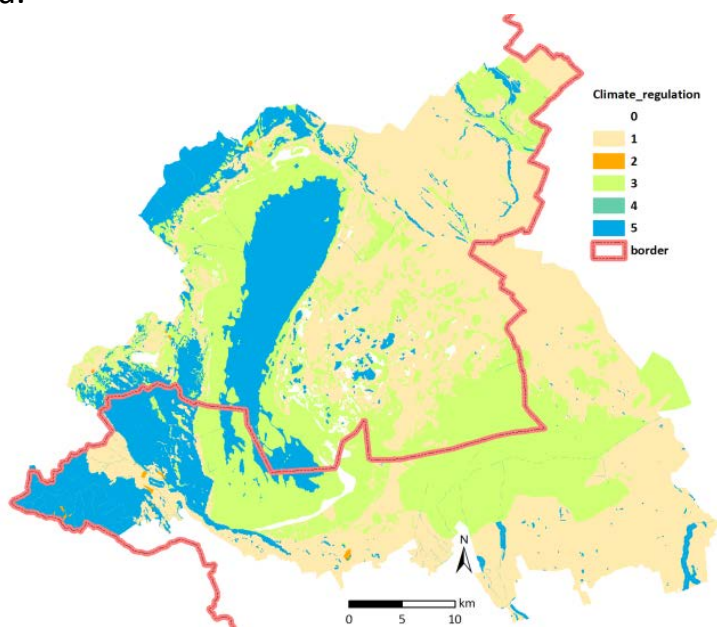

b.

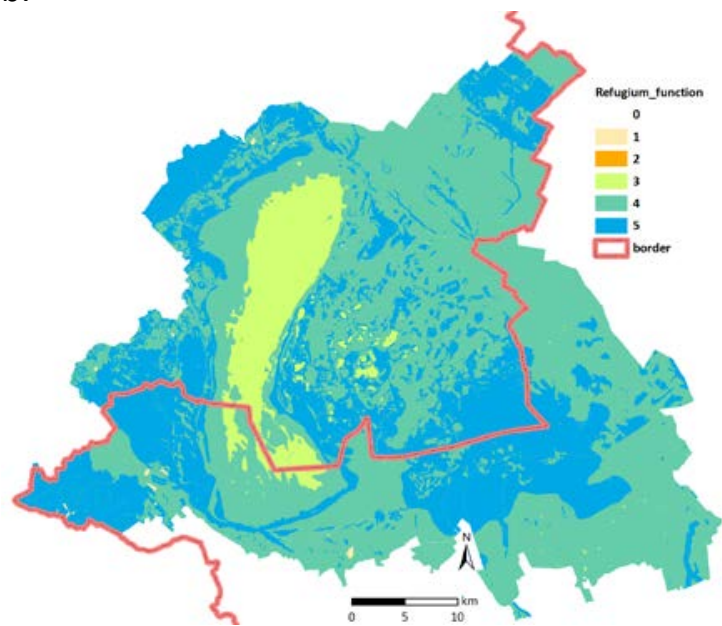

Figure 45: a. The sub-function 'climate regulation' shows higher values in the western part of the investigation area; $b$. the potential of the 'refugium' function is very high throughout the whole investigation area. $0=$ no provision, $1=$ low provision, 2 = modest provision, 3 = medium provision, 4 = high provision, 5 = very high provision.

The aggregation of the sub-functions to the main three 'potential' functions blurred to some extent the picture of the functions' provision due to the averaging. Therefore, the general picture of the three 'potential' functions looks rather similar in all Landforms, giving the highest values always to Habitat, followed by Regulation and then Provision. Depending on the area-weighting of the VEGvalues, the mean 'potential' ecosystem function looked more differentiated among the Landforms when looking at the detailed values (Table 3).

Table 3: Main 'potential' ecosystem functions in each Landform.

\begin{tabular}{llll}
\hline LANDFORM & pot Regulation & pot Habitat & pot Provision \\
\hline Landform 1 & 2.959 & 4.082 & 1.928 \\
Landform 2 & 3.279 & 3.731 & 1.971 \\
Landform 3 & 2.870 & 3.341 & 2.287 \\
Landform 4 & 2.606 & 3.171 & 2.340 \\
Landform 5 & 2.493 & 3.101 & 2.486 \\
Landform 7 & 3.648 & 4.256 & 2.785 \\
Landform 8 & 4.200 & 4.875 & 3.164 \\
\hline
\end{tabular}

a.

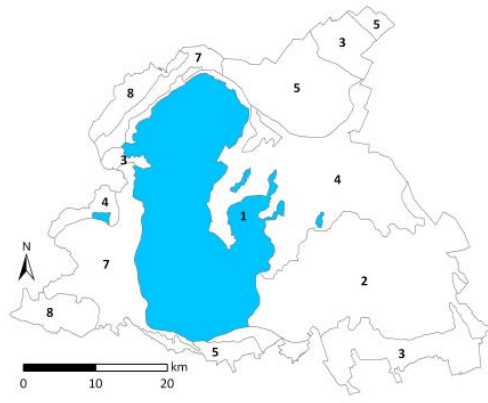

1 Lake Basin

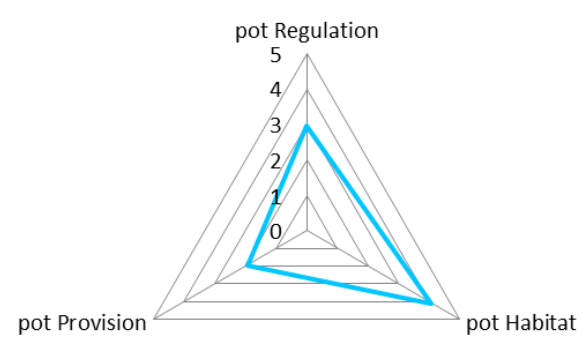


b.

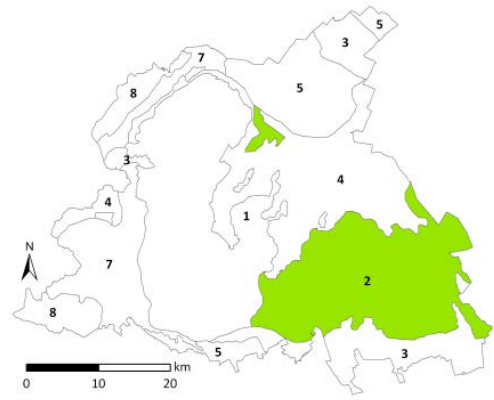

c.

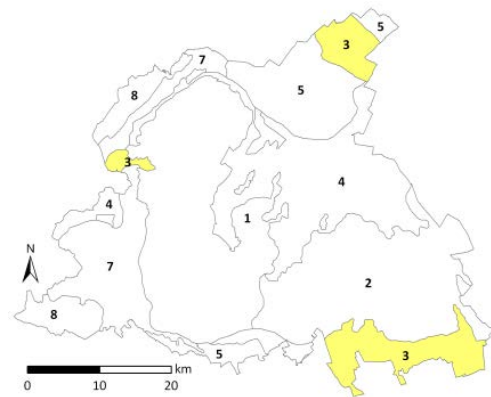

d.

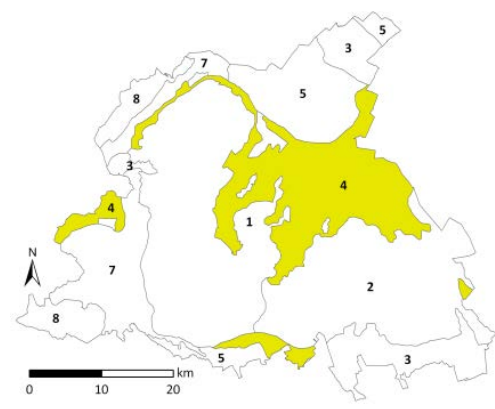

e.

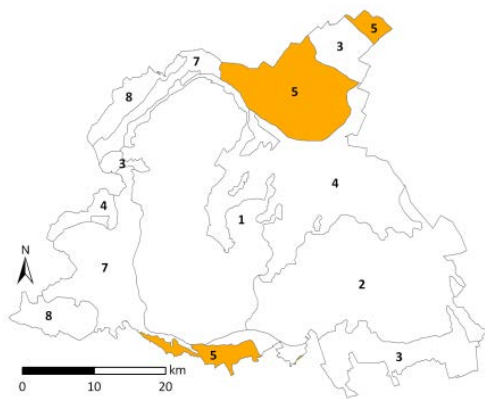

f.

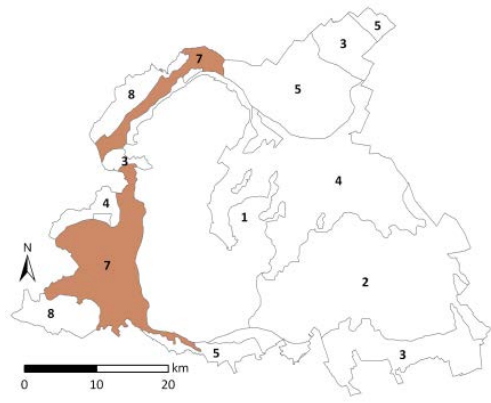

2 Marshland

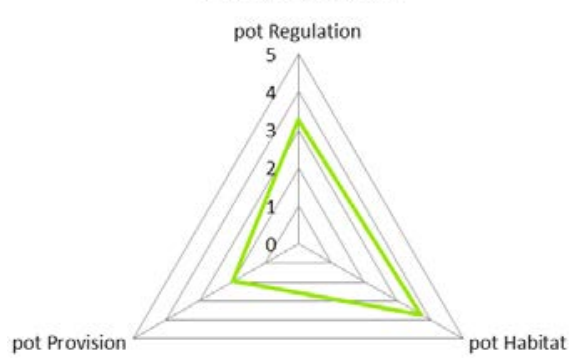

3 River floodplain

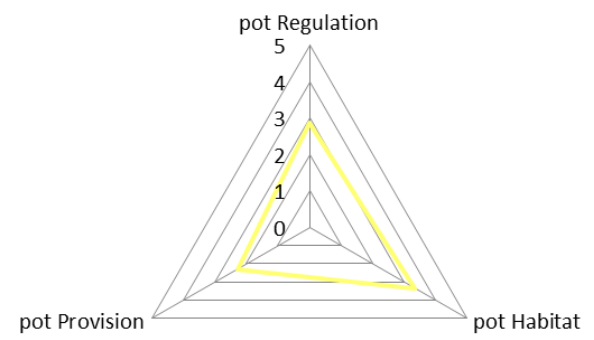

4 Low lying terrace

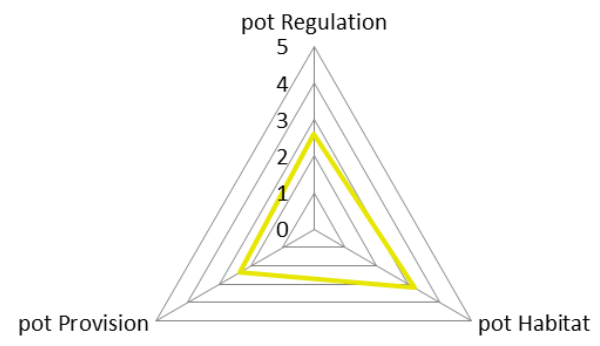

5 Elevated terrace

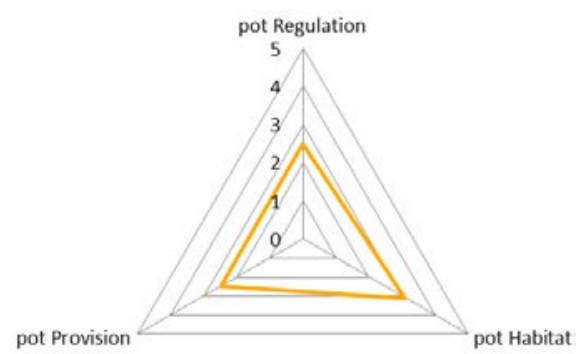

7 Hilly area and hill range

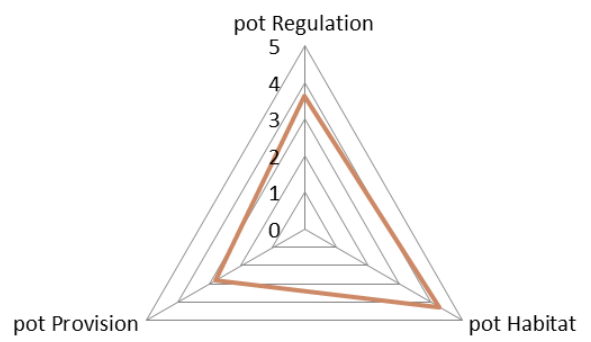


g.

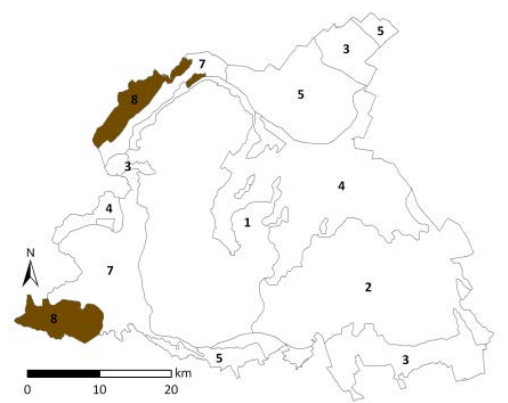

\section{Low and middle range mountains}

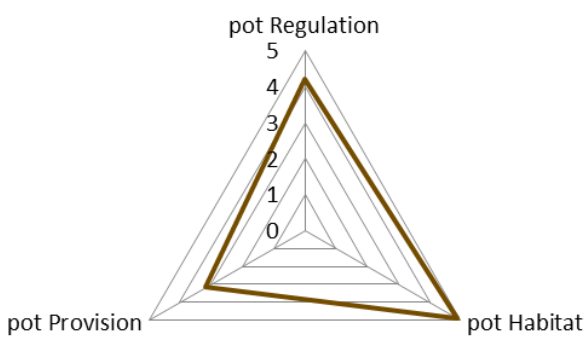

Figure 46: Location and 'potential' ecosystem functions for each Landform (a.-g.)

\subsubsection{Conclusion}

In general, the direct link between the constructed vegetation types and the main 'potential' ecosystem functions showed a high value for all functions. Only in the details, some sub-functions would be better supported and provided by other vegetation types than the ones potentially occurring in the region of Neusiedler See.

Still, not for all sub-functions, this method can be applied. The way forward to explicitly address each sub-function is to develop indicator sets targeted to each of these. But this would encompass the need of very detailed data and statistical relationships which are not available yet.

Nevertheless, our study showed the possibilities of an overview assessment appropriate to grasp the main differences between different landscapes and different vegetation and land cover types. 


\subsection{Assessment of 'recent' ecosystem functions within the Neusiedler-See region}

\subsubsection{Sampling design and spatial data}

For quantifying the actual state of certain ecosystem functions that are provided within the CCRstudy region, results of a field campaign that has been carried out in the years 2010 and 2011 (Wrbka et al., 2012) was used as the primary data source. The database applied in the frame of CCR comprises detailed information on more than 4000 single landscape elements, spanning over 35 target landscape sites of $1 \times 1 \mathrm{~km}$. The sites have been previously selected by using a stratified random sampling approach to ensure representativeness within the various geophysically varying and anthropogenically modified sub-regions, hereinafter called Land Form Types (LFTs) (KonkolyGyuró, 2010) (Figure 47). Further, stratification of the sampling process allows for up-scaling of the gathered results in order to make generalized statements on function provision throughout the whole study region.

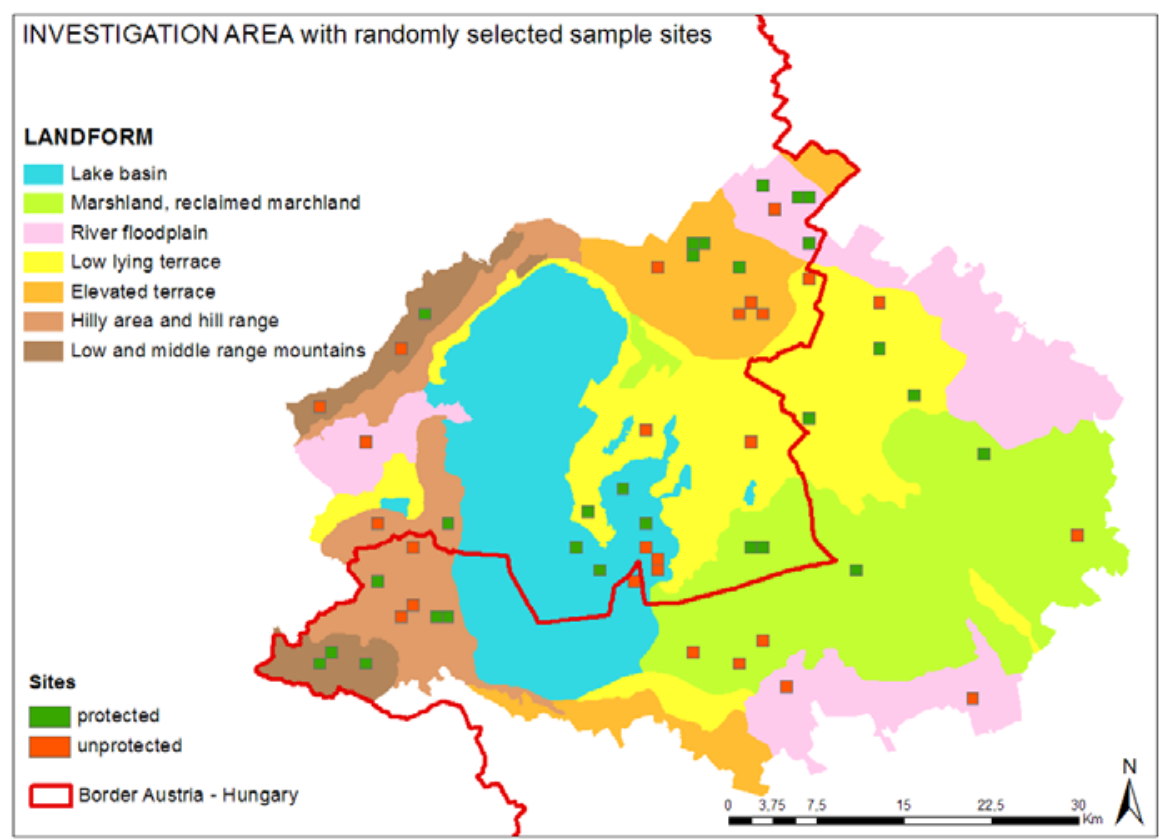

Figure 47: Selected landscape sample sites within the different Landform Types (Konkoly-Gyuró et al., 2010).

Parameters that have been mapped for each corresponding landscape element include information on basic Land Use- / Habitat Type, classified estimations on Hemerobic and Trophic State; Species Richness; Regeneration Potential; Anthropogenic and Natural Disturbance; and its Resource Potentials according to Water and Nutrients. Especially the latter parameters are in the focus of interest for this study as recent environmental conditions will certainly be altered by advancing climate change and thus affecting agricultural productivity per se (Olesen et al., 2002).

Based on a so called Capacity Matrix (see also Hermann et al., 2013, in press) that provides a classification system on the supply of certain ecosystem functions for the all distinct Land Use Types that have been identified during field research, it is possible to quantify function provision throughout different spatial levels of the target region. The capacity matrix has further been refined by a list of Resource Qualifiers (environmental variables) that are influencing in situ function provision. E.g. rather dry habitats cannot fully exploit their potential in respect to Water supply or Soil Formation but on the other hand they provide important ecological niches and refugial space for certain species guilds. In this sense, parameters that are reflecting specific site conditions and distribution of important environmental resources served as additional qualifiers to refine the values of the Capacity Matrix. 


\subsubsection{Types and definition of environmental variables}

The environmental variables of Natural Disturbance (DIN), Resource Potential Wetness (RWF), Resource Potential Dryness (RWT) and Resource Potential Nutrient Richness (RNR) (Wrbka et al., 2003) were used to additionally refine the ecosystem function provision assessment. The types of resource potentials affecting one single landscape element can either originate from natural site characteristics or being caused by anthropogenic influence. Their basic ascertainment should point out patterns of resource driven Landscape elements in the investigated area. The environmental variables identifying Anthropogenic Disturbance (DIA) and Resource Potential Nutrient Poverty (RNA) which are acting as counterparts to DIN and RNR respectively were not considered as additional qualifiers. In case of DIA, information about the state of anthropogenic disturbance is already included in the list of identified habitat types and the corresponding capacity matrix. For instance, arable fields are graduated into three classes of "intensive", "intermediate" and "extensive" management. To avoid overweighting of the factor "anthropogenic disturbance", this factor is left out of the analysis. The environmental factor RNA is not considered as additional qualifier because general interrelations to the provision of certain ecosystem functions can hardly be drawn.

\section{Scales of Resource Potential:}

In order to express the level of the resource potential of a specific landscape element, we used a scale $0-4$. Scales are starting at " 1 " only indicating the site conditions and reaching up to " 4 ", pointing out dominant resource indicating vegetation types.

[1] Scale value "1" can be assigned if the resource potential is comprehensible due to the visible site conditions but still no resource indicating species are able to occur in the investigated landscape element (e.g. intensive arable land). This can be the case, if e.g. deficiencies in seedlot vigor are visible in field dells or ridge situations. It should be regarded that damage patterns caused by herbicides must not be identified as resource driven patterns.

[2] Scale value " 2 " covers all landscape elements, where resource indicating species are already present, but a distinct vegetation type is still not identifiable. For instance, species indicating for nutrient rich conditions at field margins, or Wetness-indicator plant species of the segetal flora in fields.

[3] Scale value " 3 " is representing landscape elements, where resource indicating vegetation types are visible in places, but not yet dominant.

[4] Scale value " 4 " is representing landscape elements, where resource indicating vegetation types are dominantly present. E.g.,dry grasslands, bogs, waterbodies,...

\section{Validity Check}

As previously described, environmental variables, which have been assessed during an extensive field campaign in the years 2010 and 2011 served as additional qualifiers for the 'recent' assessment of ecosystem functions within the CCR study region. In this conjunction it was necessary to overcome some constraints that arose during the field survey:

Several field researchers were involved in the survey. Although all of them were briefed and well trained, a certain so called "inter-observer error" in the assessment of environmental parameters could not be avoided. Such problems did mainly occur for landscape elements that are sharing non-pronounced characteristics for investigated resource potentials of e.g. Wetness or 
Dryness and consequently have been classified at the lower end of the rating scales (values " 1 " and "2").

Further, the estimation of resource potentials becomes more and more difficult with increasing size of the target landscape element because the surveyor is not able to accurately classify the entire site conditions of very large patches, especially when the vegetation cover is very dense or parts of the target patch are inaccessible.

To get rid of data inconsistencies, four computer-aided assessments to proof and, if appropriate, to refine database entries were carried out:

An assessment of Solar radiation to detect Hot and Cold Spots of irradiation in combination with slope of the investigated landscape elements to refine the DRYNESS Resource Potential parameter .

An assessment to detect troughs and small depressions within the landscape that are pointing out for rather wet environmental conditions that are hardly being noticed during field research. Consequently the Resource Potential WETNESS classification could be refined.

A combined assessment of erosion, following the Revised Universal Soil Loss Equation (RUSLE) which is based on the well-known Empirical Soil Loss Model (USLE) that had been introduced by Wishmeier and Smith in 1978. The resulting erosion model was used to refine the Resource Potential NATURAL DISTURBANCE.

A plausibility check, comprising multiple selections to check and refine previously assigned levels of nutrient richness (RNR).

\section{Basic Input Data and Data Preparation}

To cover the entire transboundary study region, common applicable Digital Elevation Data was used. In the frame of this study, the latest available version (V2) of GDEM (Global Digital Elevation Map) ASTER (Advanced Spaceborne Thermal Emission and Reflection Radiometer) served as input data source. It consists of a worldwide and freely available mosaic of elevation datasets that is distributed by the Ministry of Economy, Trade and Industry (METI) of Japan in cooperation with the United States National Aeronautics and Space Administration (NASA).

Four parts of the global dataset, indicated by coordinates N47E016; N47E017; N48E016; N48E017 were downloaded to cover the study area of CCR; mosaicked to simplify data handling and clipped to the boundary of the study area to reduce computational effort in the upcoming steps.

Ad (A) - The assessment of Solar Radiation was accomplished by using ArcGIS Tool Area Solar Radiation which is part of the Spatial Analyst Tools. It calculates the amount of incoming solar radiation during a certain time period and provides a spatially explicit Global Radiation Raster. Mandatory for running this tool is only a surface elevation raster but optional additional information on e.g. the latitude of the site area, general sky conditions and transmittivity are recommended in order to achieve a more distinct resulting model. The outcomes of the approach were assigned to the sample plots by calculating mean incoming annual solar radiation (Watt Hours $/ \mathrm{m}^{2}$ ) for every single polygon within all corresponding plots.

Resource Potential Dryness (RWT) values were only modified from class "0" to class " 1 " by applying a predefined rule set: Only those polygons would be altered sharing a mean slope $\geq 5^{\circ}$ and radiation values above the median gap of their range. Slope values were derived from a reclassified version of the original DEM. Therefore the original raster size was scaled down to 5 metres using Cubic Interpolation algorithm, smoothed and then the ArcGIS tool Slope was applied to calculate slope 
values for the entire dataset. Then, mean values per Polygon were taken for the final step of the assessment.

In cases where both aforementioned criteria met, RWT values " 0 " were replaced by " 1 ", altogether resulting in 740 modifications.

Ad (B) - The detection of troughs and sinks required several methodological steps, again using the reclassified $(5 \mathrm{~m})$ DEM as the main basedata set. The approach, again conducted using ArcGIS 10 is split up into two sub-assessments that have been combined in the end for the purpose of model validation. First, a Flow Direction Raster was created, serving as input dataset for the tool Sink. The outcoming sink-raster highlights spots of sinks respectively areas of internal drainage. Subsequently, the data set has been buffered in size by 2 meters and converted into a vector dataset.

In order to check on the correctness of the described approach, a second procedure also targeting on the identification of terrain depressions was conducted. Therefore, the DEM has been inverted first and a Flow Direction Raster has been created. This dataset was taken for the calculation of an inverted Flow Accumulation Raster. Usually, flow accumulation dataset are pointing out for the downslope flow behaviour of e.g water at events with heavy rainfall. Taking inverted flow accumulation data allowed for the selection of areas that were sharing value " 0 ", indicating for depressions within the target raster. Additionally, before selecting " 0 " valued pixels and reconverting them into a vector-dataset as series of Majority Filters and a buffer algorithm ( $2 \mathrm{~m})$ were applied to smoothen and generalize the flow accumulation data.

In the final step of the assessment both outcoming datasets were compared, following the assumption that locations of sinks, selected by the "sink-assessment" are technically accurate but their spatial extension may be undersized in various cases. On the other hand, the "flowaccumulation assessment" tended towards overfitting existing troughs. In order to reach the optimal result that can be achieved by the use of available data sources, the two models have been intersected retaining only those polygons that were pointing out for existing sinks in both datasets.

Resulting information on sinks was spatially joined to the polygons of the field mapping campaign. Finally, polygons sharing a proportion of sinks $>15 \%$ and had not been pre-classified by any RWF value were selected and entries altered from " 0 " to " 1 ". All in all, this assessment affected 1013 polygons of which 670 were modified in terms of RWF valuation.

Ad (C) - The primary goal of creating a combined assessment that would quantify erosion impact on each target polygon within the CCR study region was to modify the Environmental Variable that measures Natural Disturbance (DIN). DIN basically covers all natural processes causing degradation of vegetation and/or soil caused by e.g. extreme weather events or wind erosion. However, the magnitude of impact is also strongly depending on site-based land cultivation and management techniques, geology, and location of the target polygons. In 1978, Wishmeier and Smith introduced a Formula named Universal Soil Loss Equation (USLE) that quantifies average annual soil loss of tons per hectare and year including the main driving factors of climate (R-factor), soil characteristics (Kfactor), topography (LS-factor), land management (C-factor) and support practice of erosion control (P-factor):

$$
A=R * K * L * S * C * P
$$

Due to complexity and effort of data acquisition, preparation and calculation it was not intended to draw up a highly sophisticated model that would reflect absolute soil loss rates for each of our investigated polygons in the frame of CCR but to provide an overview up on categories of soil loss that enables further validation and modification of the DIN - parameter. In this sense all available base data was used, following the assessment of Revised Universal Soil Loss Equation (RUSLE), introduced by Renard et al., 1991. Additional classification tables for e.g. the extraction of C-factor values for certain land use classes were taken from other various scientific publications and manuals as representedin the following sections: 
Calculation of R-factor: The original and definitely most precise technique to calculate rainfall erosivity (= R-factor) consists of calculating average annual values of distinct heavy rainfall events within a long time period (>20 years). Major constraints for the detailed calculation of the R-factor consisted in the lack of spatially and thematically high-resolution data on rainfall activity throughout the study region, especially for the Hungarian part no such data was available. In our case, monthly averaged precipitation data of 30 arc second $(\sim 1 \mathrm{~km})$ spatial resolution, that was freely available from the "worldclim" database, was taken for the approach. Refering to Renard et al., (1994), the authors are providing a series of alternatives how to calculate R-factor values in approximation to the detailed approach by using monthly and annual mean values of precipitation only. For regions with mean annual precipitation below $850 \mathrm{~mm}$ they suggest the following formula: $R=0.04830 * P 1.610$ $(\mathrm{P}=$ mean annual precipitation rate). It provides a coefficient of determination of 0.81 when compared to detailed assessments, which is sufficiently precise for the estimation of soil erosion in the frame of this study. Practically, the single raster data subsets from the worldclim dataset were sized down to 5 metres and annual means were calculated using the Raster Calculator tool. Then, the equation to calculate the R-factor was applied and outcomes were again related to each of the target polygons by averaging R-factor pixel values per polygon.

Calculation of LS-factor: The LS-factor basically combines to interwoven variables, namely L (slope length) and S (slope steepness) which have been treated separately in the original USLE-model. For this assessment we followed the technical guidelines provided by Mitasova et al., 2001. Again, the $5 \mathrm{~m}$ DEM of the study area served as the basic input data source. First, a slope raster was created using the tool SLOPE and setting the measurement scale to "Degree". Flow Direction and Flow Accumulation Raster datasets that have been previously calculated for the assessment of sinks were also used for this part. For the final calculation of the LS-factor following expression was executed in the Raster Calculator Environment: LS = Pow([flowacc] * resolution / 22.1, 0.4) * Pow(Sin([slope] * $0.01745) / 0.09,1.4) * 1.4$. The following steps of the procedure are corresponding to those already described in in the previous section (calculation of R-factor).

Calculation of K-factor: The K-factor, also called soil erodibility factor is pointing out for the susceptibility to detachment and transport of soil particles, caused by e.g. rainfall events and water runoff (Lastoria et al., 2008). At this, the main influencing factors determining the overall K-factor are Texture, Structure and Permeability of the soil plus the proportion of Organic matter (Wishmeier et al., 1971). These parameters were derived from three input vector datasets, particularly a geology layer covering the entire study region of CCR as well as two harmonized soil layers covering the Austrian and the Hungarian subpart, respectively. Information on the grain size of the bedrock was derived from the geology-layer and composition of the occurring soil types within the study region were taken from the soil-layers. First, the thematic layers were intersected to extract all combinations of geological formations, soil types and corresponding grain sizes. For the allocation of $\mathrm{K}$-factor category values, already existing classification schemes on K-values of geological formations and textural classes listed by Lastoria et al., 2008 and Gitas et al., 2009 were adapted for this study. Therefore, two separate lists were created first and one final average value was calculated by taking the means of each soil and textural class combination. The resulting classification scheme for assessing the $\mathrm{K}$-factor was related to the target polygons, again calculating the mean $\mathrm{K}$-factor for each polygon.

Calculation of C-factor: The C-factor comprises information on crop/vegetation cover and land management techniques that are influencing the magnitude soil erosion (cf. Lastoria et al., 2008). Commonly, existing lists of C-factor values for certain land cover classes are being used for calculation purposes, many of them built up on the application of the CORINE land cover classification scheme. For our approach various lists could be adapted from de Vente et al., 2009; Lastoria et al., 2008; Rousseva et al., 2006 and the EU LIFE-project SOILPRO. Further, another assessment is described by Gitas et al., 2009 where the Normalised Difference Vegetation Index 
(NDVI) is applied for C-factor evaluation using following formula: $C=\exp 1$ (-a $N D V I /(\beta-N D V I))$, where $a=2$ and $\beta=1$. In this study we had the opportunity to use existing fine scaled multispectral Rapid Eye satellite imagery (spatial resolution $=3 \mathrm{~m}$ ) from spring 2010 in order to calculate NDVI based C-factor values besides using existing classification schemes.

First, C-factor values from aforementioned classification tables were used to set up a comprehensive list of C-factors for the land use/cover classes that are occurring in the sample plots within the study area. Values could be relatively easily related because a conversion table linking mapped habitat types to corresponding CORINE classes has been previously set up. For further refinement, site specific information on irrigation of the target polygons was also included, hence resulting in a $40 \%$ drop of C-factor values for irrigated landscape elements, according to the classification table of de Vente et al. (2009). Both, outcomes of the NDVI-based and table-based assessments of C-factor evaluation were summarized and then divided by " 2 " to reach one final C-factor value. As stated before, final values for each target polygon were derived by calculating average values per polygon.

Calculation of P-factor: The so called support practice factor (P-factor) was simply assessed by using existing information from field mapping. The management qualifier "M31" that has been facultatively assigned during field mapping characterizes landscape elements that are processed normal to their uphill direction to mitigate soil erosion. For all landscape elements where this practice is applied a P-factor value of " 0.5 " was assigned, while all other landscape elements were assigned by a value of " 1 ".

Application of the RUSLE-formula: After calculating the single factors as described in the previous sections, the final calculation of soil erosion was conducted by applying the following formula: $A=R^{*} K * L S * C * P$. Therefore, the five single factor variables were harmonized to an equal raster size of $1 \mathrm{~m}$ and multiplied together using the Raster Calculator. Then, mean erosion values per polygon could finally be calculated. Subsequent refinement of DIN values was realized in a two stepprocess. First, assessed erosion values were categorised in 10 quantiles, followed by a selection of polygons that have been assigned "DIN=0" from the first. Then, those polygons were selected and corrected to "DIN=1" satisfying the criteria: Erosion value $\geq 5$ th and $\leq 7$ th quantile. All polygons facing erosion values $\geq 8$ th quantile were corrected to "DIN=2". All in all, around half of the total polygons were refined by this assessment, excluding all types of roads, pathways and other man made places and buildings.

Ad (D) - The plausibility check of RNR values primarily targeted on anthropogenically utilized land use types. First, all polygons of various arable land and viticulture categories were selected. All polygons rated in dryness category "RWT $\geq 1$ " or sharing a RNR-value " $\geq 1$ " were consequently removed from the selection. Further, polygons that are located in areas of prevailing soil types Sol lessive or acidic brown soils were also removed. The remaining polygons were assigned a value of "RNR=1". A similar approach was conducted targeting the class of intensively utilized meadows (WII). All polygons of "RWT $<1$ " were assigned "RNR=1" or rather "RNR=2" in case they are located in moist areas (RWF $\geq$ 1) or areas of humid black soils and other nutrient-rich soils of lowlands

\subsubsection{Refinement of the ecosystem function assessment by environmental variables}

In a first step, broader habitats were linked by expert knowledge about the different habitat types' capacities to provide various ecosystem functions. Therefore, a capacity matrix was created (see Table 4 as an excerpt). Whereas on the $x$-axis selected ecosystem sub-functions are placed, on the $y$ axis the 181 LUCs (broader habitats) are placed. At the intersections, different habitat types' capacities to provide ecosystem sub-functions were assigned. The so-called Habitat Type Function Value ranges from 0 to 5 . The higher the value, the higher the general relationship between habitat type and function: 
$0=$ no relevant link between LUC and specific function, $1=$ low relevant link, $2=$ relevant link, $3=$ medium relevant link, 4 = high relevant link, 5 = very high relevant link (adapted from Burkhard et al., 2009).

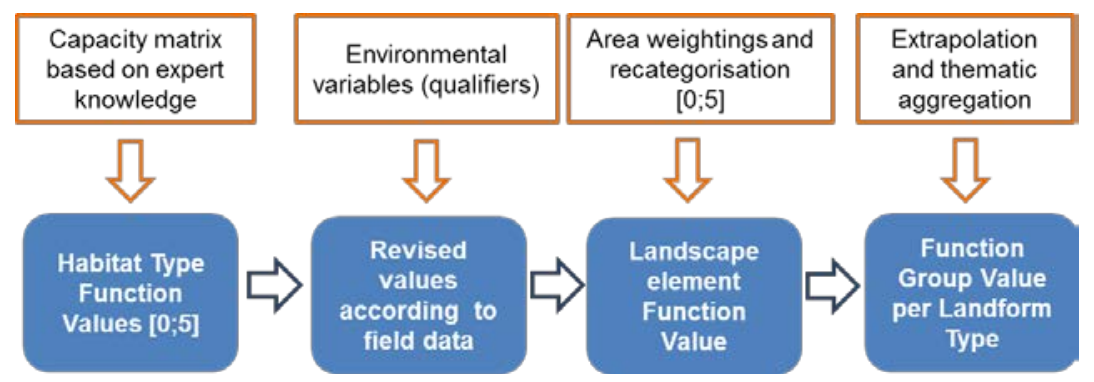

Figure 48: Assessment of the Regulation, Habitat, Provision and Carrier functions applying the habitat approach (Hermann et al., 2013, in press);

Table 4: Excerpt of the capacity matrix for the assessment of the different links between the habitat types and the related functions. The individual functions were assessed on a scale consisting of: $0=$ no relevant link between LUC and specific function, 1 = low relevant link, 2 = relevant link, $3=$ medium relevant link, $4=$ high relevant link, $5=$ very high relevant link.

\begin{tabular}{|c|c|c|c|c|}
\hline & 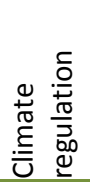 & 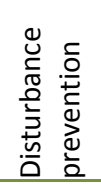 & 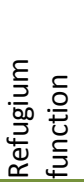 & 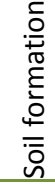 \\
\hline Grain fields extensive & 0 & 1 & 2 & 3 \\
\hline Forage crops & 0 & 2 & 1 & 3 \\
\hline Root crop extensive & 0 & 1 & 1 & 3 \\
\hline Root crop intensive & 0 & 0 & 1 & 2 \\
\hline Mixed green forests & 5 & 5 & 5 & 5 \\
\hline Wet woodlands & 5 & 5 & 5 & 5 \\
\hline $\begin{array}{l}\text { Old fallow land with tall } \\
\text { herbs }\end{array}$ & 0 & 3 & 2 & 4 \\
\hline Village paved & 4 & 1 & 0 & 0 \\
\hline
\end{tabular}

The basic Habitat Function Values were refined by formerly described environmental qualifiers. Including these habitat heterogeneities into the assessment methodology allows us to draw local as well as regional specific conclusions. The environmental qualifiers are also used as response variable to the climate change. Each of the qualifiers (RWT, RWF, RNR, DIN) has either a positive (1), a negative $(-1)$ or no influence (0) on the provision of a function (Table 5 ). 
Table 5: Qualifier matrix; the relationship between qualifiers (environmental variables) and sub-functions; (-)1 = negative influence, $0=$ no influence, 1 = positive influence

\begin{tabular}{|c|c|c|c|c|c|c|c|c|c|c|c|c|}
\hline & Eco & yste & $n$ fu & ctio & & & & & & & & \\
\hline $\begin{array}{l}\text { Environmental } \\
\text { Qualifier }\end{array}$ & 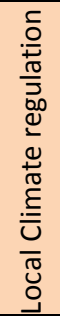 & 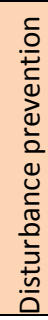 & $\begin{array}{l}\frac{1}{0} \\
\frac{0}{2} \\
\overline{5} \\
\frac{1}{2} \\
\frac{\pi}{3} \\
3\end{array}$ & 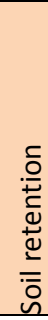 & 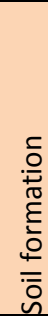 & 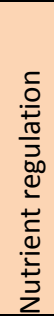 & 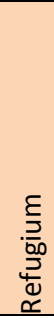 & $\begin{array}{l}0 \\
8 \\
\\
\end{array}$ & 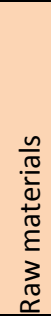 & 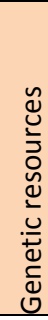 & 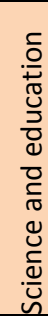 & 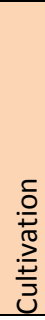 \\
\hline RWT 1 & 0 & 0 & 0 & 0 & 0 & 0 & 0 & 0 & 0 & 0 & 0 & 0 \\
\hline RWT 2 & 0 & 0 & 0 & 0 & 0 & 0 & 1 & 0 & 0 & 1 & 0 & 0 \\
\hline RWT 3 & -1 & 0 & -1 & -1 & -1 & 0 & 1 & 1 & 0 & 1 & 1 & -1 \\
\hline RWT 4 & -1 & -1 & -1 & -1 & -1 & -1 & 1 & 0 & 0 & 1 & 1 & -1 \\
\hline RWF 1 & 0 & 0 & 0 & 0 & 1 & 1 & 0 & 0 & 0 & 0 & 0 & 0 \\
\hline RWF 2 & 0 & 0 & 1 & 0 & 1 & 1 & 1 & 0 & 0 & 1 & 0 & 0 \\
\hline RWF 3 & 1 & 0 & 1 & 1 & 1 & 1 & 1 & 1 & 1 & 1 & 1 & -1 \\
\hline RWF 4 & 1 & 1 & 1 & 1 & 0 & 1 & 1 & 1 & 1 & 1 & 1 & -1 \\
\hline RNR 1 & 0 & 0 & 0 & 0 & 1 & 1 & 0 & 0 & 0 & 0 & 0 & 1 \\
\hline RNR 2 & 0 & 0 & 0 & 0 & 1 & 1 & 0 & 1 & 1 & 0 & 0 & 1 \\
\hline RNR 3 & 0 & 0 & 0 & 1 & 1 & 1 & 1 & 1 & 1 & 0 & 0 & 0 \\
\hline RNR 4 & 0 & 0 & -1 & 1 & 1 & 1 & 0 & 1 & 0 & 0 & 0 & 0 \\
\hline DIN 1 & 0 & -1 & 0 & 0 & 0 & -1 & 0 & 0 & 0 & 0 & 0 & 0 \\
\hline DIN 2 & 0 & -1 & 0 & -1 & -1 & -1 & 0 & 0 & 0 & 0 & 0 & 0 \\
\hline DIN 3 & 0 & -1 & 0 & -1 & -1 & -1 & 1 & 0 & -1 & 1 & 1 & -1 \\
\hline DIN 4 & 0 & -1 & -1 & -1 & -1 & -1 & 0 & 0 & -1 & 0 & 1 & -1 \\
\hline
\end{tabular}

\section{Ecosystem Function Calculation}

All calculation steps described in this chapter were conducted using ArcGIS 10 (ESRI, 2011). First, the capacity matrix was assigned to the already mapped landscape element database to obtain a basic habitat function value. Subsequently, the qualifier values were either added to $(+1)$ or subtracted from (-1) the original Habitat Function Values depending on the environmental variables that have been assigned to each single landscape element during field mapping. This methodological step was separately conducted for each single ecosystem function. Afterwards the modified function values were multiplied by the area (in $\mathrm{m}^{2}$ ) of each corresponding landscape element. Area weighting served to reflect the actual magnitude of function provision within each single element as e.g. a large forest patch is actually sharing a greater ability in 'local climate regulation' than a small remnant of a former forest. Area weighting was applied for all listed functions except from 'refugium' and 'genetic resources'. In case of the 'refugium' function area weighting would partly cause misleading results as habitat areal requirements for ecologically valuable key species diverge and most of them are not side-dependent. Further, patches like big arable fields that were rated rather low in terms of 'refugium' provision according to the Habitat Function Value table would have been re-designated as highly valuable refugial spaces while on the other hand valuable stepping stone elements like small woodlots or remnants of salt steppes would have been downgraded. In case of the 'genetic resources' function, a direct relationship between the areal share of the target elements and the occurrence of relevant genetic material is very vague and therefore area-weighting was not considered for this function.

After the area-weighting procedure, values were re-classified to the original scale [0-5] using quantiles. In order to obtain ecosystem function values for the entire study region up-scaling of the 
results from single landscape element level up to LFT-level was necessary. This was accomplished by applying a two-step approach. First, to receive one single value for each sub-function per sample site $(1 \times 1 \mathrm{~km})$, area-weighting of the reclassified function-values was separately conducted for each site and the average of the weighted values was calculated. In a second step, all sample-site specific function values were summed up and divided by the number of sites within each LFT to reach one final function value for each sub-region. This procedure was applied for all single LFTs except from LFT 1 (Lake Basin), which can be regarded as a special case within the study region because Lake Neusiedl itself, its adjacent Reed Belt and satellite lakes cover more than $60 \%$ of LFT 1. To take these large and inaccessible areas into account, LFT 1 was split up into 4 parts such as the terrestrial region, characterized by sample site outcomes, and the three aforementioned land units. For these areas, provision of certain ecosystem functions was derived by calculating area-based values from the Habitat Function Value table and afterwards combining them with sample site based results for the terrestrial area according to their areal-weights. This approach can be vindicated by the uniformity of land units that have been separately treated here and did not require for an additional resource qualifier assessment.

The last step of the ecosystem function assessment consisted of aggregating single sub-function values per LFT into following five main groups of ecosystem functions: Regulation, Habitat, Provision, Carrier and Information. Therefore, mean values of sub-functions that are related to the same ecosystem function main group were calculated on LFT basis. 


\subsection{Historic assessment of ecosystem functions within the Neusiedler-See region}

For the estimation of 'historical' ecosystem function provision within the CCR-study region, a previously digitized version of the $1^{\text {st }}$ military survey was taken as the basic thematic data source. First, the historical land cover categories had to be referred to values of magnitude for the provision of certain ecosystem functions. Therefore, the historical categories could be compared to recent CORINE-LC categories because historical landscape mapping had been following the common guideline of the CORINE classification system. This precondition allowed for fast and efficient relation of ecosystem function classes to the historical LC-categories. However, some values had to be refined in view of discrepancies between anthropogenic impacts on the landscape now and then (Table 6). Subsequent calculation of functions loosely followed the 'recent' assessment of EFs with the difference that the historical data encompasses the entire study area and function values could be calculated for each LFT just by area-weighted averaging function values of the occurring LCcategories. However, resource qualifiers were not included in the 'historical' EF-assessment.

Table 6: Capacity matrix for the assessment of the different links between the historical land cover categories and the related functions. The individual functions were assessed on a scale consisting of: $0=$ no relevant link between LUC and specific function, $1=$ low relevant link, 2 = relevant link, 3 = medium relevant link, 4 = high relevant link, 5 = very high relevant link.

\begin{tabular}{|c|c|c|c|c|c|c|c|c|c|c|c|c|}
\hline \multirow[b]{2}{*}{ Historical Land Cover category } & \multicolumn{12}{|c|}{ Ecosystem functions } \\
\hline & 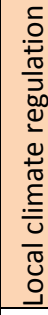 & 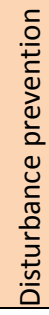 & $\begin{array}{l}\frac{1}{0} \\
\frac{0}{2} \\
5 \\
5 \\
\frac{1}{2} \\
\frac{1}{3} \\
3\end{array}$ & 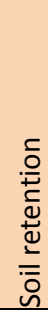 & 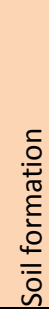 & 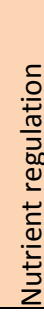 & 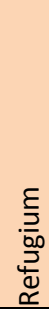 & $\begin{array}{l}\text { 음 } \\
\text { 운 } \\
\end{array}$ & 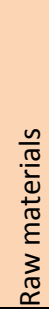 & 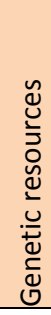 & 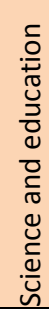 & 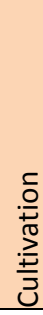 \\
\hline Mineral extraction sites & 0 & 0 & 0 & 0 & 0 & 0 & 3 & 0 & 0 & 0 & 2 & 0 \\
\hline Vinyards & 2 & 1 & 0 & 0 & 0 & 2 & 2 & 0 & 1 & 0 & 0 & 5 \\
\hline Pastures / Meadows & 2 & 2 & 2 & 2 & 1 & 2 & 4 & 2 & 0 & 1 & 2 & 4 \\
\hline Broadleaved forest & 5 & 5 & 4 & 5 & 5 & 5 & 5 & 4 & 5 & 5 & 4 & 0 \\
\hline Sparsely vegetated areas & 0 & 0 & 0 & 0 & 0 & 0 & 2 & 0 & 0 & 0 & 3 & 0 \\
\hline Inland marshes & 3 & 3 & 5 & 3 & 4 & 4 & 5 & 2 & 2 & 3 & 4 & 0 \\
\hline Other roads & 0 & 0 & 0 & 0 & 0 & 0 & 0 & 0 & 0 & 0 & 0 & 0 \\
\hline Cemetery & 3 & 3 & 3 & 3 & 2 & 3 & 2 & 1 & 1 & 0 & 0 & 0 \\
\hline Other green urban areas & 3 & 3 & 2 & 2 & 1 & 1 & 1 & 0 & 0 & 0 & 0 & 0 \\
\hline Arable land & 1 & 1 & 1 & 1 & 1 & 1 & 2 & 0 & 0 & 0 & 1 & 5 \\
\hline Garden \& market gardening & 1 & 1 & 1 & 1 & 1 & 1 & 1 & 0 & 0 & 0 & 0 & 5 \\
\hline Fruit tree meadows & 3 & 3 & 3 & 3 & 3 & 3 & 3 & 1 & 2 & 1 & 2 & 4 \\
\hline Orchard & 3 & 3 & 3 & 3 & 3 & 3 & 3 & 0 & 2 & 1 & 1 & 5 \\
\hline Bosk / Grove & 4 & 4 & 4 & 4 & 4 & 4 & 4 & 3 & 3 & 2 & 3 & 0 \\
\hline Treerow & 3 & 3 & 3 & 3 & 3 & 2 & 2 & 2 & 2 & 0 & 1 & 0 \\
\hline Neglected/mesophil grassland & 3 & 3 & 3 & 3 & 3 & 3 & 3 & 1 & 1 & 2 & 3 & 1 \\
\hline Other natural grasslands & 2 & 2 & 2 & 3 & 2 & 2 & 4 & 2 & 1 & 3 & 4 & 1 \\
\hline Natural watercourses (rivers, brooks) & 5 & 4 & 5 & 0 & 0 & 4 & 5 & 3 & 0 & 3 & 4 & 0 \\
\hline Artifical watercourses & 4 & 3 & 4 & 0 & 0 & 3 & 3 & 3 & 0 & 2 & 1 & 0 \\
\hline Natural standing water & 5 & 3 & 5 & 1 & 2 & 4 & 5 & 3 & 0 & 3 & 4 & 0 \\
\hline Artifical reservoirs & 4 & 2 & 5 & 0 & 1 & 3 & 3 & 0 & 0 & 0 & 0 & 2 \\
\hline Mixed used zone in villages & 2 & 1 & 0 & 1 & 0 & 1 & 1 & 0 & 0 & 0 & 0 & 0 \\
\hline Single houses & 0 & 0 & 0 & 0 & 0 & 0 & 0 & 0 & 0 & 0 & 0 & 0 \\
\hline Mansion houses with garden & 2 & 1 & 0 & 1 & 1 & 1 & 1 & 1 & 1 & 0 & 0 & 1 \\
\hline Single estate & 0 & 0 & 0 & 0 & 0 & 0 & 0 & 0 & 0 & 0 & 0 & 0 \\
\hline
\end{tabular}




\subsection{Assessment of 'future' ecosystem functions' potential under consideration of ongoing climate change phenomena within the Neusiedler-See region}

\subsubsection{Thresholds for environmental data for Scenario 1 (2041) and Scenario 2 (2100)}

Based on the current site condition parameters (qualifiers) moisture [RWF]; dryness [RWT]; nutrient richness [RNR] and natural disturbance [DIN] that had previously been mapped during extensive field campaigns in 2010 and 2011, checked and partly corrected a series of threshold values for predicted changes of precipitation rates and rising temperature that would alter current site conditions were set up during a series of expert discussions. In the subsequent table (Table 7) all climate induced change assumptions are summarized, addressing two upcoming scenarios (2041; 2100):

Table 7: Winter precipitation and mean winter temperature thresholds that would alter resource parameters (qualifier), such as RWT (dryness), RWF (moisture), RNR nutrient richness and DIN (natural disturbance) for the Scenario 1 (changes till 2041) and the Scenario 2 (changes till 2100).

\begin{tabular}{|c|c|c|}
\hline Resource Parameter & Scenario 1 (Changes till 2041) & Scenario 2 (Changes till 2100) \\
\hline$R W T$ & $\begin{array}{l}\text { Threshold for winter precipitation } \\
\qquad \begin{array}{c}\text { (October - March) } \\
<300 \mathrm{~mm}\end{array}\end{array}$ & $\begin{array}{l}\text { Threshold for winter precipitation } \\
\qquad \begin{array}{c}\text { (October - March) } \\
<400 \mathrm{~mm}\end{array}\end{array}$ \\
\hline$R W F$ & $\begin{array}{l}\text { Changing winter precipitation } \\
\qquad \begin{array}{c}\text { (October - March) } \\
\quad>4.3 \% \Delta\end{array}\end{array}$ & $\begin{array}{l}\text { Changing winter precipitation } \\
\qquad \begin{array}{c}\text { (October - March) } \\
>9.1 \% \Delta\end{array}\end{array}$ \\
\hline RNR & $\begin{array}{l}\text { Mean winter temperature } \\
\qquad \begin{array}{c}\text { (October - March) } \\
>5^{\circ} \mathrm{C}\end{array}\end{array}$ & $\begin{array}{l}\text { Mean winter temperature } \\
\text { (October - March) } \\
>5^{\circ} \mathrm{C}\end{array}$ \\
\hline DIN & $\begin{array}{l}\text { Changing winter precipitation } \\
\qquad \begin{array}{c}\text { (October - March) } \\
>\mathbf{4 . 3} \% \Delta\end{array}\end{array}$ & $\begin{array}{l}\text { Changing winter precipitation } \\
\qquad \begin{array}{c}\text { (October - March) } \\
>\mathbf{9 . 1 \%} \Delta\end{array}\end{array}$ \\
\hline
\end{tabular}

We decided to link our assumptions on changes that will occur in the winter period when plant growth is naturally inhibited in the study region at present, while during the actual vegetation period extreme weather events like periods of drought have already been occasionally happening in the study region. Such events will definitely increase, though most influencing factors of successful soil formation and plant growth are particularly being set by precipitation rates and mean temperature values during winter time. Our assumptions were on the one hand drawn on fundamental ecological theories as well as on studies that have been carried out during the last years in a comparable region. First, the $5^{\circ} \mathrm{C}$ threshold was considered as being crucial for successful plant metabolism processes and hence plant and crop growth in particular. In case that this threshold is exceeded for a certain period, usually some continuous days, plants are generally switching from dormancy to growing phase. Especially during the winter months, plants are currently hindered from growing by temperatures falling below this threshold. This necessarily does not mean that crop growing will be enabled during the whole winter period by upcoming climatic developments towards milder winters but it is very likely that the cultivation period of specific crops can be extended. The harvesting period of specific crops, for instance eggplants might be rescheduled to later dates while sowing will 
be possible at earlier dates for specific crops, such as grains, according to latest forecasts. Watermelons, for example might be harvested at later dates when they have attained full maturity and developed their excellent aroma. Hence, nutrient enrichment cycles would be significantly enhanced by extended periods of growth that in turn would lead to higher concentrations of nitrogen in the ground. Further, the climatic water balance, primarily depending on water storage capacity of the soil is another determining factor to ensure water supply during the vegetation period. This is particularly true for rather dry regions in the eastern parts of Austria like the Seewinkel that are influenced by central European continental climate. There, rain events in summer are rather rare and water has to be stored from rainfalls in winter and springtime. Based on annual rates of evapotranspiration after Penman (1948) that have been assessed by scientists of the University of Environmental Sciences Vienna in the comparably dry region of the "Tullnerfeld" (annual rainfall rates $\sim 570 \mathrm{~mm}$ ) we assumed precipitation rates from October-March should be at least $300 \mathrm{~mm}$ for 2041 and $400 \mathrm{~mm}$ for 2100, respectively. Otherwise, non-irrigated crops would risk drought stress during the hot and dry summer period. On the other hand, increased winter rainfall would probably lead to more humid conditions in parts of the CCR study region. Finding threshold values in this case was solved by screening downscaled climatic forecast tables, provided by our partners from the AIT (see attachments). Threshold values were defined as means of increasing change rates of precipitation over time, being set at $\mathbf{4 . 3} \%$ increase in 2041 and $9.1 \%$ in 2100, respectively. In general, an increase of precipitation totals is predicted for upcoming winter periods, while summer conditions will most likely become even drier compared to the recent situation. Along with this prediction the probability of extreme rainfall events or periods of continuous heavy rainfall in winter will become more acute, leading to reinforced natural disturbance $(D I N)$. In order to map possible changes in the natural disturbance regime acting on the region, the same threshold values of precipitation change rates have been applied.

It is a matter of fact that several habitat types would react more or less sensitive to altering climate conditions, e.g. a large forest stand shares quite a high possibility to buffer periods of drought and is also well prepared against soil erosion caused by rainfalls or flooding. On the opposite, anthropogenically modified habitats, such as arable fields do not have the capacity of resilience to climate change induced effects. In our project all occurring habitat types have been sectioned into the nine habitat main types of Agriculture; Grassland; Unfarmed Grassland; Small Semi-natural Features; Forests; Watercourses; Standing Waterbodies; Small Natural Features and Artificial Features (for more information see Hermann et al., 2013, in press).

For each habitat main type, a change in resource parameters was separately elaborated due to exceeding predefined threshold values (see Table 7). Changes are summarized in the following table: 
Table 8: Change in resource parameters (qualifier) RWT (dryness), RWF (moisture), RNR nutrient richness and DIN (natural disturbance) due to predefined threshold values, separately for each habitat main group for the Scenario 1(2041) and Scenario 2 (2100).

\begin{tabular}{|c|c|c|c|c|c|}
\hline Habitat Main Types & $\sum_{-1}^{D}$ & $\sum_{i=1}^{D}$ & 㫣 & 믈 & \\
\hline Agriculture & +2 & +1 & +1 & +2 & \\
\hline Grassland & +1 & +1 & +1 & +1 & $\curvearrowleft$ \\
\hline Unfarmed grassland & +1 & +1 & +1 & +1 & \\
\hline Small semi-natural features & +1 & +1 & +1 & +1 & оे \\
\hline Forests & 0 & 0 & +1 & 0 & $\frac{n}{N}$ \\
\hline Watercources & 0 & 0 & 0 & +1 & $\stackrel{8}{p}$ \\
\hline Standing water bodies & 0 & 0 & 0 & 0 & \\
\hline Small natural features & +1 & +1 & +1 & +1 & \\
\hline Artificial features & 0 & 0 & 0 & 0 & \\
\hline Agriculture & +2 & +1 & +1 & +2 & \\
\hline Grassland & +1 & +1 & +1 & +1 & $\simeq$ \\
\hline Unfarmed grassland & +1 & +1 & +1 & +1 & 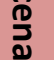 \\
\hline Small semi-natural features & +1 & +1 & +1 & +1 & ไ̄. \\
\hline Forests & +1 & +1 & +1 & 0 & $\frac{N}{N}$ \\
\hline Watercources & 0 & 0 & 0 & +1 & 용 \\
\hline Standing water bodies & 0 & 0 & 0 & 0 & \\
\hline Small natural features & +1 & +1 & +1 & +1 & \\
\hline Artificial features & 0 & 0 & 0 & 0 & \\
\hline
\end{tabular}

\subsubsection{Calculation of forecasted ecosystem function provision for two scenarios in time}

Detailed information on forecasted changes in temperature and precipitation rates within the CCRstudy region have been provided by the project partners of the AIT. Therefore, regional climate models had been generated for squares with an edge length of $10 \mathrm{~km}$, covering the entire study region and a subset of squares including the investigated samples sites were selected for further treatment. For each of the squares information on total winter precipitation (October-March), changing winter precipitation rate and mean winter temperature was separately treated by calculating mean values for the two aforementioned time periods of "2001-2041 (= Scenario 1)" and "2041-2100 (= Scenario 2)" (see Appendices 1c and 2c). Afterwards, local environmental parameters (RWT; RWF; RNR; DIN) per polygon were modified by applying the predefined threshold values referring to table Table 7. Alteration of the parametric values has been conducted case by case under consideration of specific habitat type main groups (see Table 8). We further decided to keep "0values" of RWT and RWF not affected from any changes because it is hard to estimate how average site conditions of wetness/dryness would change under changing climatic conditions.

The upcoming methodological steps are corresponding to the previously introduced assessment of ecosystem function provision that has already been described in chapter 2.5. The basic Habitat Function Values have been refined by environmental qualifiers, with the difference that the qualifiers were corresponding to the future environmental conditions of either Scenario 1 or Scenario 2. Again, results have been upscaled on Landform Type (LFT) level and visualized by a series of spiderweb diagrams. 


\section{Results and Discussion}

\subsection{Comparisons between the 'potential', 'historical' and 'recent' ecosystem function provision of the 7 Landform Types within the study region Neusiedler-See}

The results of the 'potential', 'historical' and 'recent' ecosystem function assessments are visualized by spiderweb diagrams for each Landform Type describing the trade-offs and allocation of the different functions. The figures represent the high landscape diversity within the investigation area ranging from the natural and semi-natural areas such as the shallow lake with its immense reed belt, the remaining marshland and flood plains over the extensive used hilly area to the intensive agricultural regions in the low lying terraces. Different site conditions, land cover and land use types are responsible for divergent EF distributions even within one Landform Type. While the 'potential' EF assessment is based on 'constructed vegetation types', the 'historical' and 'recent' EF evaluation is based on landcover/use types. Therefore, concerning the 'historical' and 'recent' EF evaluation a landcover/use change within one Landform Type results in a high change of EF provision.

In the Landform Type 'Lake basin' for instance, the area covered by reed belt has changed dramatically during the centuries. While the extent of the reed belt area was more or less constant during the former centuries, it had increased explosively from the beginning in the middle of the $19^{\text {th }}$ century due to drainage systems as well as the increasing intensification of agriculture. Fortunately, cutting and grazing of the reed could stem the expansion, however as livestock farming and cutting had decreased since 1960, the reed could spread again. Today, funded grazing and reed cutting projects are able to control more or less the expansion of the reed belt area. Comparing the 'historical' and 'recent' EF provision (see Figure 50) the development of the reed belt area and its EF provision is well reflected.

Also within the Landform Type 'Marshland' the distribution of the EFs is determined by the landcover/use change during the centuries. In the $18^{\text {th }}$ century the landcover types 'inland marshes' and 'other natural grassland' provided suitable living space for specialised wild plants and animals. Nowadays, drainage of the marshlands allows cultivation and leads consequently to higher Carrier and Provision functions. According to the 'constructed vegetation types', namely 'fens and alder swamp forests' and 'loess forest steppe with mixed oak forests' this Landform would provide high Habitat and Regulation function whereas the Provision function would be less provided compared to the 'historical' and 'recent' values.

Figure 56 visualises the 'historical', 'recent' and 'potential' EF distribution within the Landform Type 'River floodplain'. The area under cultivation remained more or less the same. However, the low input farming in the $18^{\text {th }}$ century ensured higher Habitat and Information functions than the intensive farming systems in recent times. The potential 'fens and alder swamp forests' landcover types would deliver high Regulation, Habitat and Provision functions.

The 'Low lying terraces' and the 'Elevated terraces' show more or less the same allocation of EFs. Both Landforms are characterised by complete lack or insignificant presence of surface water due to flood protection and/or the higher elevation of the terraces. Nowadays, predominant is the equally flat surface covered by intensive arable land parcels and peri-urban zones and by growing horticultural establishments. That is why both Landforms present the lowest values in the Provision (e.g. wild food, raw materials) and the highest values in Carrier functions at the same time. The relative high values in Regulation functions may be due to the well preserved nature conservation areas (wet grassland with high biodiversity) within these monotonous Landforms. In former times farming was mainly based on extensively managed pastures and meadows, which explains the high EF Habitat values. 
The 'recent' spiderweb values of the Landform 'Hilly area and hill range' reflects a diversified landscape including both extensive and intensive rural areas accompanied by some semi-urban settlements. The northern part of the Rust Hill range, on the foothills of the Leitha Mountain and on the small island hill 'Hackelsberg' the sunny south and west slopes have a certain Mediterranean character. With exception of the hill 'Hackelsberg', where valuable dry grassland still remain, the landscapes are intensively used mainly covered by vineyards. The historically landuse types were mainly based on arable fields and meadows. The potential 'oak hormbeam forest', pannonian bitter oaksessile oak forests' as well as the 'loess forest steppe' would provide high Provision, Habitat and Regulation functions.

The Landform Type 'Low and middle range mountains' is characterised by low mountains and foothills with low intensity human use mainly covered by closed forests. The remarkable high values of Provision, Regulation, Habitat and Information functions (Figure 68) are based on the almost homogeneous oak-hornbeam forest with fringes of thermophilous downy oak associations with some infiltration of Robinia pseudo-acacia and small grassland patches on the hillsides of the deep valleys in the Leithagebirge. The relative high 'recent' Carrier values compared to the 'historical' ones might be due to the mapped environmental variables (RWF, RWT, DIN, RNR) found in the recent field survey.

\subsection{Sensitivity of ecosystem functions to climate change in the study region Neusiedler- See}

According to the scenario figures (Figure 51, Figure 54, Figure 57, Figure 60, Figure 63, Figure 66, Figure 69) the differences between 'recent', 'scenario 2041' and 'scenario 2100' EFs are not very significant as most landcover types, especially 'waterbodies' and 'forests' seem to buffer efficiently the increasing precipitation and temperature values occurring in winter months. In general, the scenarios predict that most function values will slightly increase. Thus, the results suggest that there might be only positive responses on climate change.

However, it has to be taken into account that the scenario values are only based on the strong relationship between the environmental variables and the ecosystem functions (see chapter 2.5.3). The environmental variables in turn are strongly reliable on precipitation and temperature rates. Therefore, the scenario function values reflect only the capacity of ecosystems to provide specific services under specific environmental conditions. Biological systems are based primarily on photosynthesis, and are thus dependent on incoming radiation, which in turn is greatly modified by temperature and rainfall. Whereas the main effect of temperature is to control the duration of the period when growth is possible in each year (Rötter and van de Geijn, 1999), rainfall and soil water availability may affect the duration of growth. For many plant species moderately increasing temperature will generally be beneficial expanding their growing season as well as their suitable habitat, given that water supply is sufficient. Greater variance in environmental resources (water, nutrients) will also have a positive effect on 'refugium' function for specific species and stimulate wild plants and animals as well as the production of raw materials in general. More differentiated environmental variables lead to more different characteristics of habitats that in turn will also be more interesting for 'science and education'. Given that most investigated broader habitats are situated in well buffered landscapes, the changes in the distribution of ecosystem functions, for instance Regulation functions might therefore not be as large as in other regions.

Specific functions, in particular 'cultivation' might profit from climate change, provided that appropriate mitigation measures, such as appropriate selection of crop varieties and an adapted cultural landscape management, for example earlier sowing dates are taken into account (Schröter et al., 2005; Rounsevell et al., 2006). For many field -grown vegetable crops increasing temperature will generally be beneficial with production expanding northwards. Also grapevine, a woody perennial plant requires relatively high temperatures. A climatic warming will therefore expand the suitable production areas for a wide range of agricultural plants (Kenny and Harrison, 1992, Harrison et al., 
2000). However, in the current production areas the yield variability (fruit production and quality) may be higher under global change than at the present (Olesen et al. 2002).

Some rare or threatened species so far might also benefit from global warming as their ecological niche requires such particular conditions.

However, we have to have in mind that the assessment didn't encompass land use changes, changes of groundwater levels and extreme weather conditions, such as storms, floods and hot spells in the future. According to Essl and Rabitsch (2013) we have to reckon with more intensive and frequent extreme events as rapid climate changes also increase the probability of extreme weather situations. In many parts of the world it is not the mean climatic conditions but rather the extremes that cause changes in ecosystem structure and functioning (Mooney et al., 2009). Lower air humidity accompanied by periods of increased temperature and sunshine in the summer months, for instance can lead to physiological problems, which diminish the marketable quality of agricultural products. The increased precipitation rates in the winter months might not be able to compensate such extreme hot spells. Drought in summer and mild winter might also enhance the probability of barkbeetle infestations. The degree of the climate change impact therefore, will mainly depend on the frequency, persistence as well as the spatial and temporal occurrence of such extreme events. According to Essl and Rabitsch (2013) it will be very difficult for most ecosystems to adapt to these events in such a short period. There are likely to be important limits to the rates of climate warming that natural systems can adapt to and these should be deducible from both limits to evolutionary change and limits to the rates that species can move across the landscape tracking climate change. Therefore, estimating the impact on biodiversity and its ecosystem functions is very challenging. More work in this area would allow more reliable predications for climate change impacts on biological systems.

Figure 70 and Figure 71 show the 'recent' provision of the function 'cultivation' compared to Scenario 1 (2041) and Scenario 2 (2100) for selected landscape samples within two different Landform Types. Within the LFTs 'Elevated terrace' and 'Low lying terrace' the function 'cultivation' will slightly decrease. We assume that changing environmental conditions have negative influences on the function 'cultivation' as increasing precipitation rates in the winter months and higher temperature in the summer period will make farming more difficult under actual management conditions. Climate change mitigation measures will therefore be necessary if the function values should remain the same. 


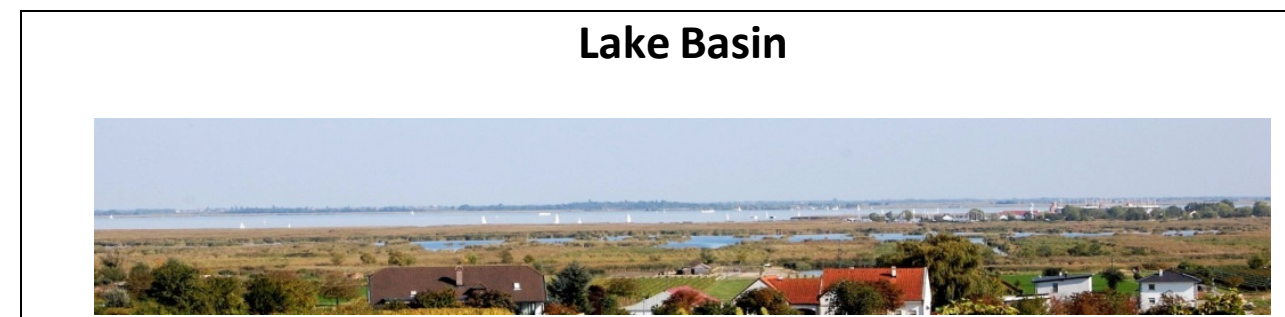

Figure 49: Surrounding area of Mörbisch. Photo: Éva Konkoly-Gyuró
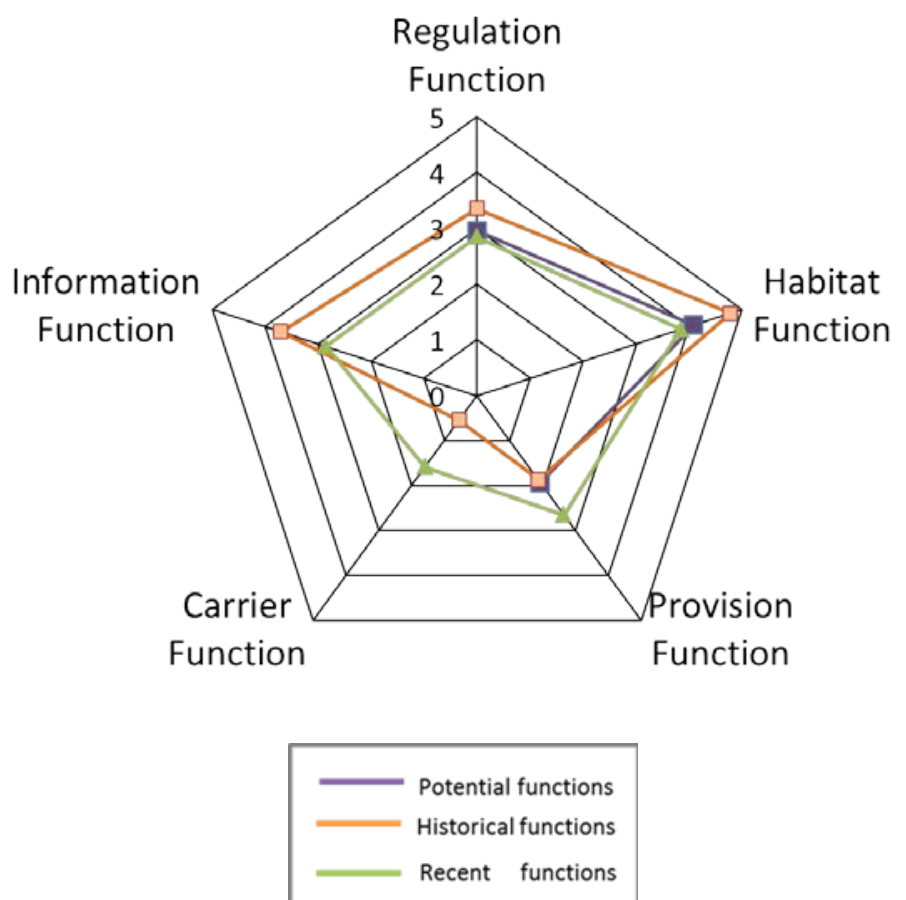

Figure 50: Allocation of the 'potential', 'historical' and 'recent' ecosystem functions in comparison for LF lake basin

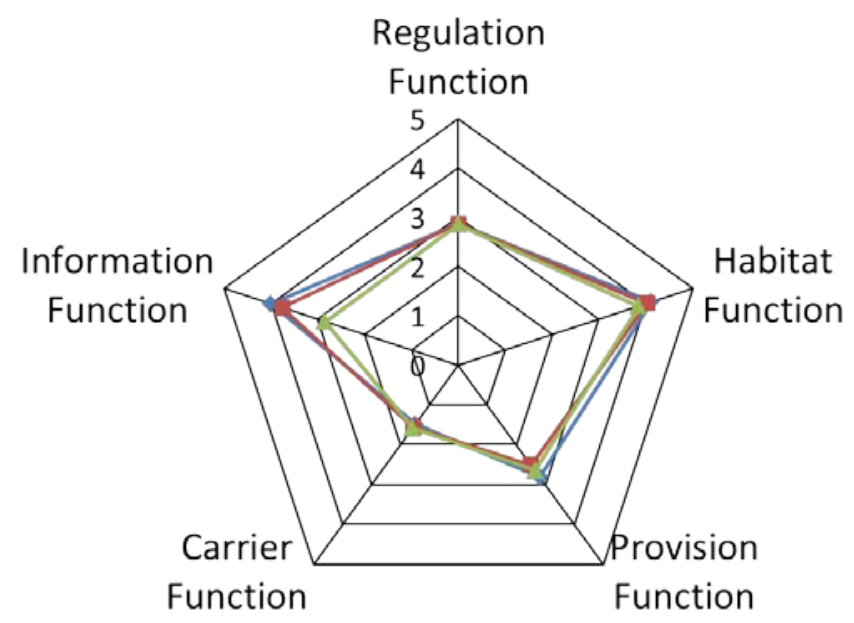

Function

Function 


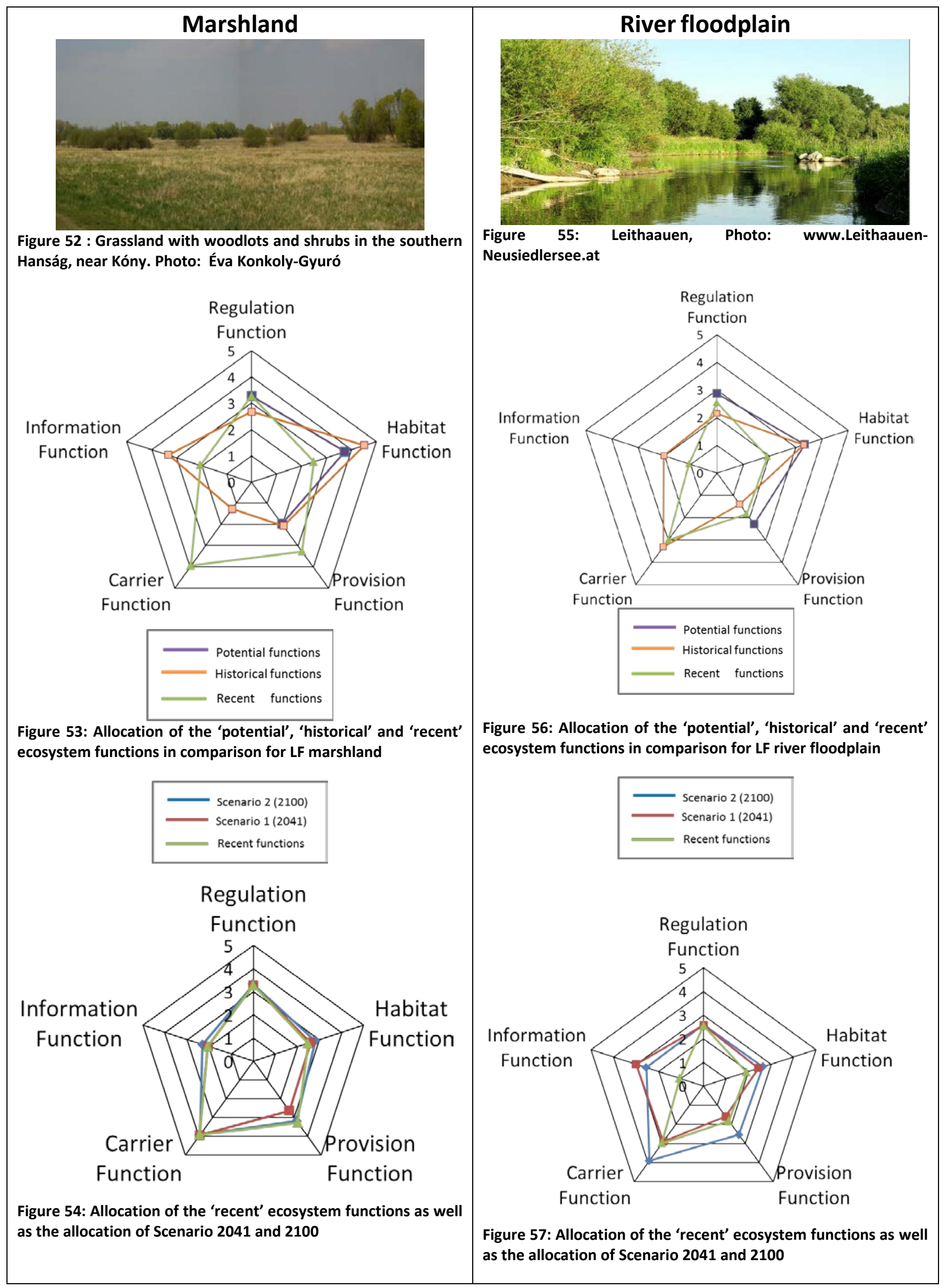




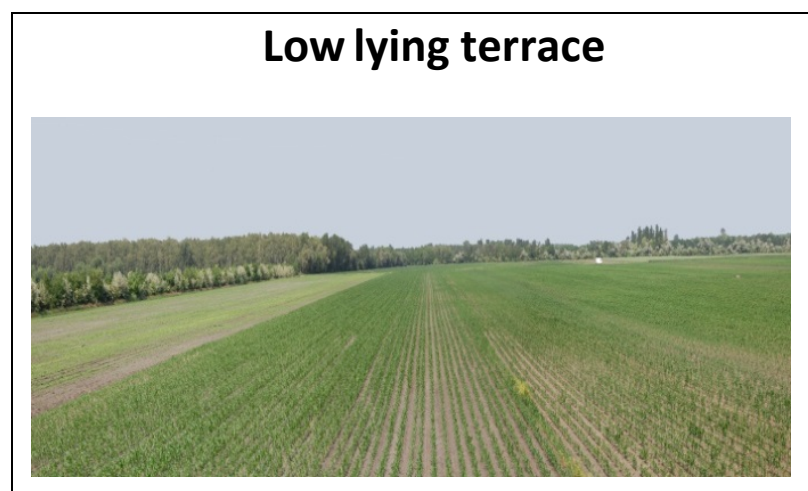

Figure 58: Flatland dominated by arable land in the north of Andau. Photo: Éva Konkoly-Gyuró
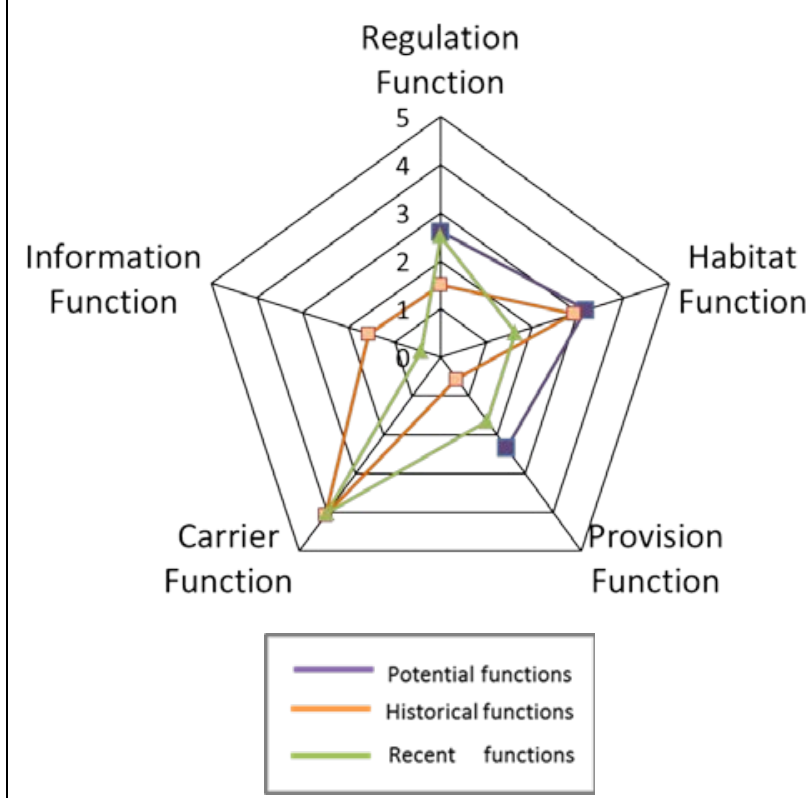

Figure 59: Allocation of the 'potential', 'historical' and 'recent' ecosystem functions in comparison for LF low lying terrace

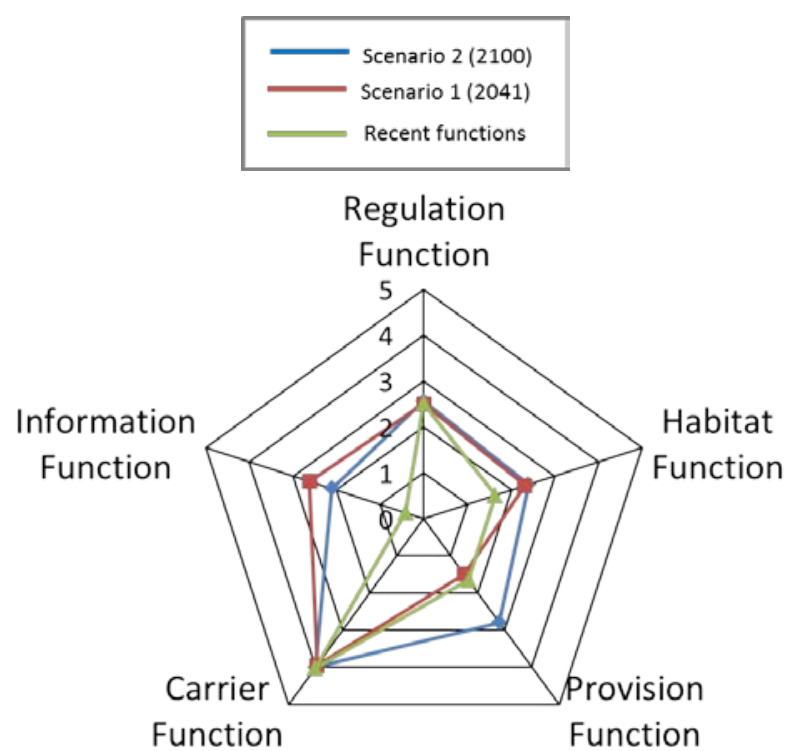

Figure 60: Allocation of the 'recent' ecosystem functions as well as the allocation of Scenario 2041 and 2100

\section{Elevated terrace}

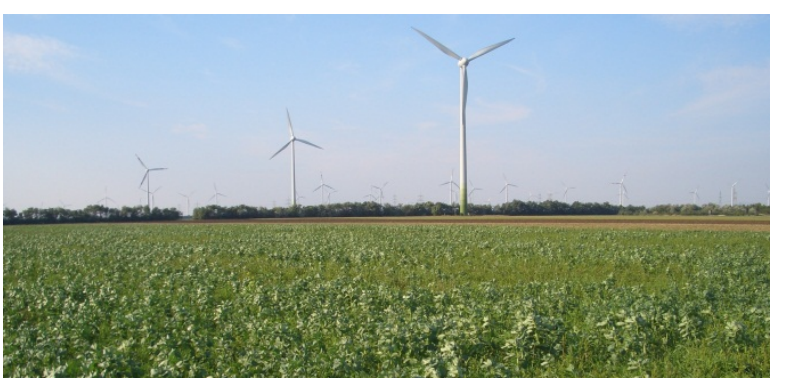

Figure 61: Wind turbines at Plateau of Parndorf. Photo:Tamara Zhuber

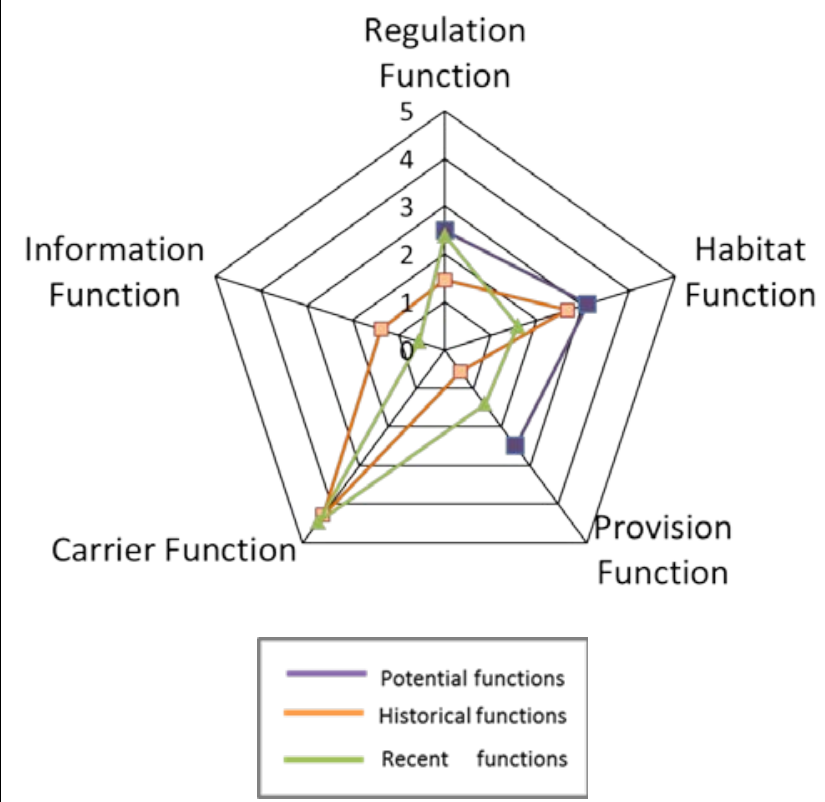

Figure 62: Allocation of the 'potential', 'historical' and 'recent' ecosystem functions in comparison for LF elevated terrace

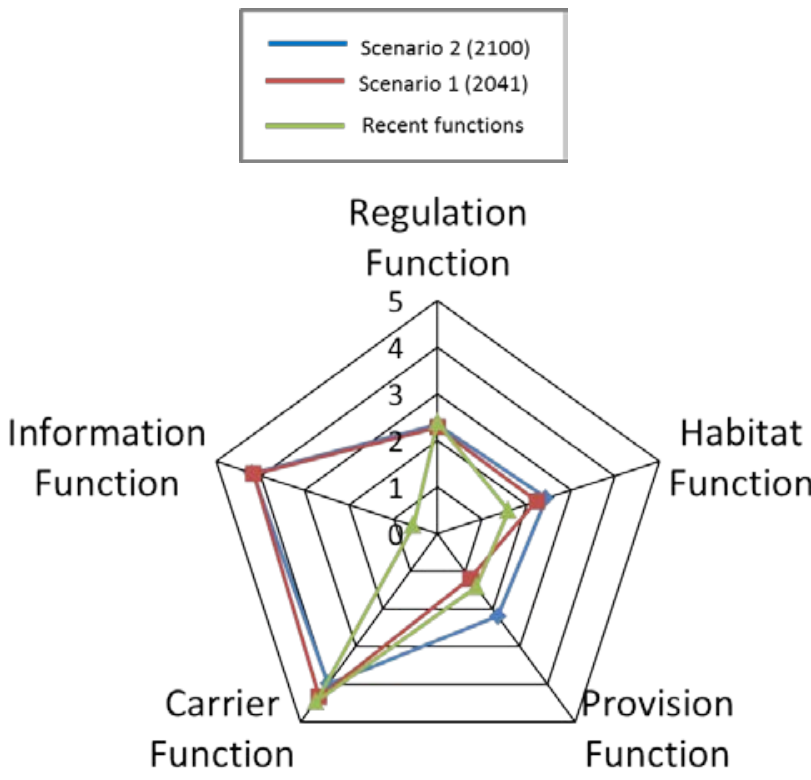

Figure 63: Allocation of the 'recent' ecosystem functions as well as the allocation of Scenario 2041 and 2100 


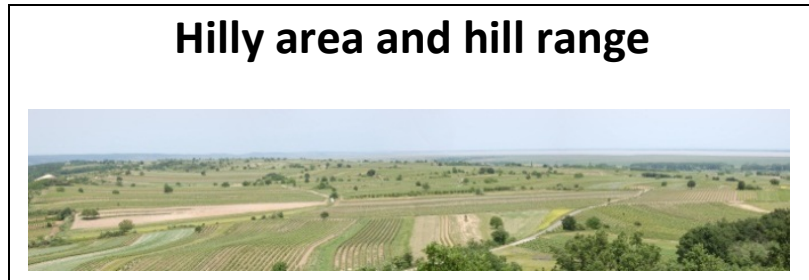

Figure 64: Panorama image of the hilly area nearby Rust and Oggau. Photo: Éva Konkoly-Gyuró
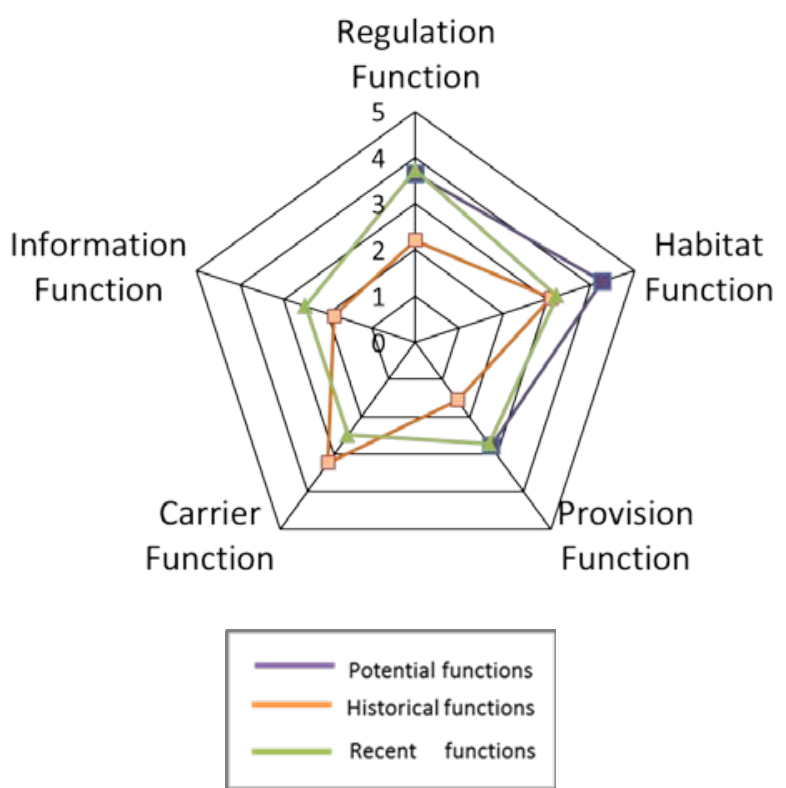

Figure 65: Allocation of the 'potential', 'historical' and 'recent' ecosystem functions in comparison for the LF hilly area and hill range

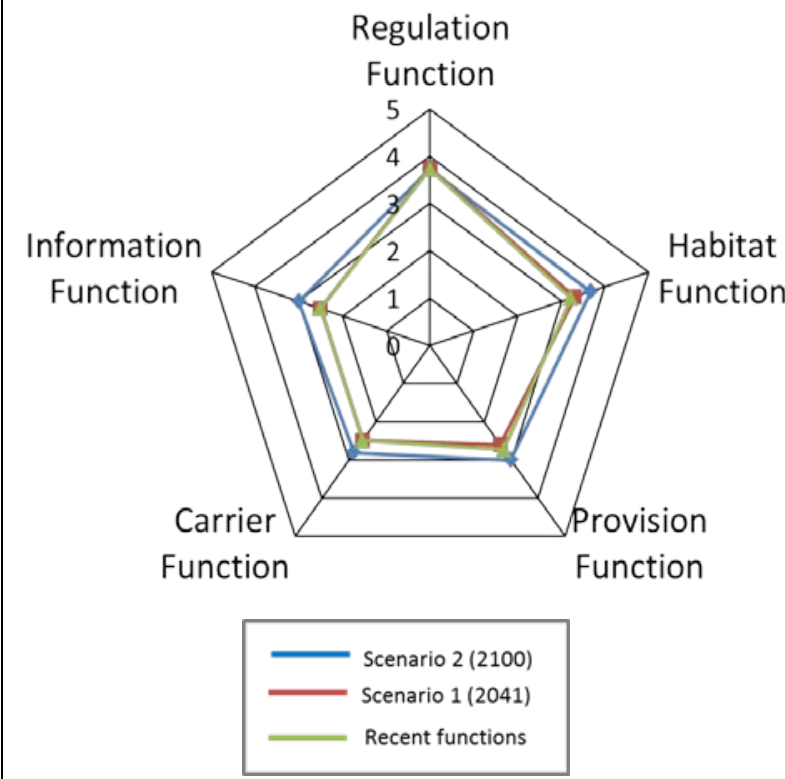

Figure 66: Allocation of the 'recent' ecosystem functions as well as the allocation of Scenario 2041 and 2100

\section{Low and middle range mountains}

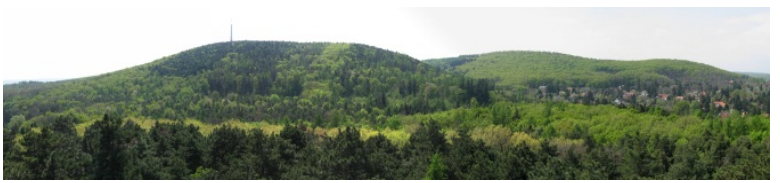

Figure 67: Panorama image of Löverek. Photo: Pal Balázs

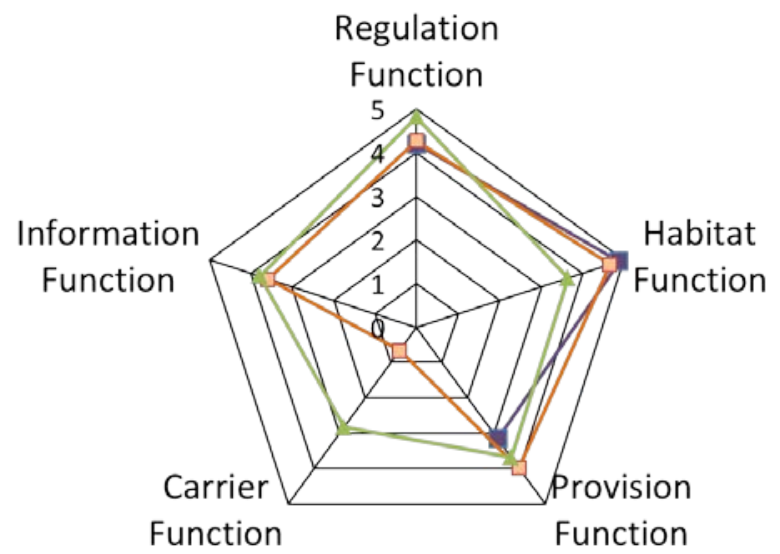

Potential functions

Historical functions

Recent function

Figure 68: Allocation of the 'potential', 'historical' and 'recent' ecosystem functions in comparison for the LF low and middle range mountains

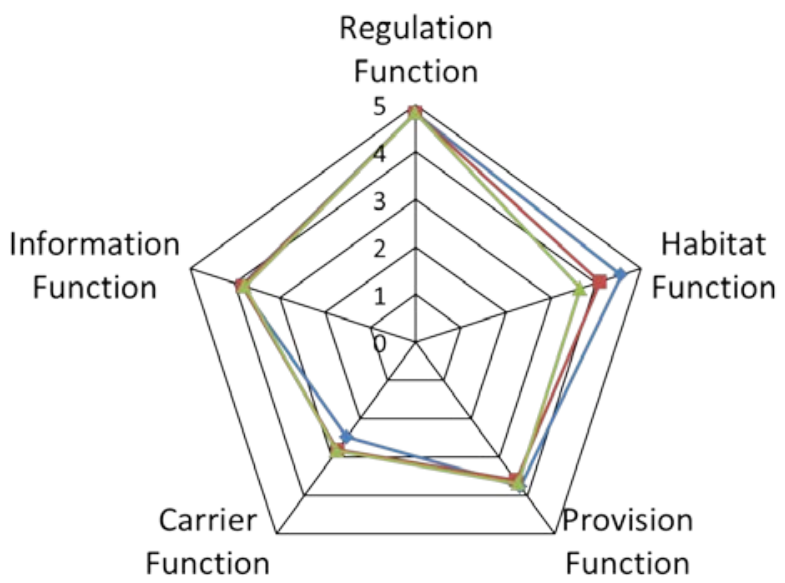

Figure 69: Allocation of the 'recent' ecosystem functions as well as the allocation of Scenario 2041 and 2100 

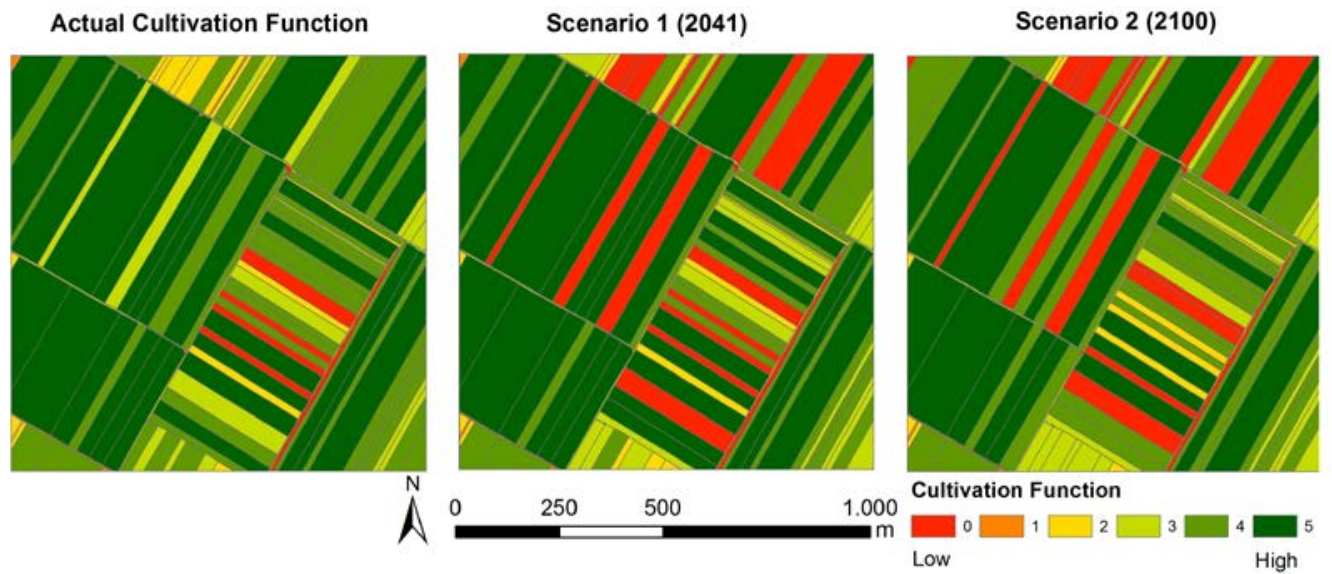

Figure 70: The recent provision of the function 'cultivation' compared to the scenario 1 and 2 for the Landform Type 'Elevated terrace'.
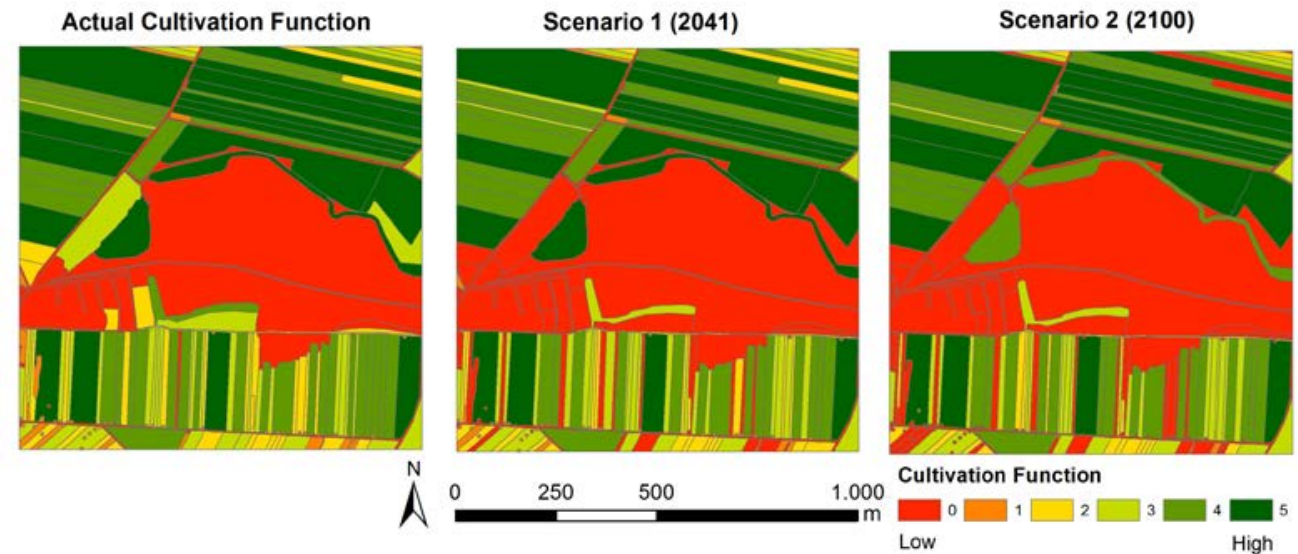

Figure 71: The recent provision of the function 'cultivation' compared to the scenario 1 and 2 for the Landform Type 'Low lying terrace'. 


\subsection{Critical view on our methods}

\section{Selection of function indicators}

Landscapes are considered as a human ecological system that provides a wide range of functions. Therefore, we build on a multifunctional view of landscape including both natural and cultural aspects. As different landscapes have different functions based on their structure and processes the individual landscape capacities to provide services are strongly linked to natural conditions: e.g. land cover, hydrology, soil conditions, fauna and flora, elevation, slope and climate as well as human impacts: mainly land use but also pollution and emissions, etc. All this information should be as detailed as possible, however finding appropriate indicators related to the specific function providing unit and exploring how functions and services are correlated with different landscape scenarios are still unresolved questions (Seppelt et al., 2011, Wallace, 2007). Current ecosystem function indicators are still limited by insufficient data and an overall low ability to convey information (Layke, 2009). In our study we aimed at assessing a wide range of functions to provide a good overview of the different function responses on climate change. Therefore, we decided to use an expert driven approach expanded by the qualifiers (environmental variables) gathered during field work to see first trends for ecosystem function assessments. In following up projects the expert evaluation values of the capacity matrix might be revised by data from monitoring, measurements, computer based modelling, targeted interviews or statistics.

\section{Scaling issues}

Some functions are even relevant at more than one scale. For instance Regulation functions can occur both at global scale ('climate regulation') and plot-scale (biological nitrogen fixation) (de Groot, 1992). Also pressures on ecosystem functions can have effects at different scales. In general physical processes on small scales are often driven by the impact on long period phenomena at large scales (climate patterns, hurricanes, fires) (Limburg et al., 2002). However, large scale processes are also strongly influenced by smaller scale occurrences, for example, microbes respire enough $\mathrm{CO} 2$ to keep many lakes and rivers supersaturated (Levin, 1992; del Giorgio et al., 1997). Hence, for the analyses of the dynamics of service supply it is very important to consider the drivers and processes at scales relevant for function generation. However, within our approach we have only focused on the function providing unit scale (broader habitat scale). To integrate effects at broader scales, e.g the landscape scale both spatial configuration of the landscape elements and effects of neighbouring features (e.g. power plant) have to be integrated.

\section{Aggregation of the sub-functions to the main ecosystem function groups}

Our approach is based on the assessment of the sub-functions at the function providing unit. In a second step they are extrapolated and aggregated to the main function groups which may result in a loss of information. For detailed analyses the single functions have to be illustrated alone (see Figure 70 and Figure 71). Another problem may arise when extrapolating the functions to the landscape scale. As the functions were assessed at the habitat scale, the effect on a broader scale could be different, in particular concerning to the environmental variables. Aggregating the numerous habitats with their different environmental variables might have blurred the results. Investigations on the extent of function delivery as well as trade-offs in function supply have to be undertaken.

\section{Data sources}

As there are differences in quality and resolution among the 'potential', 'historical' and 'recent' landscape maps a comparison between the function provisions based on broader habitats is quite difficult and only roughly possible. However, having this in mind our approach provides a good 
overview of the 'potential', 'historical' and 'recent' functions delivery, which can be used as a basis for further analyses.

\section{Climate scenario patterns}

The scenario results lead us to expect a continuous increase in average temperatures concerning all seasons by the end of the century. However, the development of total precipitation does not follow a consistent trend (see chapter 2.3.4), which makes it difficult to calculate the 'future' of function allocations. By the end of the century, the calculations show different trends of annual precipitation, but significant decreases of total precipitation during the vegetation periods, especially during the summer months. In addition, extreme weather events were not included in the calculations as already mentioned before.

\section{Conclusion}

The results present an overview of climate change effects on the capacity of ecosystems to provide services based on predicted precipitation and temperature values. Regarding our scenarios most function values will slightly increase. The Landform Types 'Low lying terrace' and 'Elevated terrace' seem to be most susceptible to environmental changes. This might be due to the fact that these Landform Types are primarily characterised by open landscapes heavily transformed by humans with low buffer functions for changing environmental conditions. These Landform Types will therefore need the most human input for climate change adaptation and mitigation measures, such as selection of appropriate crop varieties or land use change, if farming would require too much water resources. It has to be mentioned that extreme weather events, such as storms, floods and hot spells are not included within the estimations, which might have delivered more differentiated results. Jentsch et al., (2007) call for a new class of experiments that will examine the impacts of such events and to probe which systems may be most resilient to these perturbations. There are likely to be important limits to the rates of climate warming that natural systems can adapt to and these should be deducible from both limits to evolutionary change and limits to the rates that species can move across the landscape tracking climate change. Therefore, estimating the impact on biodiversity and its ecosystem functions is very challenging. More work in this area would allow more reliable predications for climate change impacts on biological systems.

Therefore, in further projects we will have to focus more on the understanding of the linkages among biological diversity, ecosystem functioning, ecosystem services and societal needs and adaptability. According to the literature (Egoh et al., 2012; Hermann et al., 2011) there are still a lot of open questions at all ends, which have to be answered. We need to develop an integrated system for mapping the stocks and flows of ecosystem functions and services, and their values, at multiple scales in order to be able to identify the most vulnerable ecosystems to natural, environmental, social and economic threats and challenges. At the same time we have to detect conservation, restoration, and natural resource management plans that mitigate the drivers of climate change. 


\section{Acknowledgments}

We would like to thank the project Bioserv (Biodiversity of ecosystem services as scientific foundation for the sustainable implementation of the Redesigned Biosphere Reserve 'Neusiedler See') funded by the Austrian Academy of Sciences and the project TransEcoNet (Transnational Ecological Networks), which was implemented through the Central Europe Programme co financed by ERDF. We would also like thank the 'Biologischen Station Illmitz', especially Prof. Herzig for providing access to the meteorological data for the Seewinkel. Our personal thanks go to Mag. Tamara Zhuber for revising the language for parts of the report. 


\section{References}

Anderson, K., Bows, A., 2011. Beyond 'dangerous' climate change: emission scenarios for a new world. Phil. Trans.R.Soc. A 369, 20-44.

Bohn, U., Neuhäusl, R., with contributions by Gollub, G., Hettwer, C., Neuhäuslová, Z., Raus, Th., Schlüter, H. \& Weber, H. 2000/2003. Map of the Natural Vegetation of Europe. Scale $1: 2500$ 000. Münster (Landwirtschaftsverlag)

Bulgaria. In: M. Morel et al. (eds) BALWOIS 2006 Conference on Water Observation and Information

Burkhard, B., Kroll, F., Müller, F., Windhorst, W., 2009. Landscapes' Capacities to Provide Ecosystem Services - a Concept for Land-Cover Based Assessments Landscape Online 15, 1-22. DOI:10.3097/LO.200915.

Cambridge Dictionary Online: COSMO-CLM (CCLM): $\underline{\text { http://www.cosmo- }}$ model.org/content/default.htm (last visit: 30 November 2011). http://dictionary.cambridge.org/dictionary/british/potential 2 (last visited: 20 April 2011)

Chan, K.M. A., Shaw, M.R., Cameron, D.R., Underwood, E.C., Daily, G.C., 2006. Conservation Planning for Ecosystem Services. DOI: 10.1371/journal.pbio.0040379.

Cleland, EE., Chuine, I., Menzel, A., Mooney, HA., Schwartz, MD., 2007. Shifting plant phenology in response to global change. Trends in Ecology \& Evolution 22:357-365.

de Groot, R.S., 1987. Environmental Functions as a Unifying Concept for Ecology and Economics. Environmentalist 7(2): 105-109.

de Groot, R.S., 1992. Functions of Nature: Evaluation of nature in environmental planning, management and decision making, Groningen (Wolters-Noordhoff BV).

de Groot, R., 2006. Function-analysis and valuation as a tool to assess land use conflicts in planning for sustainable, multi-functional landscapes. Landscape and Urban Planning 75:175-186.

De Groot, R.S., Wilson, M.A., Boumans, R.M.J. 2002. A typology for the classification, description and valuation of ecosystem functions, goods and services. Ecological Economics 41: 393-408.

De Vente, J., Poesen, J., Govers, G. et al., 2009. The implications of data selection for regional erosion and sediment yield modelling. Earth surface processes and landforms 34, 15: 1994-2007.

del Giorgio, P.A., Cole, J.J. and Cimbleris, A., 1997. Respiration rates in bacteria exceed phytoplankton production in unproductive aquatic systems. Nature, 385(6612): 148-151,

E.S.R.I. Inc., 2011. ArcMap 10. 1. ESRI Inc., Redlands, CA.

Egoh, B., Reyers, B., Rouget, M., Richardson, D.M., Le Maitre, D.C. and van Jaarsveld, A.S., 2008. Mapping ecosystem services for planning and management. Agriculture, Ecosystems \& Environment 127(1-2): 135-140.

Egoh, B., Drakou, E.G., Dunbar, M.B., Maes, J., Willemen, L., 2012. Indicators for mapping ecosystem services: a review. Report EUR 25456 EN. Publications Office of the European Union, Luxembourg Essl, F and Rabitsch, W. (eds) 2013. Biodiversität und Klimawandel Auswirkungen und Handlungsoptionen für den Naturschutz in Mitteleuropa. Springer Berlin Heidelberg.

Frondini, R., Mollo, B. and Capotorti, G., 2011. A landscape analysis of land cover change in the Municipality of Rome (Italy): Spatio-temporal characteristics and ecological implications of land cover transitions from 1954 to 2001. Landscape and Urban Planning 100, 117-128.

Fung F., Lopez A., New M., 2011. Water availability in $+2^{\circ} \mathrm{C}$ and $+4^{\circ} \mathrm{C}$ worlds. Phil. Trans. R. Soc. A 369, 99-116.

Gitas, I.Z., Douros, K., Minakou, C., Silleo, G.N., Karydas, C.G., 2009. Multi-temporal soil erosion risk assessment in N. Chalkidiki using a modified USLE Raster Model. EARSeL eProceedings 8, $1 / 2009,40-52$.

Goldman, R.L., Thompson, B.H., Daily, G.C., 2007. Institutional incentives for managing the landscape: Inducing cooperation for the production of ecosystem services. Ecological Economics 64, 333 -343 . 
Haines-Young, R., Potschin, M., 2010. The links between biodiversity, ecosystem services and human well-being. In: Raffaelli, D. \& C. Frid (eds.): Ecosystem Ecology: a new synthesis. BES Ecological Reviews Series, CUP, Cambridge.

Harrison, P.A., Porter, J.R., Downing, T.E., 2000. Scalingup the AFRC-WHEAT2 model to assess phonological development for wheat in Europe. Agric. Forest Meteorol. 101, 167-186.

Havstad, K.M., Peters, D.P.C., Skaggs, R., Brown, J., Bestelmeyer, B., Fredrickson, E., Herrick, J., Wright, J., 2007. Ecological services to and from rangelands of the United States. Ecological Economics 64, 261-268.

Hein, L., van Koppen, K., de Groot, R.S. and van lerland, E.C., 2006. Spatial scales, stakeholders and the valuation of ecosystem services. Ecological Economics 57(2): 209-228.

Hermann, A., Kuttner, M., Hainz-Renetzeder, C., Konkoly-Gyoró, É., Tirászi, Á., Brandenburg, C., Allex, B., Ziener, K., Wrbka, T. 2013, in press. Assessment framework for landscape services in European cultural landscapes - an Austrian Hungarian case study. Ecological Indicators.

Hermann, A., Schleifer, S., Wrbka, T., 2011. The Concept of Ecosystem Services Regarding Landscape Research: A Review. Living Rev. Landscape Res. 5.

Jentsch A, Kreyling J, Beierkuhnlein C., 2007. A new generation of climate-change experiments: events, not trends. Frontiers in Ecology and the Environment 5:365-374.

Kenny, G.J., Harrison, P.A., 1992. The effects of climate variability and change on grape suitability in Europe. J. Wine Res. 3, 163-183.

Kirschner A.K.T., Eiler A., Zechmeister T.C., Velimirov B., Herzig A., Mach R., Farnleitner A.H., 2002. Extremely productive microbial communities in shallow saline pools respond immediately to changing meteorological conditions. Environmental microbiology 4,9: 546-555.

Konkoly-Gyuró, É., Tirászi, A., Wrbka, T., Prinz, M., Renetzeder, C., 2010. Der Charakter grenzüberschreitender Landschaften (The character of transboundary regions). University of Western Hungary, ISBN 978-963-9883-53-6, Sopron. [in German and Hungarian].

Krachler R., 2007. Renaturierung der Sodalacken im burgenländischen Seewinkel. Plus-Lucis 1-2: 2328.

Kysely J., 2004. Mortality and displaced mortality during heat waves in the Czech Republic. Int. Journal of Biometeorology 49:91-97; DOI10.1007/s00484-004-0218-2.

Lastoria, B., Miserocchi, F., Lanciani, A., Monacelli, G. An estimated Erosion Map for the AternoPescara River Basin. European Water 21/22:29-39.

Layke, C., 2009. Measuring Nature's Benefits: A Preliminary Roadmap for Improving Ecosystem Service Indicators. Washington DC (World Resources Institute).

Lenoir, J., Gegout, JC., Marquet, PA., de Ruffray, P., Brisse, H., 2008. A significant upward shift in plant species optimum elevation during the 20th century. Science 320:1768-1771.

Levin, S.A., 1992. The Problem of Pattern and Scale in Ecology. Ecology 73(6): 1943-1967.

Limburg, K.E., O'Neill, R.V., Costanza, R. and Farber, S., 2002. Complex systems and valuation. Ecological Economics, 41(3): 409-420.

MEA 2005. Ecosystems and Human Well-being: Multiscale Assessment, Millennium Ecosystem Assessment Series, 4, Washington, DC (Island Press).

Mitasova, H., Brown, W.M., Hohmann, M., Warren, S., 2001. Using Soil Erosion Modeling for Improved Conservation Planning: A GIS-based Tutorial. http://skagit.meas.ncsu.edu/ helena/gmslab/reports/CerlErosionTutorial/denix/denixstart.h $\underline{\mathrm{tml}}$

Mooney, H., Larigauderie, A., Cesario, M., Elmquist, T., Hoegh-Guldberg. O., Lavorel, S., Mace, G.M., Palmer, M., Scholes, R., Yahara, T., 2009. Biodiversity, climate change, and ecosystem services. Current Opinion in Environmental Sustainability 1: 46-54.

Niklfeld, H., 1970/89. Natürliche Vegetation. In: Breu, J. (Ed.). Atlas der Donauländer, p. 171 .

O'Neill, R.V., De Angelis, D.L., Waide, J.B., Allen, T.F.H., 1986. A hierarchical concept of ecosystems. Princeton University Press, Princeton New Jersey USA.

Odling-Smee, L., 2005. Dollars and sense. Nature 437,614-616.

Olesen, J.E. and Bindi, M., 2002. Consequences of climate change European agricultural productivity, land use and policy. European Journal of Agronomy 16: 239-262. 
Österreichisch - Ungarische Gewässerkommission 1996. 40 Jahre Österreichisch- Ungarische Gewässerkommission, 1956-1996. Bundesministerium f. Land- und Forstwirtschaft, A-1010 Wien.

Penman, H.L., 1948. Natural evaporation from open water, bare soil, and grass. Proc. Roy. Soc. London A 193:120-146.

Potschin, MB and Haines-Young, RH., 2011. Ecosystem services : Exploring a geographical perspective. Progress in Physical Geography 35, 575. Online version: http://ppg.sagepub.com/content/35/5/575 (accessed 20 August 2012).

Prinz, M.A., Wrbka, T. and Reiter, K., 2010. Landscape change in the Seewinkel: Compari-son among Centuries. In Andel, J., Bicik, I., Dostal, P., Lipsky, Z. and Shahneshin ,S. G. (eds.). Landscape Modelling. Geographical Space, Transformation and Future Scenarios, pp. 123-132. Springer.

Renard, K.G., Foster, G.R., Weesies, G.A., Porter, J.P., 1991. RUSLE - revised universal soil loss equation. J. Soil water Conserv., 46(1):30-33.

Renard, K.G., Freimund, J.R., 1994. Using monthly precipitation data to estimate the R-factor in the revised USLE. J. Hydrol., 157: 287-306.

Rötter, R., van de Geijn, S.C., 1999. Climate change effects on plant growth, crop yield and livestock. Clim. Change 43, 651-681.

Rounsevell, MDA., Reginster, I., Araujo, MB., Carter, TR., Dendoncker, N., Ewert, F., House, JI, Kankaanpää, S., Leemans, R., Metzger, MJ., Schmit, C., Smith, P., Tuck, G., 2006. A coherent set of future land use change scenarios for Europe. Agric Ecosys Env 114:57-68.

Rousseva, S., Lazarov, A., Stefanova, V., Tsvetkova, E., Malinov, I., 2006. Soil erosion assessments in Bulgaria. In: M. Morel et al. (eds) BALWOIS 2006 Conference on Water Observation and Information System for Decision Support, 23-26 May 2006, Ohrid, Republic of Macedonia paper No 153) http://balwois.mpl.ird.fr/balwois/administration/full_paper/ffp-608.pdf.

Ružicka, M., Miklos, L., 1990. Basic premises and methods in landscape ecology planning and optimization. In: Zonneveld, I.S. and Forman, R.T.T. eds. Changing landscape, an ecological perspective. Springer-Verlag: 233-260.

Sanderson, B.M., O'Neill, B.C., Kiehl, J.T., Meehl, G.A., Knutti, R., Washington, W.M., 2011. The response of climate system to very high greenhouse gas emission scenarios. Environ. Res. Lett. 6; doi:10.1088/1748-9326/6/3/034005.

Schröter, D. et al., 2005. Ecosystem service supply and vulnerability to global change in Europe. Science 310: 1333-1337.

Seppelt, R., Dormann, C.F., Eppink, F.V., Lautenbach, S., Schmidt, S., 2011. A quanti-tative review of ecosystem service studies: approaches, shortcomings and the road ahead. Journal of Applied Ecology 48, 630-636.

SOILPRO - monitoring for soil protection (LIFEO8 ENV/IT/00428 SOILPRO). SOILPRO is a project financed among the LIFE+ (Environment Policy and Governance) projects. http://www.soilrpo.eu

TEEB (ed.), 2010. TEEB - The Economics of Ecosystems and Biodiversity for Local and Regional PolicyMakers.

http://www.teebweb.org/ForLocalandRegionalPolicy/localandRegionalPolicyMakersChapter Drafts/ta bid/29433/Default.aspx.

Thomas, CD., Cameron, A., Green, RE., Bakkenes, M., Beaumont, LJ., Collingham, YC., Erasmus, BFN., Siqueira, MFD., Grainger, A., Hannah, L. et al., 2004. Extinction risk from climate change. Nature 427:145-148.

Van Buskirk, J., Mulvihill, RS., Leberman, RC., 2009. Variable shifts in spring and autumn migration phenology in North American songbirds associated with climate change. Global Change Biology 15:760-771.

Wallace, K.J., 2007. Classification of ecosystem services: Problems and solutions. Biological Conservation 139(3-4), 235-246.

Westman, W.E., 1977. How much are natures services worth. Science 197(4307), 960-964. 
Willner, W. and Grabherr, G. (Eds.) 2007. Die Wälder und Gebüsche Österreichs. Spektrum Akademischer Verlag, Elsevier.

Wishmeier, W.H., Johnson, C.B., Cross, B.V., 1971. Soil erodibility nomograph for farmland and construction sites. J. Soil Water Conserv. 26, 189-193.

Wishmeier, W.H., Smith, D.D., 1978. Predicting rainfall erosion losses - a guide to conservation planning. Agriculture Handbook No. 537, USDA, Washington.

Wrbka, T., Hainz-Renetzeder, C., Kuttner, M., Hermann, A., Brandenburg, C., Ziener, K., Allex, B., Liebl, U., Czachs, C., Konoly-Gyuró, É., Tirász, Á., Balázs, P., Bacsárdi, V., 2012. Biodiversity and Ecosystem Services as scientific foundation for the sustainable implementation of the Redesigned Biosphere Reserve "Neusiedler-See". Report OEAW, Wien.

Wrbka, T., Peterseil, J., Szerencsits, E., Schneider, W., Suppan, F., Beissmann, H., Kiss, A., Plutzar, C., Schmitzberger, I., Thurner, B., Hengsberger, R., Tutsch, G.., 2003. Landschaftsökologische Strukturmerkmale als Indikatoren der Nachhaltigkeit. Endbericht des Forschungsprojekts SINUS im Rahmen des Forschungsprogramms Kulturlandschaft des Bundesministerium für Bildung, Wissenschaft und Kultur.

Zampieri, M. and Lionello, P., 2010. Simple statistical approach for computing land cover types and potential natural vegetation. Climate Research 41: 205-220. 


\section{Appendices: Spatially differentiated representations of scenario results by decades for the period 2010 - 2100}

Appendices 1a-f: Mean total precipitation per decade and relative change compared to 2001-2010

Appendices 2a-f: Mean temperature per decade and change compared to 2001-2010

Appendix 1a

Mittlerer Jahresniederschlag [mm]
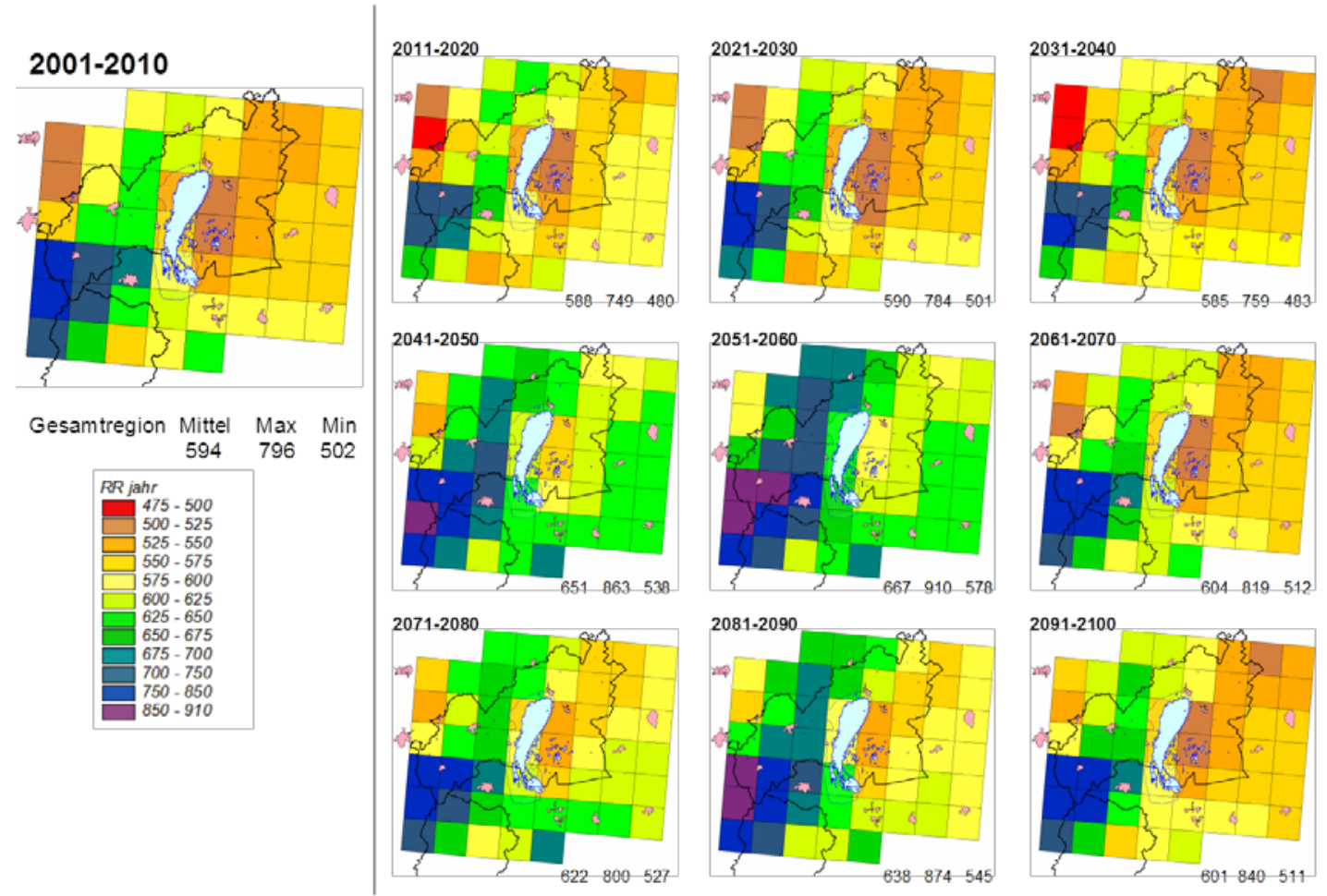


\section{Appendix 1b}

Mittlerer Jahresniederschlag

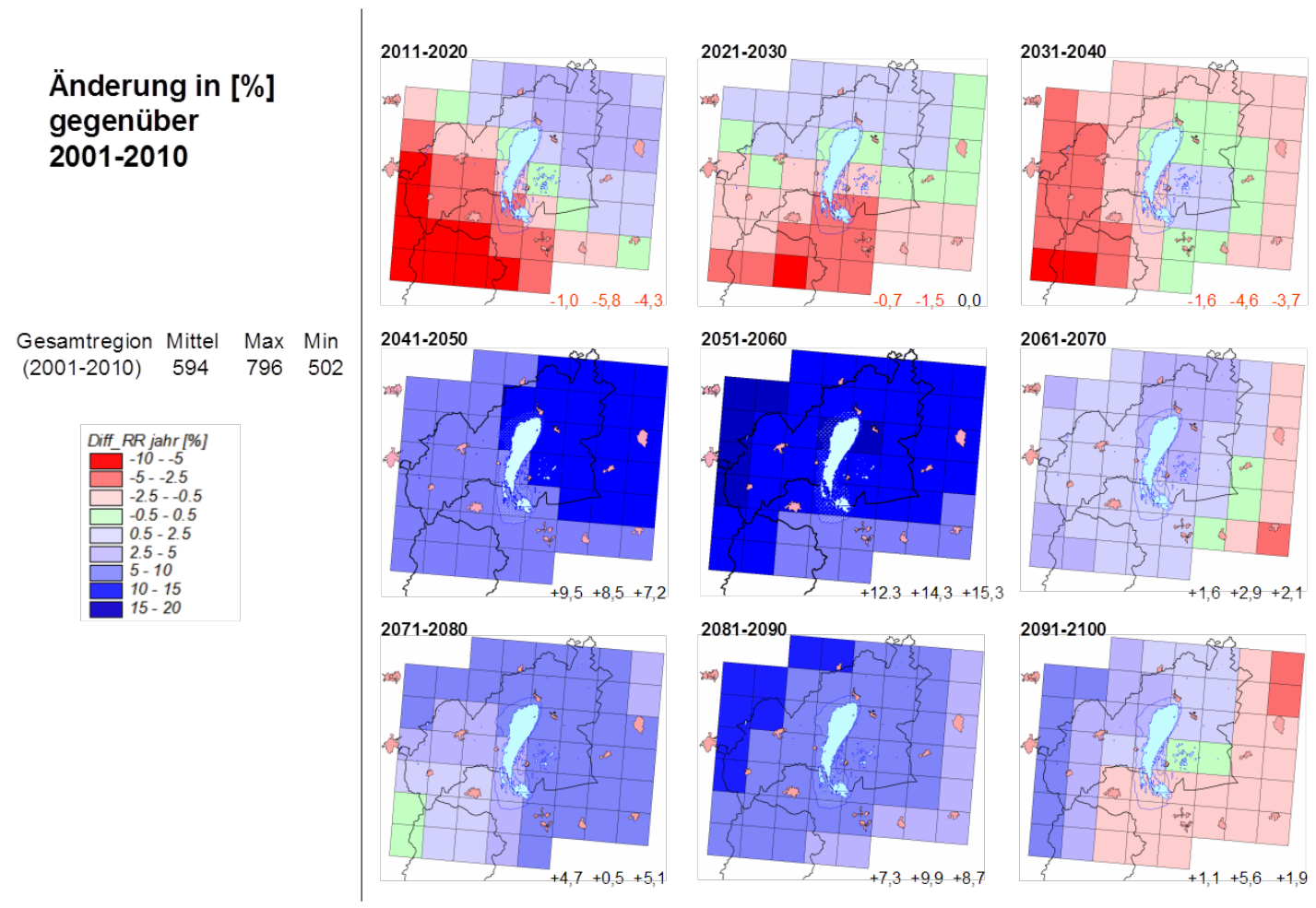

Appendix 1c

Mittlerer Niederschlag vor der Vegetationsperiode (Okt-Mrz) [mm]

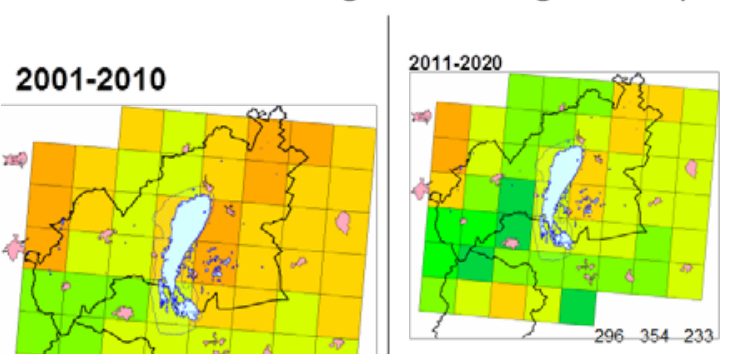

\{ 3

Gesamtregion Mittel Max Min $269 \quad 320 \quad 208$

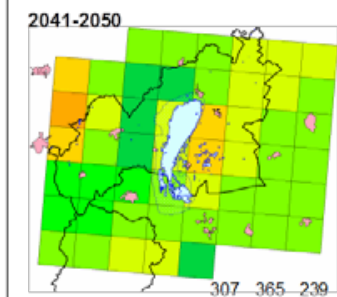

2071-2080

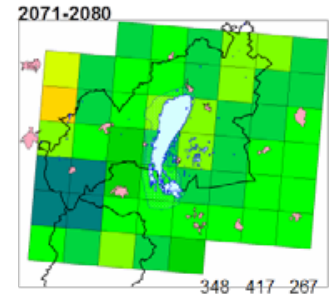

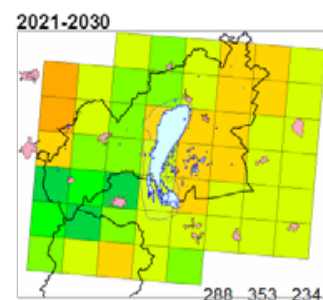

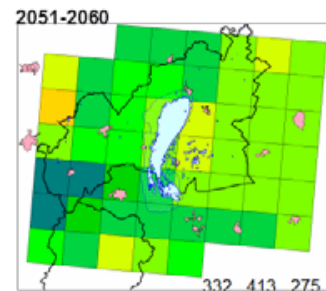

2081-2090

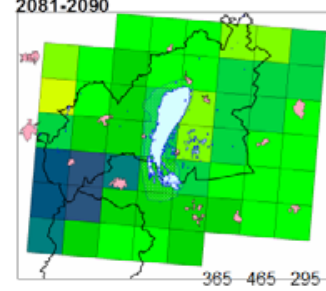

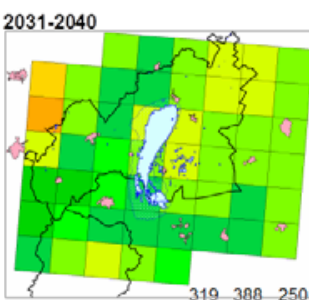

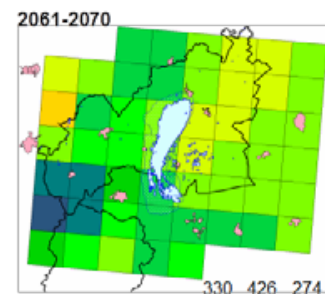

2091-2100

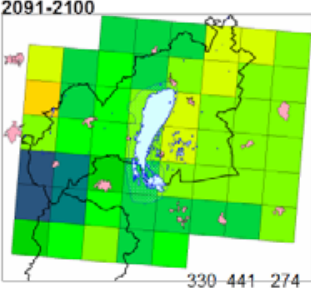


Appendix 1d

Mittlerer Niederschlag vor der Vegetationsperiode (Okt-Mrz)

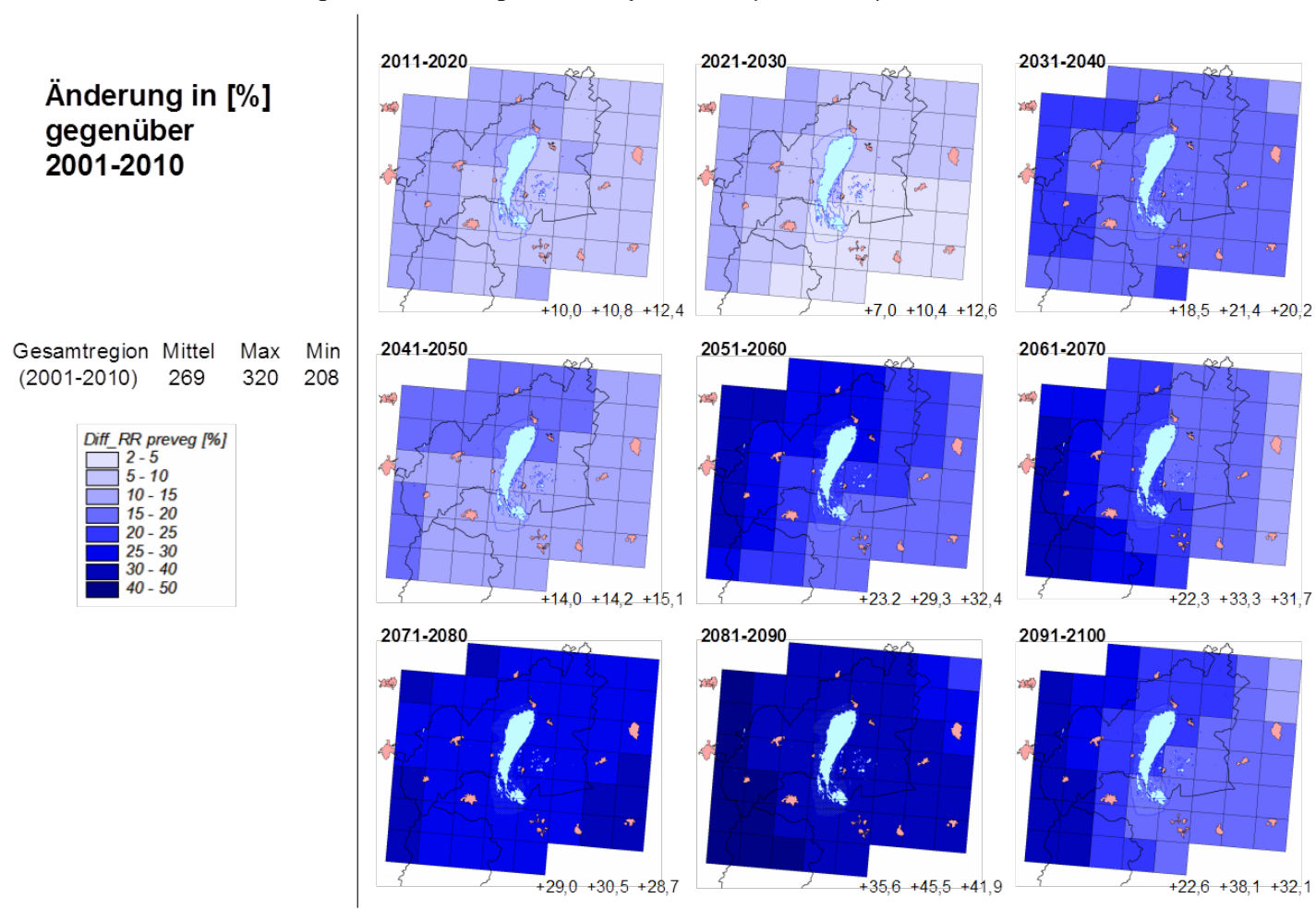

Appendix 1e

Mittlerer Niederschlag in der Vegetationsperiode (Apr-Sept) [mm]
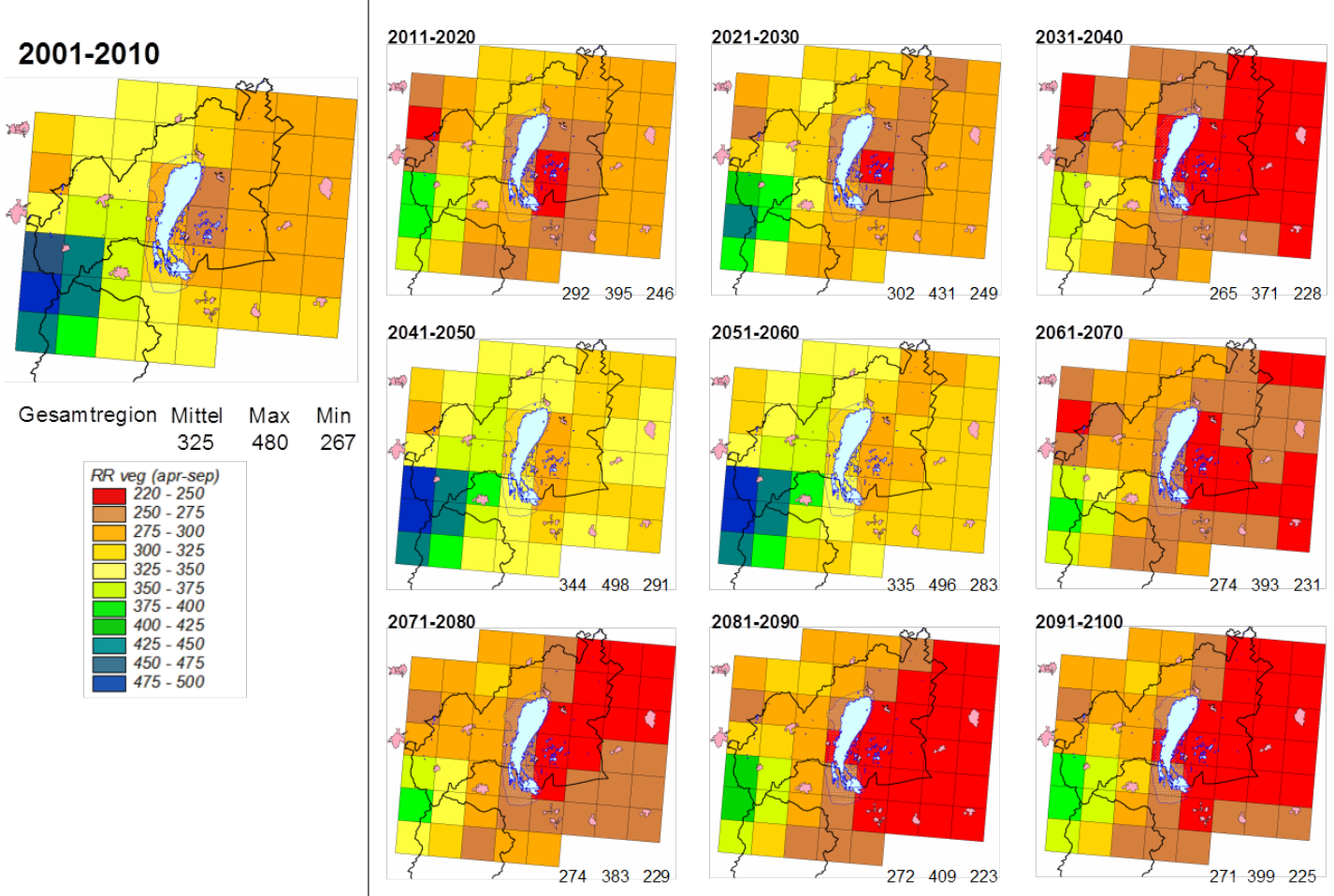
Appendix $1 f$

Mittlerer Niederschlag in der Vegetationsperiode (Apr-Sept)

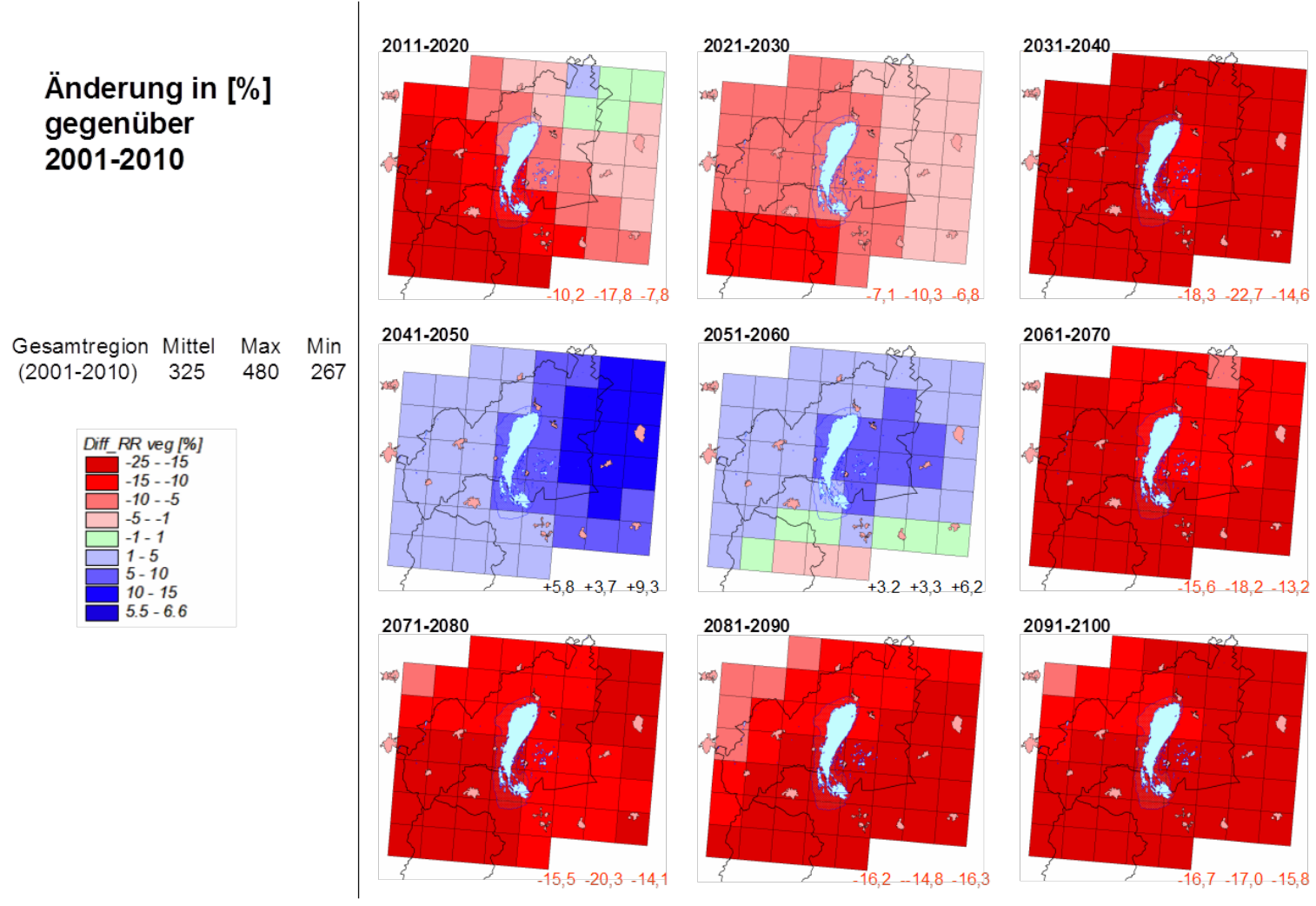

Appendix 2a

Mittlere Jahrestemperatur $\left[{ }^{\circ} \mathrm{C}\right]$

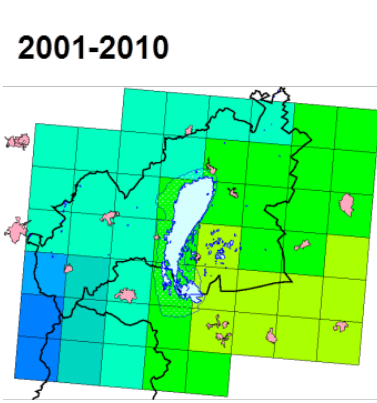

Gesamtregion Mittel Max Min

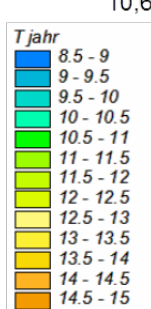

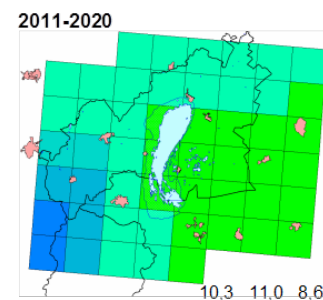

2041-2050
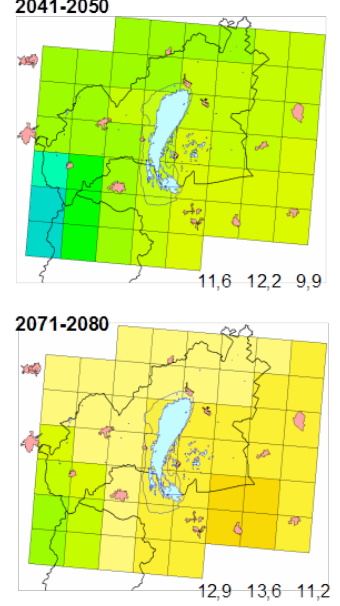
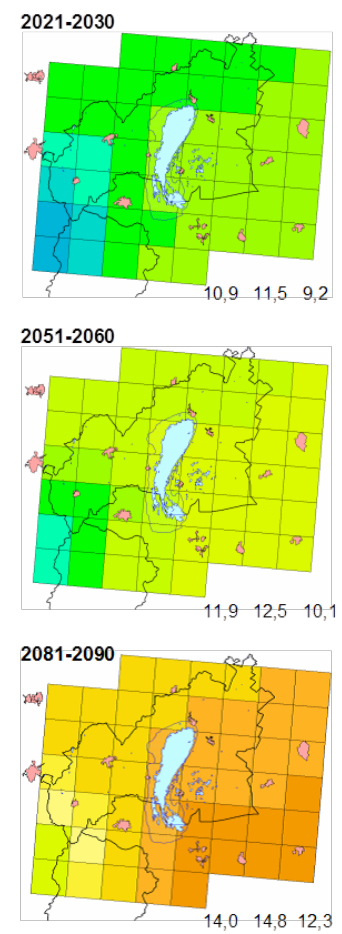

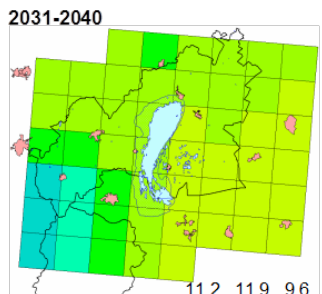

2061-2070
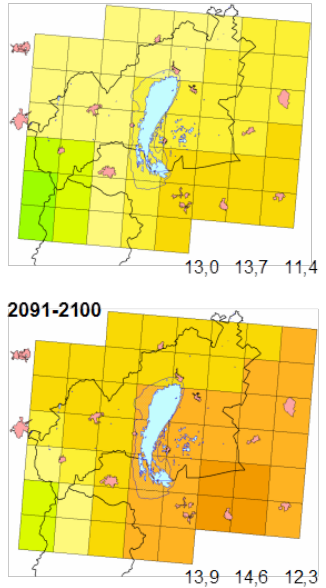
Appendix 2b

Mittlere Jahrestemperatur

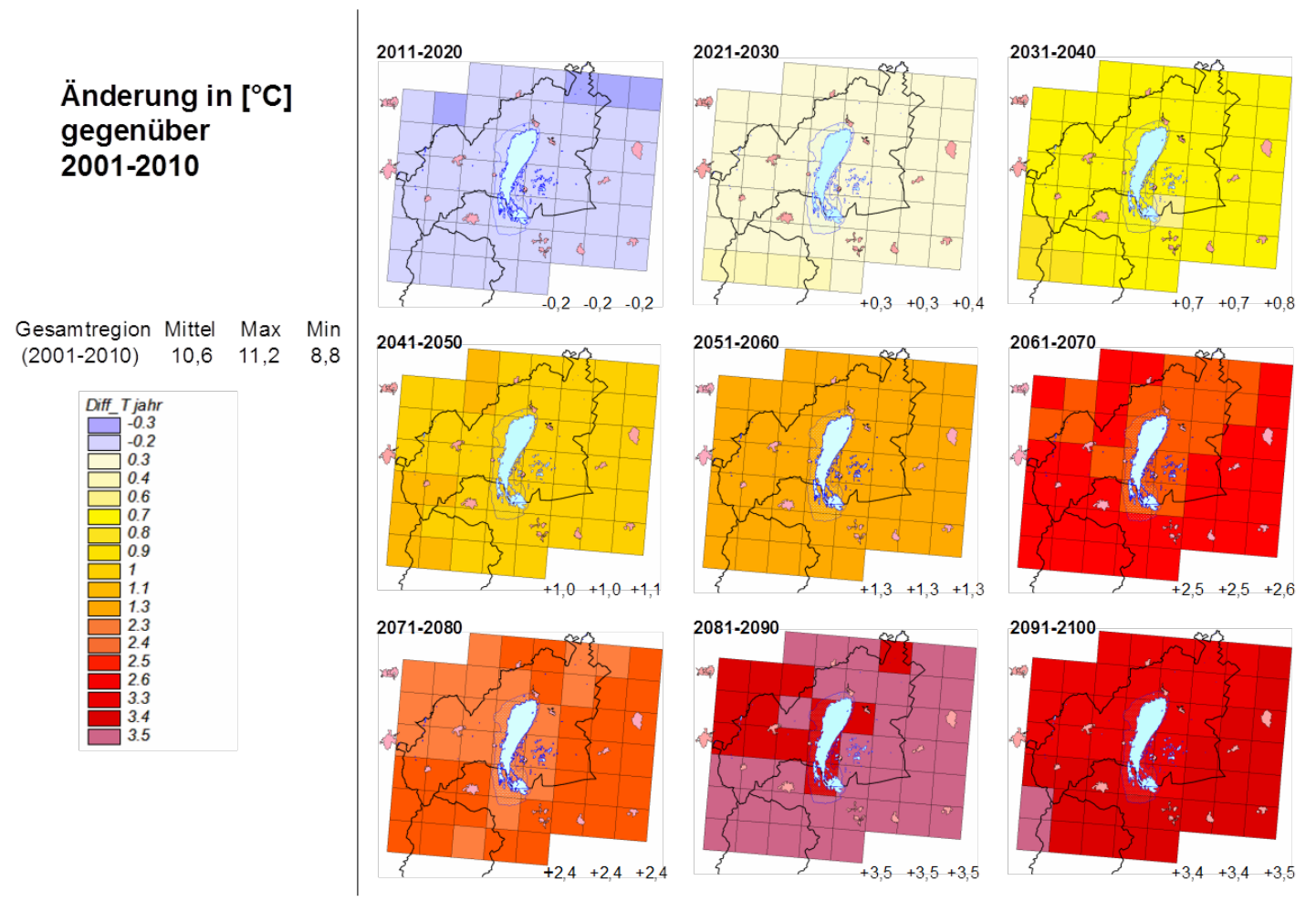

\section{Appendix 2c}

Mittlere Temperatur vor der Vegetationsperiode (Okt-Mrz) $\left[{ }^{\circ} \mathrm{C}\right]$
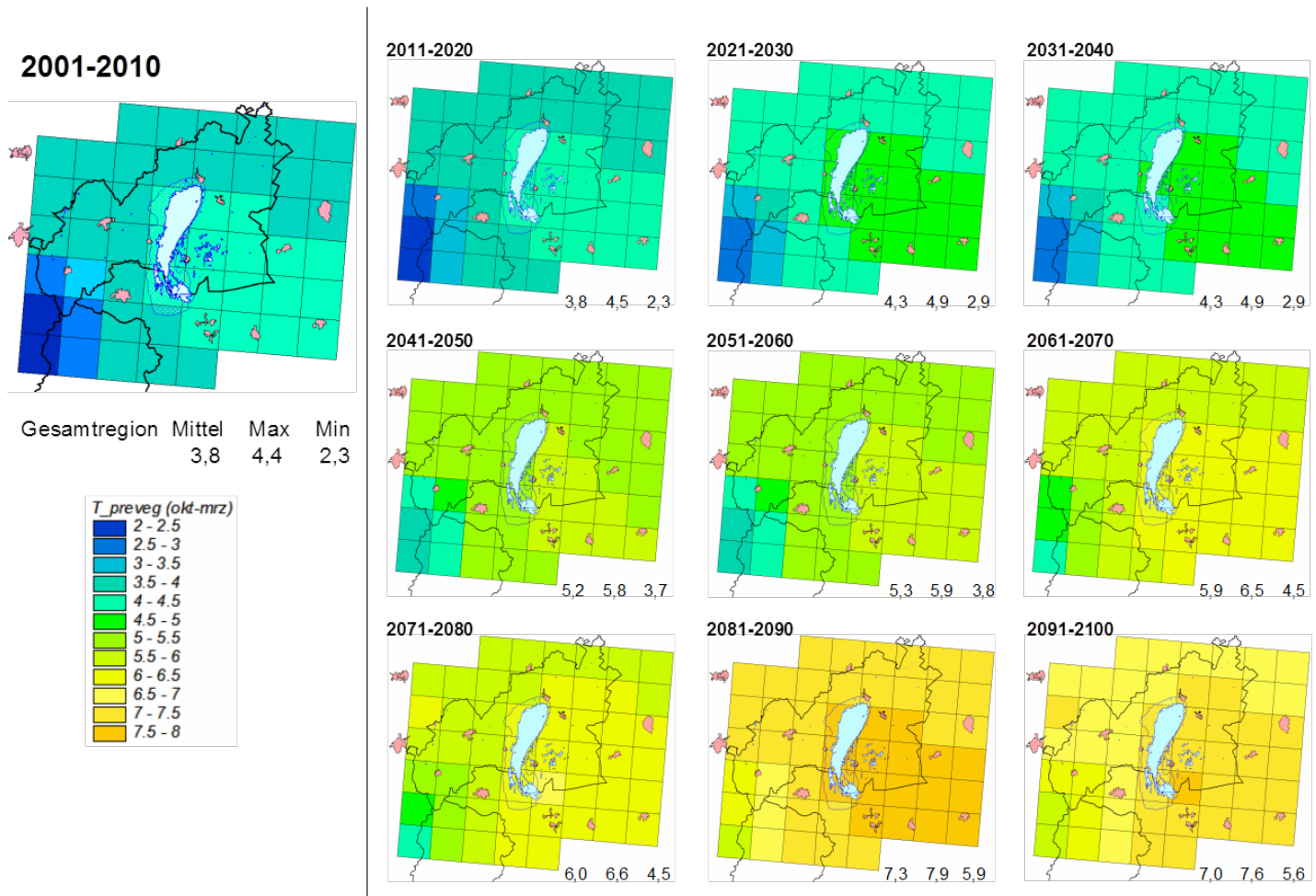


\section{Appendix 2d}

Mittlere Temperatur vor der Vegetationsperiode (Okt-Mrz)

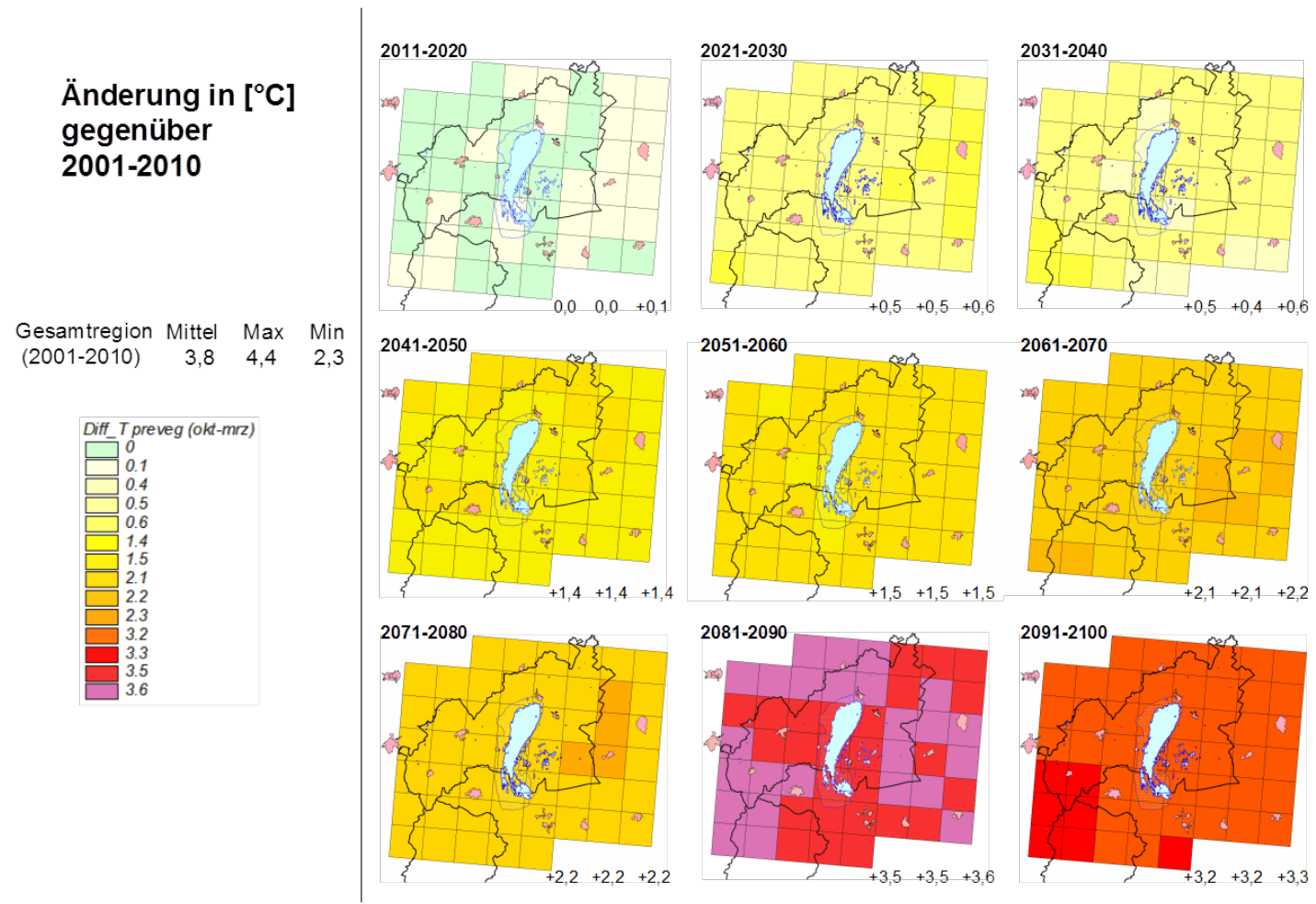

\section{Appendix 2e}

Mittlere Temperatur in der Vegetationsperiode (Apr-Sept) $\left[{ }^{\circ} \mathrm{C}\right]$

2001-2010

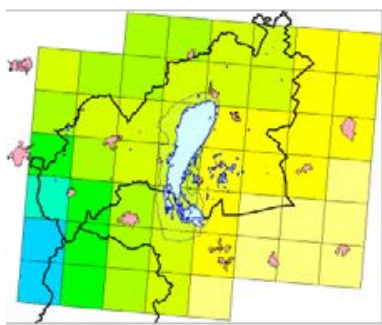

Gesamtregion Mittel Max Min

\begin{tabular}{|r|}
\hline$T$ veg (apr-sep) \\
$15-15.5$ \\
$15.5-16$ \\
$16-16.5$ \\
$16.5-17$ \\
$17-17.5$ \\
$17.5-18$ \\
$18-18.5$ \\
$18.5-19$ \\
$19-19.5$ \\
$19.5-20$ \\
$20-20.5$ \\
$20.5-21$ \\
$21-21.5$ \\
$21.5-22$ \\
\hline
\end{tabular}
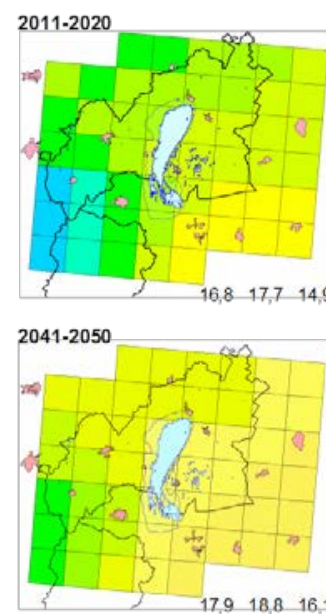

2071-2080

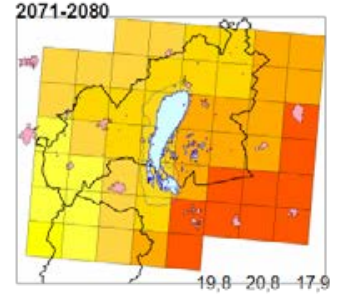

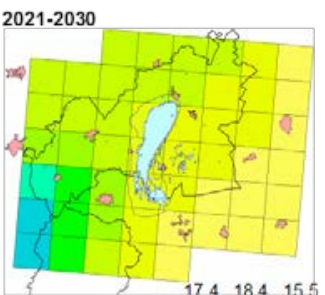
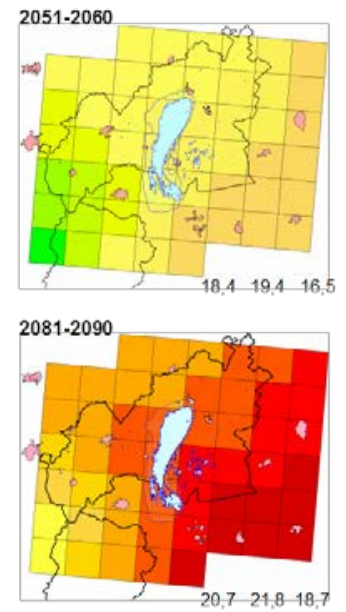
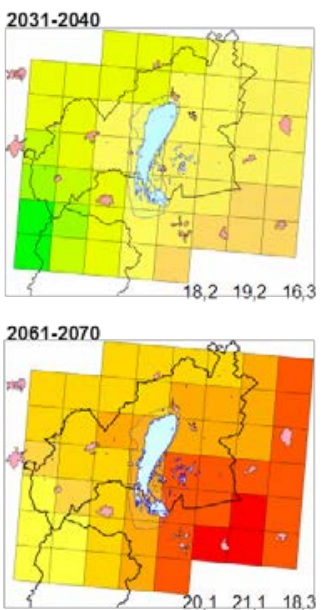

2091-2100

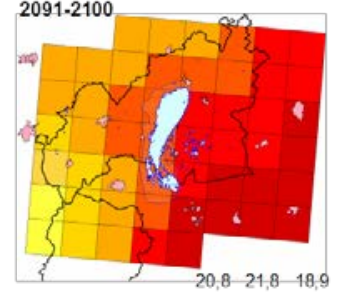


Appendix $2 f$

Mittlere Temperatur in der Vegetationsperiode (Apr-Sept)

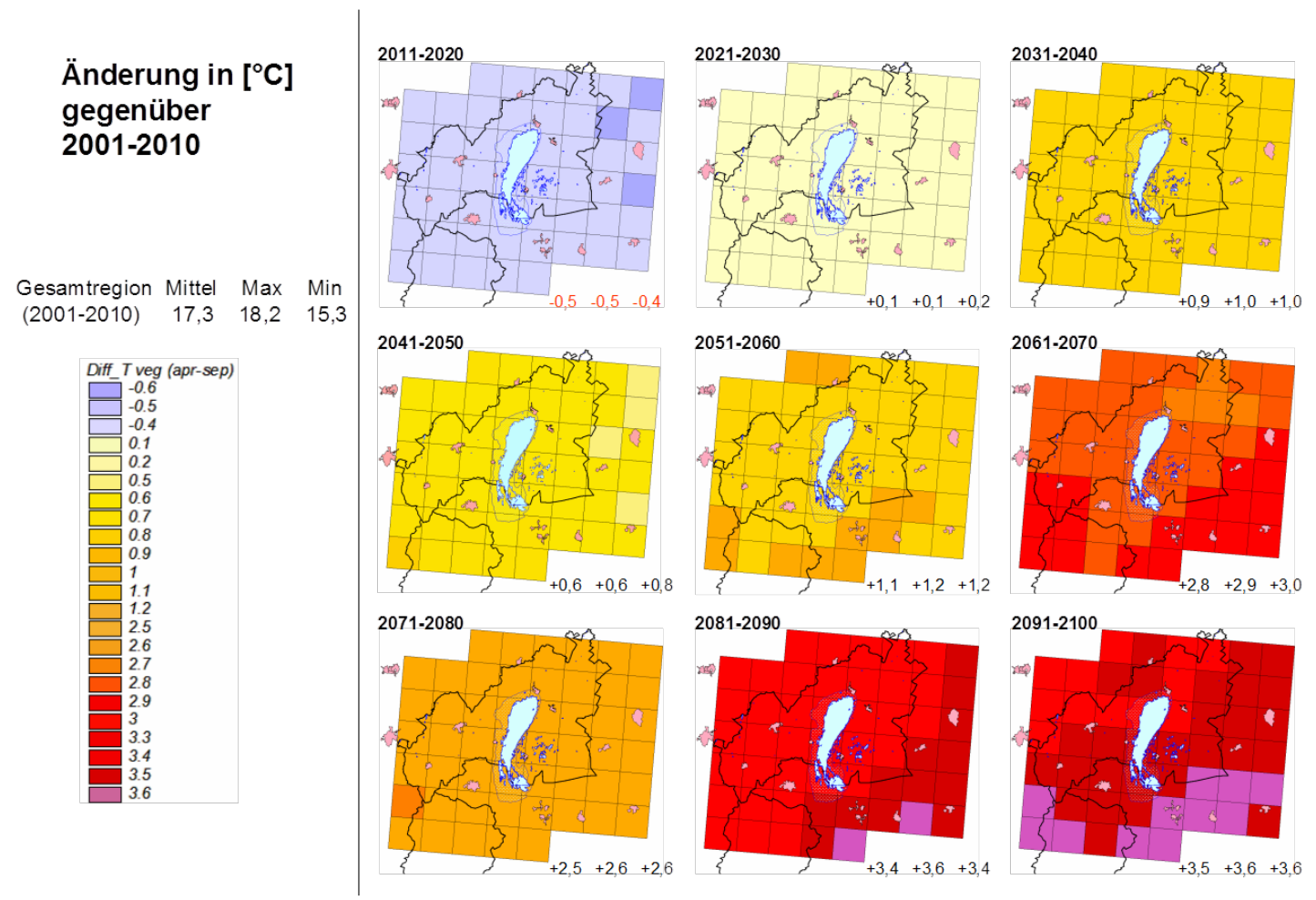

